University of Missouri, St. Louis

IRL@UMSL

Dissertations

UMSL Graduate Works

4-23-2012

\title{
Organizational Responsiveness to Anti-offshoring Institutional Pressures
}

Shaji Ahmed Khan

University of Missouri-St. Louis, shajikhan@umsl.edu

Follow this and additional works at: https://irl.umsl.edu/dissertation

Part of the Business Commons

\section{Recommended Citation}

Khan, Shaji Ahmed, "Organizational Responsiveness to Anti-offshoring Institutional Pressures" (2012). Dissertations. 373.

https://irl.umsl.edu/dissertation/373

This Dissertation is brought to you for free and open access by the UMSL Graduate Works at IRL @ UMSL. It has been accepted for inclusion in

Dissertations by an authorized administrator of IRL @ UMSL. For more information, please contact marvinh@umsl.edu. 


\title{
Organizational Responsiveness to Anti-offshoring Institutional Pressures
}

\author{
Shaji A. Khan \\ M.S., Computer Science, Governors State University, 2001 \\ B.A., Governors State University, 2000 \\ B.Com., Osmania University (Hyderabad, India), 1998
}

A Dissertation Submitted to the Graduate School at the University of MissouriSt. Louis in Partial Fulfillment of the Requirements for the Degree Doctor of Philosophy in Business Administration with an Emphasis in Information Systems

April 2012

\author{
Dissertation Committee \\ Dr. Mary Lacity, Ph.D. (Chair) \\ Dr. Natalia Mintchik, Ph.D. \\ Dr. Dinesh Mirchandani, Ph.D. \\ Dr. Joseph Rottman, D.Sc.
}




\section{Table of Contents}

\section{Acknowledgements}

Abstract

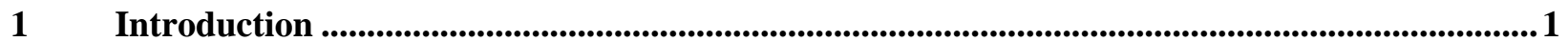

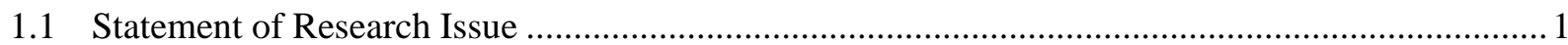

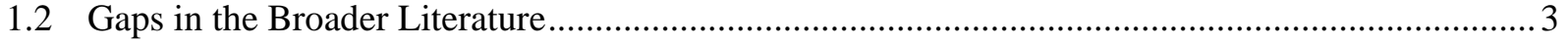

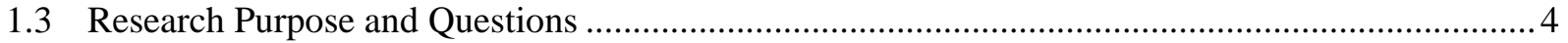

2 Anti-offshoring Institutional Pressures ......................................................................................................5

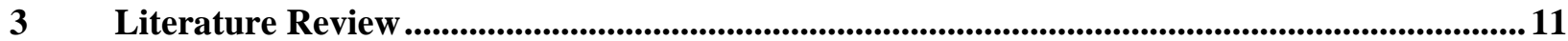

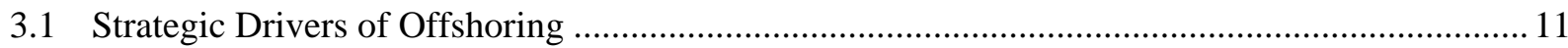

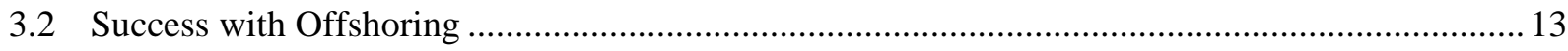

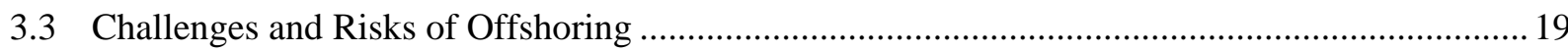

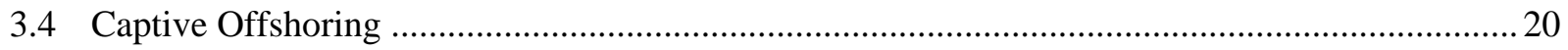

3.5 Institutional Explanations of Outsourcing and Offshoring decisions ......................................... 22

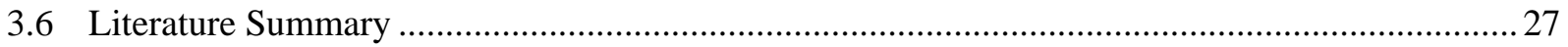

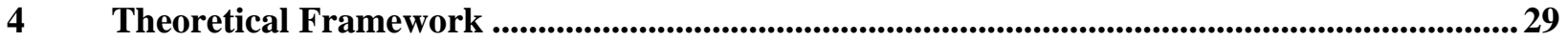

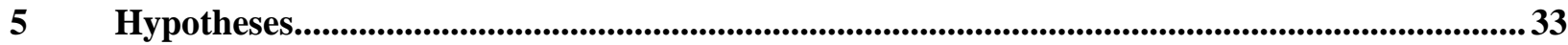

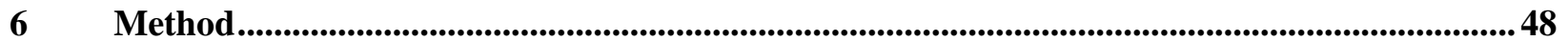

6.1 Data Collection Approach and Target Respondents .............................................................. 48

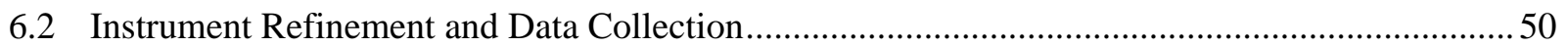

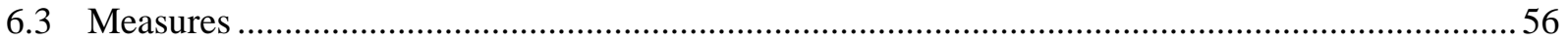

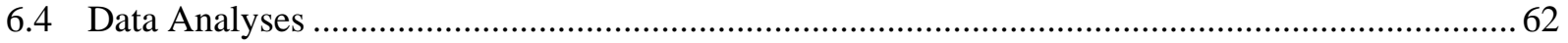

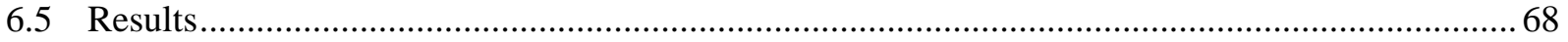

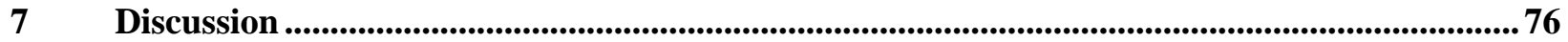

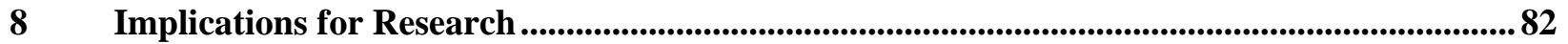

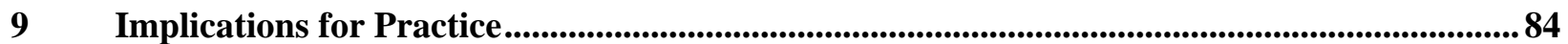

10 Limitations and Suggestions for Future Research ................................................................ 86

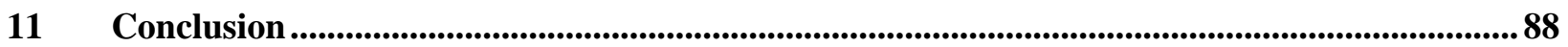

\section{LIST OF TABLES}

TABLE 1 Demographic Characteristics of the Sample 
TABLE 2 Factor Loadings and Cronbach's Alphas for Multi-item Constructs................................. 63

TABLE 3 Means, Standard Deviations (s.d.), and Correlations ................................................................69

TABLE 4 Results of Moderated Hierarchical Regression Analyses for Organizational

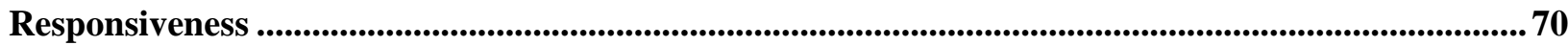

TABLE 5 Summary of Hypotheses Testing Results .........................................................................75

\section{LIST OF FIGURES}

FIGURE 1 Hypothesized Relationships ............................................................................................................34

FIGURE 2a Plot of Interaction between Social Legitimacy and Offshoring Success.......................... 74

FIGURE 2b Plot of Interaction between Regulatory Environment Uncertainty and Offshoring Success ............................................................................................................................................................................. 74

\section{LIST OF APPENDICES}

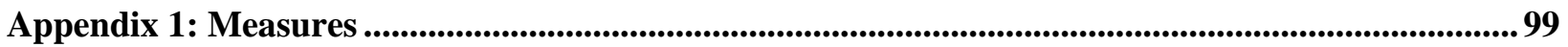

Appendix 2: Summary of Key Challenges and Risks in IT Sourcing .................................................. 102 


\section{Acknowledgements}

I wish to begin by expressing my sincere gratitude to Dr. Mary Lacity for chairing this dissertation and for helping me at every step of this process. Thank you very much Dr. Lacity. Thank you for your guidance, your ability to see things through, your help with data collection, and for your patience. Also, many thanks for teaching me to consider the relevance of my research for practice. I sincerely appreciate all that you have done for me.

I also wish to thank my dissertation committee members, Dr. Natalia Mintchik, Dr. Dinesh Mirchandani, and Dr. Joseph Rottman for their extremely valuable feedback and support. Thank you all very much. Your guidance and feedback tremendously improved the quality of this dissertation. Also, thank you for your prompt responses, every time I needed help, despite your busy schedules.

I sincerely thank Eric Simonson, Managing Partner, Research, at Everest Group--for providing me with access to an invaluable pool of potential respondents for data collection. I also thank Eric and his team for going through multiple iterations of the questionnaire and for helping conduct the survey.

I earnestly thank all study participants for their valuable time and insights.

Finally, I much appreciate the tremendous support from my wife Dr. Jintong Tang who motivated me to pursue a Ph.D. I am also grateful for our precious son Ayaan A. Khan who provided the motivation to actually finish it!

Thank you.

Shaji A. Khan 


\title{
Organizational Responsiveness to Anti-offshoring Institutional Pressures
}

\begin{abstract}
This study explores the extent to which organizations are responsive to pressures from institutional constituents against offshoring of information technology and business processes. Drawing on a theoretical framework that integrates institutional and strategic explanations, it proposes that organizational responsiveness to anti-offshoring institutional pressures is a function of both the characteristics of such pressures as well as organizations' prior success with offshoring. Results based on moderated hierarchical multiple regression analyses on survey data from 84 offshoring client organizations indicate the following.

First, both greater organizational expectations of enhanced social legitimacy obtained from compliance and mimetic influences from other organizations led to greater organizational responsiveness. Second, despite the strong precedent, organizational dependence on a key pressuring constituent had no effect. Third, both conflict of institutional expectations with organizational goals and greater regulatory environment uncertainty reduced responsiveness. Fourth, surprisingly, organizational success with offshoring had no direct effect on responsiveness. However, it attenuated the otherwise strong positive effect of social legitimacy and exacerbated the negative effect of regulatory environment uncertainty. Implications of these findings for research and practice are discussed.
\end{abstract}




\section{INTRODUCTION}

Offshoring ${ }^{1}$ of Information Technology (IT) and Business Processes (BP) has grown dramatically during the past decade and is expected to continue growing (e.g., Willcocks, Cullen, and Craig, 2010). For example, in the year 2010, IT offshoring alone was estimated to be a $\$ 70$ to $\$ 80$ billion market with a capacity to grow to about half of the currently $\$ 800$ billion IT outsourcing market (Iyengar, 2011a). Parallel to this explosive growth, negative sentiments surrounding offshoring have evolved within the realms of public opinion and concerns of professionals from relative quiescence to a much broader back-lash and political uproar against offshoring (e.g., Mankiw and Swagel, 2006; Rottman and Lacity, 2004). A September 2010, legislative attempt in the United States (U.S.) Senate titled "S.3816 - Creating American Jobs and Ending Offshoring Act" illustrates ${ }^{2}$ the extent to which such broader anti-offshoring institutional pressures ${ }^{3}$ have become pervasive.

\subsection{Statement of Research Issue}

Despite the anti-offshoring institutional pressures, it is difficult to imagine that offshoring as a sourcing strategy will disappear. The current levels of offshoring and future growth projections seem to suggest otherwise. For example, industry predictions from organizations such as Gartner, IDC, Everest, and NASSCOM suggest an annual IT offshoring growth rate of

\footnotetext{
${ }^{1}$ For the purposes of this study, we define offshoring broadly. It refers to the process of sourcing business functions supporting domestic or global operations from abroad, in particular from lower-cost emerging economies, either through a wholly owned subsidiary (captive offshoring), a third-party provider (offshore outsourcing), or a hybrid arrangement [e.g., Manning, Massini, and Lewin, 2008].

${ }^{2}$ This bill failed to become law. Section 2 provides an in-depth examination of anti-offshoring institutional pressures within the United States

${ }^{3}$ The phrase 'anti-offshoring institutional pressures' is used here broadly to denote expectations or demands from institutional constituents that organizations should reduce or eliminate offshoring. The institutional constituents include, but are not limited to, the general public and public opinion, governments, regulatory structures, laws, professions, and interest groups. This view of institutional constituents and pressures is consistent with prior literature (e.g., Oliver, 1991; Goodstein, 1994; Scott, 1987; DiMaggio and Powell, 1983; Meyer and Rowan, 1977).
} 
12\% or higher during the years 2010-2015 (Lacity, Khan, Yan, and Willcocks, 2010). Gartner Research found that in light of increased cost pressures due to the recession, many organizations reported renegotiating existing domestic outsourcing contracts for a lower dollar amount in exchange for lower levels of service and/or more offshore delivery (Iyengar, 2011a; Tramacere, 2011). From this perspective, the extent to which organizations engage in offshoring seems to be more a function of economic imperatives and organizations' strategic considerations than of antioffshoring institutional pressures.

On the other hand, it is unreasonable to assume that organizations will outright resist such pressures. Smith and McKeen (2004) reported that executives are cognizant of the "optics of offshoring" and consider such issues in making offshoring decisions. Research firm Technology Partners International, suggests that during 2011, "U.S. and Canadian companies exhibited growing preferences to keep outsourced work within their countries, often because of sensitivity about data security or offshoring in general” (Reynolds, 2011). A ‘CIO Magazine' article (Overby, 2010) suggested that IS executives can prepare for potential anti-offshoring legislation (a significant manifestation of anti-offshoring pressures) by dealing with suppliers which have a larger U.S. presence and/or by incorporating contractual provisions to buffer against significant anti-offshoring legislation (Overby, 2010). An indirect indicator of such responses from organizations is the ramping up of onshore delivery capabilities by offshore service providers (Iyengar, 2011b).

In summary, it is difficult to imagine organizations as invariably conforming or resistant to anti-offshoring institutional pressures. That is, the extent to which organizations are responsive to institutional pressures for the elimination (or at least reduction) of offshoring remains an empirical question. Indeed, organizational responses related to offshoring may not be 
dichotomous in this regard: They are likely to fall on a continuum ranging from conformity to resistance. But what explains the extent to which organizations are responsive to such pressures?

\subsection{Gaps in the Broader Literature}

The current offshoring literature predominantly points to the economic and strategic drivers of offshoring. While labor costs savings remain the primary economic driver of offshoring (e.g., Kaiser and Hawk, 2004; Khan and Fitzgerald, 2004; King and Torkzadeh, 2008; Rao, Poole, Raven, and Lockwood, 2006; Sobol and Apte, 1995), a variety of strategic considerations have evolved. These range from access to qualified personnel, faster delivery speeds, business or process performance improvements, access to new markets (e.g., Carmel and Tjia, 2005; Kaiser and Hawk, 2004; Rao et al., 2006; Sobol and Apte, 1995), and the conduct of core activities such as innovation (Lewin, Massini, and Peeters, 2009; Willcocks et al., 2010). There is ample indication in the literature that firms do accrue the strategic benefits which initially led them to consider offshoring (e.g., Lewin and Peeters, 2006a; Lewin and Peeters, 2006b; Tate et al., 2009). The literature also suggests that there is substantial variation in terms of the extent of benefits derived by client firms (e.g., King and Torkzadeh, 2008; Lacity and Rottman, 2008).

While the strategic aspects of offshoring are well studied, unfortunately, the current offshoring literature is silent on the impact of anti-offshoring institutional pressures. Further little is empirically known about the prominence of organizational strategic considerations vis-à-vis institutional considerations. Given its critical relevance for clients, suppliers, and public policy in terms of both client and supplier countries, scholars have called for a more systematic examination of such broader institutional pressures against offshoring and their impact on the future of sourcing (Lacity et al., 2010 pp. 414-415). 


\subsection{Research Purpose and Questions}

Thus, the purpose of this research is to develop and test a theory based model that relates both the characteristics of anti-offshoring institutional pressures and organizations' strategic considerations with organizational responsiveness to anti-offshoring institutional pressures. We develop a conceptual model based on Oliver's (1991) theoretical framework and test its predictions using data from a survey of 84 offshoring client organizations. The context of this study is information technology and business process offshoring.

Specifically, the model draws on Oliver's (1991) theoretical framework to suggest the following. 1) Characteristics of anti-offshoring institutional pressures will predict organizational responsiveness to such pressures. 2) The greater the organizations' success with offshoring the lower the organizational responsiveness. 3) Interactions between organizations' success with offshoring and characteristics of anti-offshoring institutional pressures will also predict organizational responsiveness.

Thus, this research addresses the following broad questions in the context of offshoring.

1) How responsive are organizations to anti-offshoring pressures?

2) Do characteristics of anti-offshoring pressures determine organizational responsiveness?

3) Does organizational success with offshoring determine organizational responsiveness?

4) Does success with offshoring interact with characteristics of anti-offshoring pressures to determine organizational responsiveness?

In terms of delimiting the purpose of this research (Creswell, 2009) it 1) does not take a pro- or anti-offshoring stance 2) is not concerned with the potential consequences of organizational conformity or resistance to anti-offshoring institutional pressures, and 3) is not an attempt to assess the "true" macro-economic and societal impacts of offshoring. 
The rest of this manuscript is organized as follows. In section 2, we examine antioffshoring institutional pressures in detail. In section 3, we review literature on the drivers and outcomes of offshoring with a particular focus on institutional theory based explanations of outsourcing decisions. Next, we describe the theoretical framework which forms the basis for this study in section 4. In section 5, equipped with the literature review, theoretical framework, and a better understanding of the nature of anti-offshoring institutional pressures, we develop a set of hypotheses. In section 6, we then describe the research methodology. Following this, we discuss the research findings (section 7), describe the implications for research (section 8) and practice (section 9), and list the limitation and suggestions for future research (section 10) prior to concluding.

\section{ANTI-OFFSHORING INSTITUTIONAL PRESSURES}

Anti-offshoring institutional pressures are part of a broader backlash against global labor arbitrage. Just as earlier attempts of manufacturing firms to move production to destinations with lower overall costs of doing business, the phenomena of IT and BP offshoring began to gather negative sentiments (Gupta, Seshasai, Mukherji, and Ganguly, 2007). These anti-offshoring pressures are evident across a broad spectrum of institutional constituents, such as the political spheres, state and federal level legislative attempts to curb offshoring, public opinion, professionals, and special interest groups such as labor unions, among others. The logic held behind anti-offshoring pressures is simple: offshoring hurts labor market and firms should curb offshoring so as to prevent domestic jobs from being sent offshore (Mankiw and Swagel, 2006).

The political backlash against offshoring became vociferous when high profile politicians joined the fray (Mankiw and Swagel, 2006). For example, in the United States, 2004 presidential 
candidate Senator John Kerry made a series of comments such as "We will repeal every single benefit, every single loophole, every single reward for any Benedict Arnold CEO or corporation that take [sic] American jobs overseas." This was happening at the backdrop of growing negative public opinion about offshoring. In November of 2003 a public outcry was cited as the reason, the Governor of the state of Indiana cancelled a $\$ 15.2$ million contract previously awarded to an Indian IT supplier, Tata Consultancy Services (TCS) ${ }^{5}$. A 2004 UBS/Gallup opinion poll of investors revealed that "[M]ost investors not only oppose outsourcing ${ }^{6}$, but also support strong actions to limit its use by corporate America. (Jacobe, 2004a, emphasis added)." Broader public opinion polls showed a similar backlash and an anti-offshoring stance. A CNN/USA Today/Gallup poll revealed that $60 \%$ of Americans considered a negative impact of offshoring on U.S. jobs to be an important issue that is likely to affect their vote in the coming 2004 presidential election (Jacobe, 2004b). Parallel to this, media commentators such as Lou Dobbs, formerly at $\mathrm{CNN}$, made a virtue out of condemning offshoring. In a rather interesting exposition, Lacity and Rudramuniyaiah (2009) analyzed the public opinion with respect to outsourcing and offshoring as reflected in U.S. and Indian political cartoons. Based on content analyses of 165 cartoons from U.S. and India, the authors found that U.S./Western cartoons typically portrayed outsourcing and offshoring negatively. Common themes were job loss for workers and poorer customer service for consumers. The Indian cartoons, on the other hand, typically depicted jobs gained as well as the labor and infrastructure constrains caused by the rapid growth of IT and BP offshoring (Lacity and Rudramuniyaiah, 2009).

\footnotetext{
${ }^{4}$ (Reported in Washington Times editorial as John Kerry's statement following a win in the southern primaries in Virginia and Tennessee; Washington Times Editorial, May 30, 2004; Similar statements reported in The Wall Street Journal, February 12, 2004)

${ }^{5} \mathrm{http} / / / \mathrm{www}$. computerworld.com/s/article/87537/State agency_cancels_controversial_outsourcing_deal (Retrieved on $04 / 01 / 2011$ )

${ }^{6}$ The term "outsourcing" is often used in the popular press and common parlance to denote "offshoring"
} 
Professional associations such as the Programmers Guild maintain offshoring and workvisas (e.g., H1-b and L-1 visas that allow foreign nationals to temporarily work in the United States) as key issues. They continue to call for action against offshoring and for elimination of work visa programs. ${ }^{7}$ Calls for action include, contacting legislature, rebutting "pro-offshoring studies", and protests/demonstrations against large corporations which offshore. Powerful union groups such as the American Federation of Labor and Congress of Industrial Organizations (AFL-CIO) and the Communication Workers of America - Local 4250 have also long been vocal and active against offshoring and work visas ${ }^{8}$. Further, research has shown that professionals in the United States are wary of offshoring. For example, IT professionals perceive it as a threat to their job security, believe that it has a negative impact on their work and family life, and are predominantly in favor of union based and legislative protectionist measures against IT offshoring (Bruce and Martz, 2007; Knapp, Sharma, and King, 2007). Even senior IS scholars have acknowledged that the negative perceptions of all IT jobs being offshored have caused a serious decline in enrollments within IS and Computer Science programs across U.S. universities (e.g., Hirschheim, Loebbecke, Newman, and Valor, 2007; Hirschheim and Newman, 2010; Kaarst-brown, 2010). While some consider this to be primarily a problem of incorrect perceptions (Hirschheim and Newman, 2010), others have acknowledged that offshoring is the new reality (Beulen, 2010). Yet others argue that offshoring has an overall positive impact on national economy but recognize the significant negative sentiments toward it (Gupta, 2010).

\footnotetext{
${ }^{7}$ Programmers Guild, available online at: http://www.programmersguild.org/offshoring.asp (Retrieved on March 25, 2011).

${ }^{8}$ AFL-CIO, available online at: http://www.aflcio.org/aboutus/thisistheaflcio/ecouncil/ec03112004i.cfm and http://act.aflcio.org/c/18/p/dia/action/public/index.sjs?action_KEY=760 (Retrieved on March 25, 2011). Communication Workers of America - Local 4250, available online at: http://www.cwalocal4250.org/outsourcing/ (Retrieved on March 25, 2011)
} 
The anti-offshoring public sentiments and political rhetoric have also transformed into antioffshoring legislative attempts (Shao and David, 2007). Lawmakers at the state and federal levels have proposed bills which either directly target offshoring or have an indirect impact on it. In terms of legislative attempts at directly restricting offshoring, bills barring government contractors from performing work outside the respective state or United States have emerged. Other bills include: preference systems for contract awards at the state level; mandatory disclosure of geographical location in calls to and from offshore call centers; ban on transmission of personal or financial information of customers abroad without complying with a set of conditions; mandatory disclosure about activities relating to offshoring, such as lay-offs and outsourcing production; and economic sanctions such as elimination of state assistance to businesses that have laid off American employees and shifted jobs to a foreign country (Canto and van Gorp, 2007; Gupta and Sao, 2009; Manley and Hobby, 2006; Mordecai, 2005). Other legislative attempts are indirect but perhaps more potent. These include bills surrounding data privacy, labor negotiations, protection of intellectual property, bureaucratic preconditions on offshore contracts, and visa policies aimed at either restricting the number of foreign workers or increasing the costs of obtaining work visas (Canto and van Gorp, 2007; Gupta and Sao, 2009). Notable among such legislative attempts was the 2005-2006 proposal at the Federal level, by the then Senator Hillary Clinton of New York, termed the "Safeguarding Americans from Exporting Identification Data Act' or 'SAFE-ID Act'.” The proposed law sought to bar the transmission of any personally identifiable information of a U.S. citizen to any entity in a foreign country unless a set of standards was first met, including allowing consumers to prevent the transmission of such information. 
The National Foundation of American Policy claims that between 2003 and 2007 alone upwards of 400 bills attempted to curb offshoring in one way or another of which only 12 became law 9 . For example, year 2004 legislation in Tennessee (Tennessee House Bill 2344) gives preference to data entry and call center operations vendors who ensure that the services are provided by U.S. citizens ${ }^{10}$. Another example is the 2005 legislation in New Jersey (New Jersey Senate Bill 494) which prohibits state contract work from being performed offshore ${ }^{10}$.

The latest wave of anti-offshoring institutional pressures seems to coincide with the global economic crisis which began around 2008 and appears to be stronger than before. In 2008, the then presidential candidate Barack Obama stated while campaigning "I will stop giving tax breaks to companies that ship jobs overseas, and I will start giving them to companies that create good jobs right here in America. ${ }^{11 "}$ In September 2010, with the unemployment rate in the United States hovering around $10 \%$ and the $111^{\text {th }}$ Congressional Session nearing its end, democrats lead by Senator Richard Durbin (D-IL) introduced just such a bill titled, "S.3816 Creating American Jobs and Ending Offshoring Act." The proposed bill sought to amend the tax code in order to create American jobs and prevent the offshoring of such jobs. While the bill failed to become law, President Obama, officially criticized the opponents of this bill in White House press statements. In the weekly presidential address dated September 25, 2010 the president stated that "when we recently closed one of the most egregious loopholes for

\footnotetext{
${ }^{9}$ National Foundation for American Policy available online at http://www.nfap.com/pdf/0407OutsourcingBrief.pdf (Retrieved, March 25, 2011). Foundation website: http://www.nfap.com

${ }^{10}$ State of Connecticut General Assembly, Office of Legislative Research, Report \# 2004-R-0647, September 14, 2004 and 2004-R-0241, March 9, 2004. Available online at http://www.cga.ct.gov/2004/rpt/2004-R-0647.htm and http://www.cga.ct.gov/2004/rpt/2004-R-0241.htm (retrieved on June 18, 2011). See,

http://www.cga.ct.gov/olr/sitesearch.asp by searching for "outsourcing" for additional state level regulatory restrictions

${ }^{11}$ CIO Magazine: September 2, 2008, Patrick Thibodeau. Available online at: http://www.cio.com/article/447091/Obama_Speaks_Out_Against_Offshore_Outsourcing (Retrieved March 25, 2011).
} 
companies creating jobs overseas, Republicans in Congress were almost unanimously opposed.

The Republican leader John Boehner attacked us for it, and stood up for outsourcing, instead of American workers. ${ }^{12,}$ The President also cited an overwhelming public opinion against outsourcing as evident from the "America Speaking Out" initiative by the Republican Party. Among other things, the initiative involved inviting citizens to suggest ideas for job creation on the "America Speaking Out" website ${ }^{13}$. Indeed, a post against "outsourcing of jobs from America" received the most interest and close to 5000 "thumbs up" votes.

A border security bill was passed in July 2010 that had a provision for a steep increase in the visa fees for H1-b and L-1 visas. These increases in visa fees were estimated to add about $\$ 250$ million to the annual visa fee expenditures for the Indian IT industry ${ }^{14}$. In the same month, the state of Ohio banned offshore work for government contracts. In the back drop of such changes, and the proposed introduction of the bill S.3816, the Indian offshoring industry began to show its concern. In September 2010, a high profile delegation led by the Indian industry group, National Association of Software and Services Companies (NASSCOM) and comprising senior representatives from Indian firms such as Wipro, Infosys, and TCS, visited Washington to voice its concern with law makers. Mr. Ameet Nivsarkar, NASSCOM Vice-President summarized the purpose of this visit: "It is a focused delegation. The idea is to make sure that we communicate

\footnotetext{
${ }^{12}$ White House Weekly Address: September 25, 2010. Available online at: http://www.whitehouse.gov/the-pressoffice/2010/09/25/weekly-address-president-obama-gop-leadership-standing-outsourcing-and-s (Retrieved March 25, 2011).

${ }^{13}$ America Speaking Out Website: http://www.americaspeakingout.com/browse/questions/in/job-creation (Retrieved March 25, 2011)

${ }^{14}$ The Hindu - Business Line, September 14, 2010. Available online at: http://www.thehindubusinessline.in/2010/09/15/stories/2010091552280700.htm (Retrieved, March 25, 2011).
} 
our disappointment on the anti-outsourcing rhetoric, and also ensure that it does not become a trend in the US. ${ }^{15}$ "

In summary, regardless of the debate over whether such anti-offshoring institutional pressures are appropriate, necessary, or effective (Mankiw and Swagel, 2006), the above synopsis indicates that these pressures do exist. Thus, it is important to assess how characteristics of anti-offshoring pressures affect the strategic offshoring responses of offshoring client organizations. We review literature on offshoring next.

\section{LITERATURE REVIEW}

As mentioned in section 1, the purpose of this study is to examine the impact of both institutional and strategic considerations on the extent of organizational responsiveness to antioffshoring institutional pressures in the context of their IT and BP offshoring initiatives. Thus, it seems pertinent to understand the strategic drivers of offshoring, the benefits organizations derive from offshoring, and the challenges and risks faced in doing so. Similarly, it is important to assess the extent to which institutional explanations account for outsourcing related decisions and the extent to which strategic considerations and institutional aspects act in conjunction with each other. In the following sub-sections, we review the offshoring literature across these areas and conclude the literature review with a broad summary.

\subsection{Strategic Drivers of Offshoring}

Researchers have investigated a variety of factors that may predict and/or explain organizations' offshoring decisions. Factors related to the internal motives of client firms and the

\footnotetext{
${ }^{15}$ The Hindu - Business Line, September 14, 2010. Available online at: http://www.thehindubusinessline.in/2010/09/15/stories/2010091552280700.htm (Retrieved, March 25, 2011).
} 
nature of the transactions have been reported to play a role in the decision to offshore (Lacity et al., 2010; Lacity, Solomon, Yan, and Willcocks, 2011).

In terms of the motivations to offshore, cost reduction is by far the most dominant driver reported in the literature (Lacity, Khan, and Willcocks, 2009). Both earlier studies (e.g., Clark, Jr., Zmud and McCray 1995; Lacity, Hirschheim and Willcocks 1994) and more recent ones (e.g., Fisher, Hirschheim and Jacobs 2008; Gonzalez, Gasco and Llopis 2005a; Lin, Lin and Huang 2007) have repeatedly shown that a client organization's desire or need to reduce costs was a key driver for domestic outsourcing decisions (Blaskovich and Mintchik, 2011; Lacity et al., 2010). Similarly, cost reduction has been widely cited as the primary reason organizations are attracted to lower cost offshore destinations (e.g., Kaiser and Hawk, 2004; Khan and Fitzgerald, 2004; King and Torkzadeh, 2008; Rao, Poole, Raven, and Lockwood, 2006; Sobol and Apte, 1995).

Other drivers for sourcing IT and BP related services through an offshore model include, access to expertise/skills of global suppliers, business or process performance improvements, enhancing service levels, warding off competitive pressures, improving flexibility and scalability, achieving faster delivery of IT and BP related services, and access to new markets in offshore destinations (e.g., Carmel and Tjia, 2005; Currie, Michell, and Abanishe, 2008; Hutzschenreuter, Lewin, and Dresel, 2011; Kaiser and Hawk, 2004; Rao et al., 2006; Sobol and Apte, 1995). Organizational motives to achieve scalable operations and improve time-for-delivery of services have been particularly more prominent in studies focusing on BP related decisions (Lacity et al., 2011). 
In terms of attributes of the transactions, some have observed that potential increases in the transaction costs related to finding, evaluating, and managing offshore suppliers may discourage firms from offshoring (Smith and McKeen, 2004). Indeed, many studies report such increases in production and transaction costs as outcomes of offshoring (King and Torkzadeh, 2008; Lacity and Rottman, 2008). Similarly, a potential increase in business risks (Smith and McKeen, 2004), concern for data security and protecting intellectual property (Gokhale, 2007; Sobol and Apte, 1995), and a relatively high degree of interdependence among tasks (Mirani, 2007), have been reported to be negatively related to the decision to offshore.

Further, based on insights from a focus group of senior IT managers representing a variety of companies across broad industry types, Smith and McKeen (2004) indicate that senior IT managers are typically cognizant of several risk factors associated with offshoring and often take these into account in making IT offshoring decisions. The senior IT managers in their focus group alluded to higher than expected transaction costs, reduced control on the delivery of IT services, legal and political uncertainties with respect to offshore destinations, cultural differences, and social justice issues. Smith and McKeen's (2004) finding of 'social justice' related issues need particular elaboration given the study purposes. The authors mention that their focus group members "were very aware of the 'optics' of offshore outsourcing." For example, one member stated that "public perceptions are important to us."

\subsection{Success with Offshoring}

Having looked at the literature on offshoring decisions, it is important to also consider the literature which examines whether such organizations achieve the desired benefits (e.g. cost savings) from offshoring initiatives. Majority of empirical research on this issue focuses on explaining variation in the outcomes of offshoring as a function of a variety of factors. However, 
relatively few studies directly describe the extent to which firms achieve the desired benefits. Nevertheless, a few sources do provide a clear indication of the organizational benefits of offshoring. These studies suggest that firms often accrue important cost and non-cost benefits from offshoring. Further, this literature suggests that offshoring has evolved beyond the traditional labor arbitrage paradigm and now includes strategic aspects such as innovation and global access to qualified talent (e.g., Lewin et al., 2009).

The “Offshoring Research Network” (ORN) at Duke University's Fuqua School of Business conducts a multi-year survey of a sample of firms regarding their outsourcing and offshoring initiatives. The survey covers of a variety of business processes including IT and software development. The 2004 survey was targeted to a sample of 650 U.S. Forbes 2000 companies. Findings based on responses from 90 companies indicate that firms' expectations from offshoring were either met or exceeded (Lewin and Peeters, 2006a). The reported median range of achieved cost savings across various types of offshore implementations were between $30-40 \%$. In addition, about $15 \%$ of offshore implementations led to cost savings of $50 \%$ or more. Similarly, in terms of operational service levels Lewin and Peeters (2006a p. 232) reported that $74 \%$ of offshore implementations met service level expectations within the first 12 months of implementation. Overall, the authors suggested that strong positive performances were legitimizing the practice of offshoring across a wide variety of business processes, including IT, and predicted that the trend is expected to continue.

Findings from the 2007-2008 Offshoring Research Survey pertaining to the outcomes of offshoring indicate that firms in general report a variety of benefits which go beyond costsavings. Further, the extent of benefits reported was generally higher for those firms which had a corporate-wide offshoring strategy than those which did not. For example, across the types of 
functions offshored, $44 \%$ of the firms without a corporate offshoring strategy reported as having achieved 'improved organizational flexibility' where as $75 \%$ of the firms which had a corporate wide strategy reported achieving the same benefit. Other benefits at the company-level include increased productivity/efficiency, increase in firm's overall competitiveness, better access to qualified personnel, better focus on core competencies, improved service quality, firm growth, and process improvements (Lewin, 2008). Further, and in contrast to reports from the 2004 survey, the 2007-2008 survey reveals that firms achieved lower than expected cost savings but those with existing offshoring strategies fared better in this regard. For example, in terms of IT offshoring, firms without a functional offshoring strategy expected to the tune of 55\% (median values) of savings but reported achieving about 30\%. However, those firms with an overall offshoring strategy expected $40 \%$ and achieved 35\%. Overall, firms obtained higher savings after having implemented corporate-wide offshoring strategies (Lewin, 2008).

Tate, Ellram, Bals and Hartmann (2009) used a multi-theoretical lens to study the evolution of offshoring through a multiple-case study of 9 large Western organizations. In-depth interviews and archival data analyses indicated that in line with the primary motivation of costreduction, firms did accrue cost related benefits. The study also indicates that as firms progressed in their offshore endeavors they also realized substantial non-cost benefits and began to anticipate such benefits in the future. Those firms which engaged in IT offshoring reported such varied benefits as gaining a foothold in a new geography, increased quality in products and services, access to educated employees, scalability improvements, flexibility, organizational learning, and improvements in business processes. Among these, access to qualified talent, quality, and process improvements were the most cited. For example, one respondent from an 
Automotive company offshoring IT services "stated that its offshore provider is better at quality management and documentation than available onshore providers (Tate et al., 2009 pp. 517)."

Based on a four-phase Delphi study comprising of 10 senior professionals with considerable experience in offshoring, Gokhale (2007) reports that executives believe that overall benefits from offshoring include cost savings, improvements in "time-to-market", scalability in terms of labor, round the clock development work, and access to new technologies, tools, and techniques which an organization may not currently possess (Gokhale, 2007). The executives also demonstrated consensus in that it is essential to have quantifiable added value metrics to ultimately define success with an offshoring initiative (Gokhale, 2007).

Bhalla, Sodhi, and Son (2008) attempted to assess if there is any link between the extent of offshoring and the performance (sales, profit as a percentage of sales, average annual sales per employee, and average annual profit per employee) of 144 of the Global Fortune 500 list of companies during the 5 year period from 1999 to 2004. Based on archival data from public announcements related to offshoring activities of the sample firms, the authors conclude that they could not find any direct or clear evidence between the extent of offshoring and firm performance. Their regression analyses did indicate that IT offshoring was positively related to average annual sales. The authors do not view their results as definitive indication of a lack of benefits from offshoring and suggest that future research may incorporate better measures of performance such as metrics at the business unit or department level (Bhalla et al., 2008). Indeed, it is quite possible that the performance indicators chosen in this study may be too distal from the benefits of offshoring. 
Rottman and Lacity (2008) conducted 45 interviews and analyses of a large volume of documents at a major bio-tech firm in the United States which offshored 21 IT projects to six suppliers in India. The authors observe that juxtaposed against the promised benefits of offshore outsourcing such as lower IT costs, faster delivery speeds, and ability to focus on core capabilities, IT managers often struggle to realize full potential of offshoring. Rottman and Lacity (2008) found that while documents and reports by the senior management suggested that projects were consistently successful in delivering substantial cost savings, those intricately involved with the projects rated them poorly in terms of cost, quality, and productivity. For example, the head of the project management office observed that while the organization may have saved money on hourly labor costs, if other factors such as the extra effort in managing these projects and delayed delivery are taken into account, the organization may have actually lost money. The authors concluded that the firm's strategy to replace domestic contractors with cheaper offshore suppliers was a poor fit with the firm's social and cultural contexts and that the firm's project management processes were incompatible with those of the offshore suppliers.

Similar sentiments are echoed elsewhere. For example, in summarizing the findings of the studies submitted to the 2008 MIS Quarterly special issue on Information Systems Offshoring, King and Torkzadeh (2008) report that some studies found that rather than reducing costs, offshoring leads to increases in production and transaction costs. Also, while some studies reported a favorable stock market reaction to offshoring in general, others provide evidence suggesting that financial markets favor domestic outsourcing over offshoring when a firm's motive is to improve process quality (King and Torkzadeh, 2008).

Dibbern, Winkler and Heinzl's (2008) study posed the question why is there so much variation in economic success between off-shored projects if the wage-differential, cited as the 
primary offshoring motivation, is in fact so high. In particular they explored what types of "extra costs" do clients incur in offshore projects; and how/why do these extra costs for clients vary between projects. Defining client extra costs as "all costs in terms of time, effort, and resources spent by the client organization that go beyond the actual payments to the vendor (p. 335 emphasis added)," Dibbern et al. (2008) drew on Transaction Cost Economics (TCE) theory and the Resource Based View (RBV) in conducting a study of six offshored IT related projects to India. Their results indicated that the client faced extra costs in four types of activities involved in offshored projects: 1) requirements specification and design, 2) knowledge transfer, 3) control, and 4) coordination. Further, whenever projects required higher levels of client-specific knowledge, the incurred extra costs were substantially higher than when general knowledge was needed. Interestingly, the extra costs were primarily due to increased efforts in managing knowledge asymmetries between client and vendor and not due to the traditionally assumed logic (TCE based) of opportunistic behavior by vendors. They also found that a supplier's prior experiences with related client projects reduced the level of extra costs but could not fully offset the increase in extra costs when the projects were highly client-specific. Finally, cultural and geographic distance between client and supplier increased a client's extra costs. Cultural and geographic distance also interacted with level of required client-specific knowledge, such that the effect of client specific knowledge requirements on greater extra costs was even stronger when cultural and geographic distance was greater.

In summary, there is a good indication that firms often accrue cost and non-cost benefits from offshoring. Both industry reports and academic research suggest that the benefits of offshoring are indeed important for organizations. However, while there are more than a few 
instances of success stories related to offshoring, some empirical studies suggest that success is elusive and often contingent on a variety of factors.

\subsection{Challenges and Risks of Offshoring}

Parallel to these, are a collection of prescriptive and empirical studies which highlight the risk factors associated with offshoring. Appendix 2 summarizes some of the major challenges and risks related to domestic outsourcing, offshoring, and netsourcing. Domestic outsourcing and netsourcing are included to provide a frame of reference for ascertaining challenges and risks which are unique to offshoring.

As detailed in Appendix 2, scholars attribute some risks to the clients and suggest that the onus lies on them to ensure success with sourcing arrangements. Examples include developing and retaining appropriate capabilities in-house, effectively managing suppliers, having realistic expectations of cost savings, and drafting and negotiating proper contracts (e.g., Bahli and Rivard, 2003; Earl, 1996). Other challenges and risks are supplier-specific and include lack of capabilities, financial viability, ability to attract and retain human capital (e.g., Jurison, 1995; Sullivan and Ngwenyama, 2005). Yet others are clearly endemic to market and hybrid sourcing arrangements - that is, those related to the transactions, relationships, and agency problems. These include hidden costs, supplier lock-in, difficulties in performance easurement/monitoring, opportunistic behavior, communication problems, and differences in organizational cultures (e.g., Bahli and Rivard, 2003; Earl, 1996; Iacovou and Nakatsu, 2008; Taylor, 2006).

Appendix 2 also indicates that while the three sourcing initiatives share many similar challenges and risks, some are particular to offshoring. For example, the three factors related to socio-political risks, national culture differences, and negative impact on client image are 
especially related to offshoring (e.g., Iacovou and Nakatsu, 2008; Kliem, 2004; Sakthivel, 2007).

Similarly, some risks and challenges such as communication problems, data security, and intellectual property protection become more severe in the offshore context (Goodman and Ramer, 2007; Iacovou and Nakatsu, 2008). Further, factors such as communication problems and cultural differences may interact with other elements in the offshore context and can significantly erode the possible cost related benefits (Dibbern et al., 2008).

\subsection{Captive Offshoring}

The sections 3.1 to 3.3 primarily dealt with offshore outsourcing, i.e. engaging an offshore supplier for IT and BP work. Captive offshoring, on the other hand, refers to use of wholly owned and operated subsidiaries located in offshore locations that perform work for the parent company (Lewin and Peeters, 2006a; Oshri, Kotlarsky, Rottman, and Willcocks, 2009a). Research on captive offshoring is relatively limited as compared with offshore outsourcing (Oshri et al., 2009a; Oshri, Kotlarsky, and Willcocks, 2009b). Nevertheless, some work in this area addresses the extent of captive offshoring, reasons for engaging in captive arrangements, the different types of captive arrangements, and challenges in captive offshoring.

Early research indicated that the extent of captive offshoring for IT related services was rather limited. For example, Lewin and Peeters (2006a) reported that 89\% of IT related offshore implementations were [offshore] outsourced while only $11 \%$ were part of captive arrangements. This is compared to $69 \%$ percent of captive operations for finance and accounting business processes (Lewin and Peeters, 2006a). However, Carmel and Agarwal (2002) observe that captive IT offshoring was more likely to be done by IT firms. Four out of eight major IT firms in their study had extensive captive offshoring operations ranging from 400 to 2000 professionals working in offshore captive centers (Carmel and Agarwal, 2002). Based on interviews with 
senior executives, the authors summarized the reasons these firms engaged in captive arrangements as resembling the classic "build versus buy" arguments. The firms preferred "having vertical integration and an internal locus of control (Carmel and Agarwal, 2002 p. 72)." Specific reasons identified by respondents include faster ramp-up times, advantages in terms of security and intellectual property protection, and compatibility with internal software engineering methodologies and work processes. The authors add that the technology companies also wanted to maintain strong in-house technical capabilities (Carmel and Agarwal, 2002).

From a broader perspective, Oshri et al. (2009a) report that there are two primary reasons for investing in a captive subsidiary offshore. One is to reduce costs (relative to domestic operation) and the other to seek penetration in growth areas. Other reasons include access to qualified personnel (Oshri et al., 2009b). Correspondingly, firms may pursue different types of captive arrangements or strategies that go beyond the basic captive center model where the parent company wholly owns the captive operations and the captive center provides services only to the parent firm.

Oshri et al. (2009b) identify three such broad strategies: hybrid, shared, and divested. Hybrid strategy entails the captive center providing services to the parent firm but in so doing it may further outsource (to local vendors in the offshore destination) traditionally non-core activities. The benefits include higher value work for the parent company while at the same time helping reduce overall costs. Shared strategy means that the captive center provides services to the parent firm but also seeks external clients. The rationale behind such arrangements is that the captive center becomes a profit center while at the same time reducing the overall unit costs by increasing the volume of work performed by the center. Divestment strategy may be adopted when the captive center has developed large scale operations which have brought the costs down 
to the scale of offshore vendors. In such a scenario, the parent company assesses divestment when it is assured that the captive center will continue to provide services and the service levels will not be negatively affected. In addition to these three broad strategies, captive centers may take on other arrangements. These include "build-operate-transfer" (BOT) models where offshore suppliers initially setup and run a captive center only to later transfer it to a client based on certain terms and conditions. Joint-ventures are also possible but typically carry the BOT arrangement (Oshri and Corbett, 2011; Oshri et al., 2009a; Oshri et al., 2009b).

Overall, firms engage in captive offshoring arrangements primarily to maintain internal control, protect intellectual property, reduce the exposure of core competencies to third-party suppliers, access qualified personnel, and increase access to new markets (Carmel and Tjia, 2005; Kotlarsky and Oshri, 2008). At the same time, firms have been reported to face significant challenges of increasing costs, high levels of employee attrition, and lack of integration with the firm's overall global strategy (Oshri et al., 2009b).

\subsection{Institutional Explanations of Outsourcing and Offshoring decisions}

The institutional perspective in a broad sense deals with the processes that define and explain institutionalization in organizational environments and the influences of such processes on organizations (DiMaggio, 1988; DiMaggio and Powell, 1983; Meyer and Rowan, 1977; Oliver, 1991; Powell and DiMaggio, 1991). There are several variants of institutional theory which differ in their approaches and focuses (Scott, 1987). The approach most commonly studied in the IS literature deals with the impacts of the institutional context on organizations (Mignerat and Rivard, 2009). The premise of this approach holds that organizational actions are the product of ideas, beliefs, and values that originate in the institutional context (Greenwood and Hinings, 1996; Meyer and Rowan, 1977; Zucker, 1987). Meyer and Rowan (1977 p. 340) 
observe that "organizations are driven to incorporate the practices and procedures defined by prevailing rationalized concepts of organizational work and institutionalized society. Organizations that do so increase their legitimacy and their survival prospects, independent of the immediate efficacy of the acquired practices and procedures."

Prominent among this approach is work on Institutional Isomorphism (DiMaggio and Powell, 1983) which seeks to explain and predict homogeneity in organizational forms and practices within a given organizational field. The term isomorphism captures the process of homogenization (DiMaggio and Powell, 1983). DiMaggio and Powell (1983) identify three mechanisms though which institutional isomorphic change occurs: 1) coercive isomorphism, 2) mimetic isomorphism, and 3) normative isomorphism. Coercive isomorphism stems from formal and informal pressures exerted on organizations by other organizations upon which they are dependent and through the cultural expectations in the society within which organizations function. Mimetic isomorphism is when organizations model themselves on other organizations. This results from uncertainty which acts as a powerful force driving imitation when organizational technologies are poorly understood, goals are ambiguous, or when the environment creates symbolic uncertainty (DiMaggio, 1988; DiMaggio and Powell, 1983; Powell and DiMaggio, 1991). Normative isomorphism is said to be primarily a product of professionalization in terms of formal education and professional networks.

As mentioned earlier, IS literature primarily draws on work which explicates the institutional effects on organizational processes and structures and particularly the isomorphic pressures which bring about such changes (Mignerat and Rivard, 2009). Scholars have addressed varied aspects such as IT innovation, IS development and implementation, and IT adoption and use (Mignerat and Rivard, 2009). In this section, we discuss the Outsourcing literature which 
either explicitly invokes such aspects of institutional theory or utilizes it to provide post-hoc explanations of outsourcing decisions. We include institutional explanations of broader outsourcing decisions as opposed to only offshoring decisions as literature on institutional explanations for offshoring, in particular, is rather sparse.

Conceptualizing outsourcing as an "administrative innovation," Loh and Venkatraman (1992) analyzed 60 IT outsourcing contracts reported in the press between the period 1988 and 1990. Testing competing diffusion models pertaining to the influence sources responsible for diffusion of IT outsourcing, they found that outsourcing behavior of other organizations (what Loh and Venkatraman termed 'internal sources of influence') was a better explanatory mechanism of the diffusion pattern of IT outsourcing than the influences from mass media reports and vendor communications (i.e. 'external-influences'). Further, they found strong evidence that mimetic influences dominated the diffusion patterns in the post-Kodak regime of their sample. That is, following the landmark announcement of Kodak to outsource, firms clearly displayed imitative behavior in outsourcing. Loh and Venkatraman (1992) discussed this so called "Kodak-effect" as being consistent with the "social visibility" related arguments of Mahajan et al. (1988) and with the ideas of institutional isomorphism presented by DiMaggio and Powell (1983).

Hu, Saunders, and Gebelt (1997) replicated the Loh and Venkatraman (1992) study with a broader archival data set of 175 firms which outsourced IS functions during 1985 to 1995. However, they found no evidence of the "Kodak-effect" but reported that mixed-influence (i.e. both internal and external influences sources) is a dominant influence factor in the IT outsourcing diffusion process (Hu et al., 1997). Regardless of the difference in findings, both studies indicate that institutional influences from peer organizations, media reports, and supplier 
communications played a role in organizations engaging in outsourcing. Loh and Venkatraman (1992) and Hu et al. (1997) do not indicate whether outsourcing in their samples involved offshore outsourcing.

Miranda and Kim (2006) reported that their study departed from prior outsourcing studies adopting an institutional perspective in that they considered institutional structures emanating from within the organization as opposed to the traditional focus on external structures and their influence on organizations. Their focus was to understand whether professional or political contexts (in a surveyed sample of 214 city governments) fostered differential application of the Transaction Cost Economics logic to outsourcing decisions. The authors hypothesized that those city governments which operate in a professional logic will follow Transaction Cost Economics' core prescriptions and those operating under a political logic will follow the opposite. That is, differences between the professional and political institutional contexts will lead to different paradigms of outsourcing related decisions. The authors found mixed support for their model. The institutional context moderated the TCE variables of opportunism, transaction frequency, and bounded rationality. However, the effects of core TCE variables such as asset specificity and uncertainty remained unaltered by the institutional logic being followed. The authors attributed their results, which were both counter to TCE and to their hypothesized moderating impact of the institutional context, to resource munificence and other characteristics of their sample of city government organizations. Miranda and Kim's (2006) study did not indicate whether the outsourcing budgets (their dependent variable) of city governments included offshore outsourcing.

Jayatilaka and Hirschheim (2009) conducted an interpretive field study of the influences of institutional processes and IT-driven considerations on the changes in organizations' IT 
sourcing arrangements overtime. The authors found that changes in sourcing arrangements they observed were often exclusively associated with either an institutional orientation or an ITdriven orientation but rarely both. The authors drew on DiMaggio and Powell's (1983) coercive, mimetic and normative pressures of isomorphic change to understand institutional influences. On the other hand, they viewed IT-driven considerations as non-cost aspects such as systems development efficiency, technology access, productivity, business support from IT, and IT effectiveness (p. 98). In terms of the sourcing outcomes (satisfaction with IT sourcing arrangements) the authors contend that satisfaction depended more on what orientation (institutional versus IT-driven) firms had than on the actual IT sourcing arrangements themselves. Further, an institutional orientation is likely to lead to a less satisfactory sourcing arrangement than an IT-driven orientation - although just having an IT-driven orientation on its own may not be sufficient (Jayatilaka and Hirschheim, 2009 p. 101).

Ang and Cummings (1997) was the only study which directly questioned the then prevalent view that organizations are passive players in light of institutional influences. Taking institutional influences from peer banks and federal regulators for information systems outsourcing within banks as their study context, the authors contended that despite strong institutional influences for outsourcing, banks may enact different strategic responses to such pressures. Specifically, they studied economic factors such as perceived economic gain from conformity to institutional pressures, financial capacity to resist institutional pressures, and transaction costs implied by conformity as moderators of the relationships between institutional influences and banks' extent of IT outsourcing. They further hypothesized that the size of a bank will affect each of the interactions between institutional influence and the above mentioned moderators (i.e. three way interactions). Their study was restricted to the banking industry and 
employed survey data from 243 banks in the United States. Given their dependent variable was dichotomous (outsourcing or insourcing) the authors employed a series of hierarchical moderated logistic regression analyses to test separate models related to each of their two-way and threeway interaction hypotheses. Their results overwhelmingly indicate that when institutional influences involved potential regulatory sanctions, banks were mostly likely to comply with pressures to outsource. Further, this pattern was almost similar for both large and small banks.

Ang and Cumming's (1997) finding is consistent with Oliver's (1991) assertion that acquiescence to institutional pressures best serves the organization's interests when legal coercion is high and/or when it is strictly enforced. With respect to influences from peer banks, Ang and Cummings (1997) found that banks responded to internal considerations more than to institutional pressures from peers. In addition, larger banks tended to pay more attention to economic contingencies than smaller banks when institutional influences from peers were considered. Overall, while Ang and Cummings (1997) acknowledge Oliver's (1991) ideas of a range of possible strategic responses by organizations, they only consider whether organizations outsource (acquiesce) or insource (defy). Further, given their study was restricted to the banking industry, it is unclear how variation in regulatory pressures, for example, when institutional enforcement, vigilance, and sanctions for noncompliance vary or are more moderate (Oliver, 1991); may have changed the results reported in this study. Ang and Cummings (1997) also do not indicate whether outsourcing in their sample of banks involved offshore outsourcing.

\subsection{Literature Summary}

Overall, the literature suggests that while labor costs savings remains the primary strategic driver of offshoring, a variety of other strategic considerations have evolved. These range from access to qualified personnel to core activities such as innovation (Lewin et al., 2009; Willcocks 
et al., 2010). The review also indicates that there are a range of benefits from offshoring (e.g., Lewin and Peeters, 2006a; Lewin and Peeters, 2006b; Tate et al., 2009) but there is substantial variation in the outcomes of offshoring in terms of the benefits derived by client firms (e.g., King and Torkzadeh, 2008; Lacity and Rottman, 2008) and that firms often have to contend with significant challenges and risks.

Noticeably absent from the literature is an explicit consideration of the broader institutional environment in relation to either the drivers or consequences of offshoring, especially when institutional processes against offshoring are concerned. Although the broader Information Systems (IS) literature in general and IT outsourcing literature in particular has drawn on institutional theory (e.g., Hu et al., 1997; Loh and Venkatraman, 1992), a majority of prior work has tended to exclusively focus on explaining processes of conformity and isomorphism. See Mignerat and Rivard (2009) for a broader critique of institutional research in IS. While such work is immensely valuable, it downplays the roles of organizations' concerns with respect to their task environments and active agency in their adaptation to the institutional environments (Covaleski and Dirsmith, 1988; Goodstein, 1994; Oliver, 1991; Perrow, 1985).

This research attempts to address this gap by studying the impact of the nature of antioffshoring institutional pressures on organizational responsiveness. Further, it explicitly considers internal and strategic considerations of organizations to account for organizational active agency and strategic adaptation in light of institutional expectations. We next discuss the theoretical framework. 


\section{THEORETICAL FRAMEWORK}

Oliver's (1991) theoretical framework integrates institutional and resource dependence theories to demonstrate how organizations' strategic responses may vary from passive conformity to active resistance in response to institutional pressures. The level of responsiveness in turn depends on a set of factors related to the nature and context of the institutional pressures themselves (Oliver, 1991). The framework addressed a criticism of the institutional perspective that it tended to downplay the role of organizational self-interests and active agency in organizational adaptation and responses to institutional pressures and expectations (Covaleski and Dirsmith, 1988; DiMaggio, 1988; Powell and DiMaggio, 1991; Scott, 1987). For example, Scott $(1987 ; 1991)$ argued that just as is the case with an organization's technical or task environments, an organization may be expected to exercise 'strategic choice'(Child, 1972) in relation to its institutional environments and when responding to institutional pressures (Scott, 1991). Oliver suggested that institutional theory can and should accommodate interest-seeking, active behavior of organizations and this is possible if "organizations' responses to institutional pressures and expectations are not assumed to be invariably passive and conforming across all institutional conditions (1991, p. 146)." Building on this argument, Oliver (1991) identified a continuum of strategic responses to institutional pressures. She theorized that, depending on a number of factors, such as the degree to which institutional pressures constrain organizational discretion and the dependence of organizations on institutional constituents, organizations may respond to institutional pressures in a variety of modes ranging from passive compliance with to - active defiance of institutional pressures (Goodstein, 1994).

Oliver (1991) suggests that the predictive dimensions related to this conformity or resistance surround both the willingness and the ability of organizations to conform to institutional 
pressures. These dimensions take into account the nature of the institutional pressures and considerations of the organizational task environments (Goodstein, 1994). Oliver (1991) describes the characteristics of these institutional determinants of strategic responses in terms of five factors: cause, constituents, content, control, and context.

The cause of the institutional pressures refers to the underlying rationale for such pressures. It is the set of expectations or intended objectives that lead institutional stakeholders such as the state, to exert pressures on organizations. These reasons for external pressures may be oriented toward 1) enhancing an organization's legitimacy or social fitness (for example, pressures on organizations to 'go green'); or 2) improving its efficiency or economic fitness (for example, exhorting not-for-profit organizations to be more 'business like'). To the extent an organization perceives that institutional demands can enhance its legitimacy or economic fitness, it is more likely to be responsive and less likely to resist institutional pressures (Meyer and Rowan, 1977; Oliver, 1991).

Aspects related to the institutional constituents (including the state, professions, political and special interest groups, and the general public, among others) themselves may also impact the level of organizational resistance to institutional pressures. These aspects include 1) the degree of multiplicity of constituent expectations and 2) the dependence of organizations on external constituents. To the extent that the institutional field is fragmented as a result of divergence or multiplicity in constituents' expectations, full compliance with institutional pressures will be difficult and resistance more feasible (Oliver, 1991; Pache and Santos, 2010; Powell and DiMaggio, 1991). Resistance to institutional pressures is also more likely when organizational dependence on external actors is limited or when the external constituents have lower perceived power (resource derived or normatively sanctioned). The greater the extent to 
which institutional constituents control resources or exert power the more difficult it will be for organizations to resist their expectations (DiMaggio and Powell, 1983; Pfeffer and Salancik, 1978).

Two dimensions related to the content of the pressures themselves also predict the degree of resistance: 1) The degree to which institutional pressures conflict with organizational goals, and 2) the extent to which the institutional pressures constrain organizational discretion. Organizations are less likely to resist to the extent that institutional expectations are compatible or consistent with internal organizational goals and plans. Similarly, resistance is more likely if compliance with institutional expectations means a loss of autonomy in terms of managerial discretion (Finkelstein and Hambrick, 1990) and internal control over processes and outputs (Oliver, 1991; Pfeffer and Salancik, 1978).

The nature of institutional control, that is, the means by which institutional pressures are exerted on organizations will also predict organizational response. Oliver (1991) identifies at least two distinct processes by which pressures are imposed: 1) legal coercion and 2) voluntary diffusion. When broader institutional expectations begin to get shaped into the force of law or government mandate, organizations are made more aware of the public interests (Oliver, 1991). To the extent that consequences of nonconformity are severe and the legal mandate is broadly applicable and enforced, compliance with institutional pressures is more likely (DiMaggio and Powell, 1983; Oliver, 1991). While regulatory mandates are imposed by means of authority, institutional pressures or expectations may also arise when the norms and expectations have been voluntarily adopted and diffused through an organizational field (DiMaggio and Powell, 1983; Goodstein, 1994; Scott, 1987). 
Finally, at least two aspects of an organization's environmental context, 1) environmental uncertainty and 2) the degree of interconnectedness, may also affect organizations' conformity or resistance to institutional demands and expectations. When the environmental context of institutional influence is highly uncertain, organizations are more likely to comply with institutional pressures so as to reduce uncertainty (DiMaggio and Powell, 1983; Oliver, 1991; Pfeffer and Salancik, 1978). Similarly the extent to which the institutional environment is highly interconnected it facilitates widespread diffusion of institutional norms and demands and increases the likelihood of conformity (DiMaggio and Powell, 1983; Meyer and Rowan, 1977; Oliver, 1991).

In summary, Oliver's (1991) framework identifies the five institutional factors of cause, constituents, content, control, and context and the 10 predictive dimensions ( 2 each) within them as determinants of the levels of organizational responsiveness to institutional pressures. Oliver (1991) suggested that depending on the study context, empirical applications of this framework may either predict the degree of responsiveness or focus on individual strategic responses (such as acquiescence, compromise, avoidance, defiance, and manipulation). In line with prior studies (Julian, Ofori-Dankwa, and Justis, 2008; Milliken, Martins, and Morgan, 1998) we limit this model to predicting the degree of organizational responsiveness to institutional pressures and examine dimensions of the institutional factors which are most pertinent to this study's context (e.g., Goodstein, 1994; Ingram and Simons, 1995).

Using Oliver's (1991) framework, prior research has examined pressures which required organizations to alter their processes or outputs (Oliver, 1991; Pfeffer and Salancik, 1978). These studies include explanations of organizational responses to broad institutional pressures for employer involvement in work-family issues (Goodstein, 1994; Ingram and Simons, 1995; 
Milliken et al., 1998). Yet others have partly drawn on this theory in studying specific pressures from interest groups (i.e. a single institutional constituent group) attempting to influence the restaurant industry to reduce fat content in their food offerings (Julian et al., 2008). Overall, this framework is suitable for studying questions of the form "how do organizations strategically respond to institutional pressures and what factors affect organizational responses (Goodstein, 1994p. 352)." Thus, this framework lends itself to the study of anti-offshoring institutional pressures which impact how organizations source information technology and business processes.

In the next section, we develop hypotheses incorporating specific dimensions of the five institutional factors which predict organizational responsiveness to anti-offshoring institutional pressures.

\section{HYPOTHESES}

Incorporating Oliver's (1991) theoretical framework discussed earlier, we posit that the level of organizational responsiveness to anti-offshoring institutional pressures will depend on five factors pertaining to the nature of such pressures mapped across the respective predictive dimensions under cause, constituents, content, control, and context. These are 1) Social Legitimacy (cause), or organizational expectations that greater responsiveness will enhance an organization's legitimacy or social fitness. 2) Dependence on Federal and State Governments (constituents), the degree to which organizations are dependent on pressuring constituents. 3) Organizational Plans for Offshore Portfolio (content), that is, an organization's plans to increase, maintain, or decrease its offshore headcount. 4) Complying Actions of other Firms (control), that is, knowledge of focal executives that executives at other firms are lowering the extent of 
offshore engagements. 5) Regulatory Environment Uncertainty (context), the degree to which executives perceive the regulatory environment with respect to offshoring as unpredictable. In addition, we incorporate 6) Organizational Success with Offshoring as a key organizational consideration with respect to offshoring. Success with Offshoring is also posited to moderate the effects of all five institutional factors. The hypotheses outlined below specify these effects and Figure 1 summarizes the hypothesized relationships within the theoretical framework.

\section{FIGURE 1}

\section{Hypothesized Relationships}

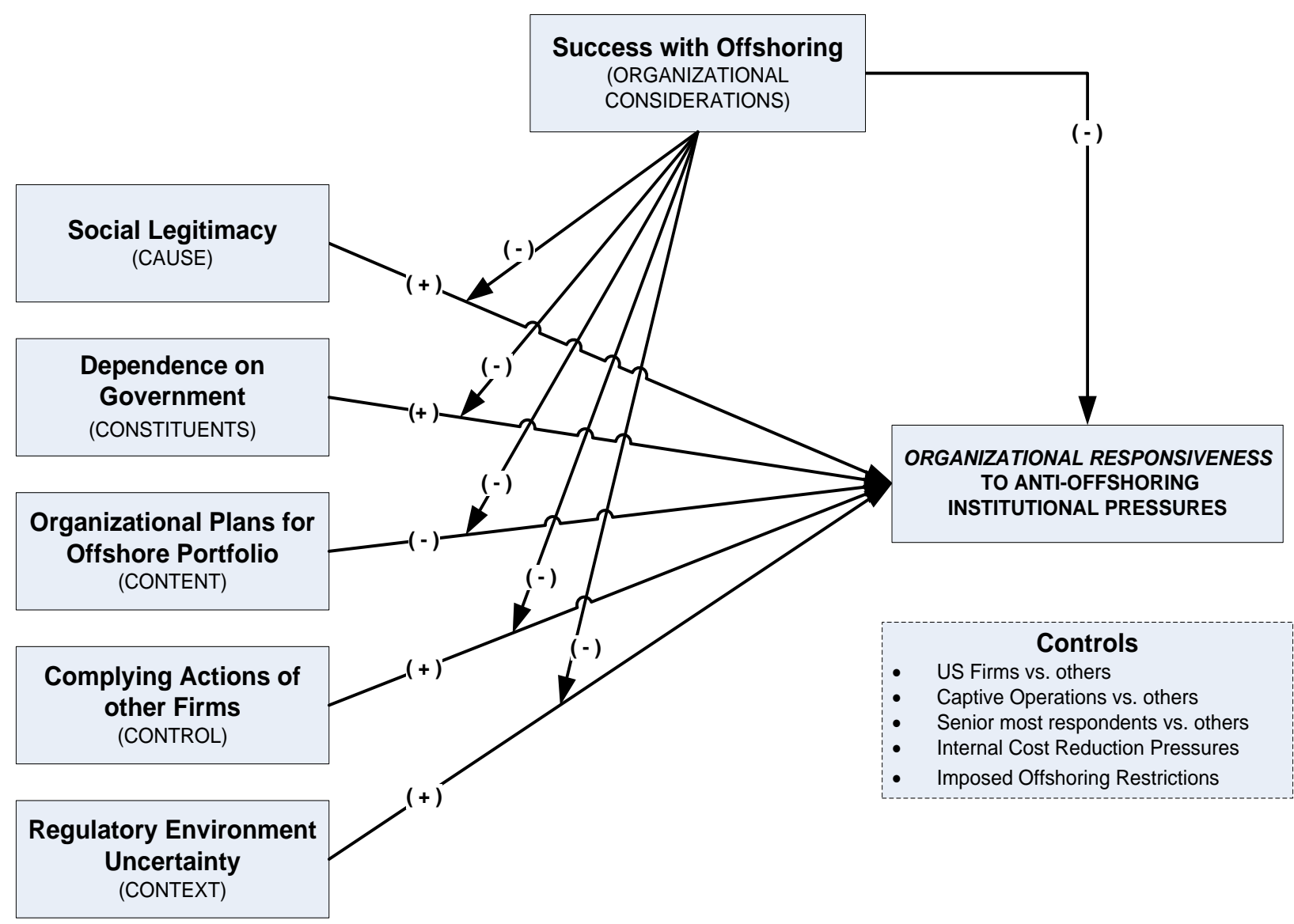




\section{Social Legitimacy and Organizational Responsiveness}

As discernable from the analysis of institutional pressures against offshoring discussed earlier, underlying these pressures seems to be a set of normative beliefs based on the rationale that organizations should play a more active role in reducing the overall level of unemployment in the United States instead of exacerbating it by moving jobs offshore. Such a rationale and the ensuing pressures seem akin to requiring organizations to reduce pollution, deliver safe products and services, to promote health and safety of employees, or adopt work-family initiatives - all of which are geared toward making organizations more socially fit or acceptable (Goodstein, 1994; Ingram and Simons, 1995; Oliver, 1991). Oliver (1991) suggests that the choice between conformity and resistance to institutional pressures will depend on the degree to which the organization agrees with and values the intentions that institutional constituents are attempting to achieve in pressuring the organization to be more socially accountable. This line of reasoning is consistent with Suchman's (1995) arguments that organizations conform to their environments to obtain either or both pragmatic or moral legitimacy and can be understood based on both a strategic view of instrumentally managing legitimacy (Dowling and Pfeffer, 1975; Pfeffer and Salancik, 1978) and the institutional view of obtaining legitimacy as the essence of conformity to institutional processes (DiMaggio and Powell, 1983; Oliver, 1991; Suchman, 1995).

When an organization anticipates that conformity will enhance its social fitness (that is, it would be viewed as more socially responsible or accountable), acquiescence will be the most probable response to institutional pressures (Oliver, 1991). To the extent that organizational actors perceive that not engaging in offshoring or reducing the current extent of offshoring will help enhance the organization's social legitimacy in the eyes of institutional and other stakeholders, it is more likely to conform to institutional pressures against offshoring. That is, if 
an organization believes that it will be viewed as socially responsible and as "doing the right thing" by "not sending jobs overseas" it is likely to lean toward conformity. On the other hand when organizations are skeptical about the social legitimacy or strategic utility of conformity, they are more likely to resist (Oliver, 1991). Accordingly, we hypothesize the following:

Hypothesis 1: The greater the degree of social legitimacy perceived to be attainable from conformity to anti-offshoring institutional pressures, the greater the organizational responsiveness.

\section{Dependence on Governments and Organizational Responsiveness}

The power-dependence relationships between an organization and critical institutional constituents also play an important role in organizational resistance to institutional pressures. Drawing on resource dependence theory, Oliver (1991) suggests that an organization will be less likely to resist external pressures when it is dependent on the sources of these pressures (Pfeffer and Salancik, 1978). Theorists have further observed that power accrues to those who control resources (Pfeffer, 1981), and that the possession of such power makes a stakeholder important to managers (Mitchell, Agle, and Wood, 1997). In the context of this study, one of the most important institutional stakeholders is the Government or specifically, Federal and relevant State Government(s). Government and government policies enacted through legislation have control over critical resources that shape firms' competitive environments (Hillman and Hitt, 1999). As a result there is substantial interdependence between a firm's economic or competitive environment and public policy (Baron, 1995). Further, government decision makers have the ability to alter the size and structure of markets, to affect the demand of products and services, and to alter the cost structure of firms through various types of legislation (Hillman and Hitt, 1999). Governments have power to channel valuable resources toward or away from a firm and 
to use multiple "carrots and sticks" (e.g. tax, data privacy/security, and labor laws) to pressure firms (Kassinis and Vafeas, 2006).

Further, as issues such as offshoring, progress through local to national public awareness with increased media exposure and interest group involvement, they eventually enter the legislative or regulatory arena (Greening and Gray, 1994; Mollitor, 1977). Legislative attempts, such as the S.3816 - Creating American Jobs and Ending Offshoring Act in United States Senate exemplify such eventual transition. The above bill was proposed with a specific aim to reduce or eliminate tax benefits to corporations that send jobs overseas and to increase tax benefits to those that create domestic jobs. The corporate political activity literature suggests that firms often take pulse of the regulatory climate with respect to issues that are salient to them in anticipation of public policy changes (Hillman, Keim, and Schuler, 2004; Mollitor, 1977).

In sum, to the extent organizations are highly dependent on Federal or State Governments they are less like to resist demands for reduced offshoring or fulfillment of government contracts using local labor as opposed to offshore labor. On the other hand, when dependence on Federal or State Governments is low more resistant strategies represent minimal risks to organizational interests because the organization is no longer held captive by its dependence (Oliver, 1991). In such cases partial conformity or even avoidance in the form of ceremonial conformity will be more likely (Oliver, 1991). This leads to the following hypothesis:

Hypothesis 2: The greater the degree of organizational dependence on Federal and State Governments, the greater the organizational responsiveness.

\section{Organizational Plans for Offshore Portfolio and Organizational Responsiveness}

Along with cause and aspects related to the constituents, the content of the institutional pressures is also relevant. One dimension of the content of pressures is the consistency or 
congruence of institutional expectations with organizational goals and policies (Goodstein, 1994; Oliver, 1991). Organizations will be more responsive to institutional expectations when such expectations are compatible with internal goals and plans and less likely to be responsive when internal logics of production and technical considerations are at odds with institutional expectations. In such instances institutional expectations may be precluded by organizational goals and policies that give greater weight to technical and/or economic standards against which performance of most organizations is primarily assessed (Goodstein, 1994; Oliver, 1991). Ingram and Simons (1995) showed that public sector organizations where more likely to be responsive than private sector organizations to institutional expectations regarding organizational involvement in work-family issues. The authors conclude that organizations with goals consistent with institutional pressure are more likely to respond (p. 1476).

Organizational plans with respect to offshoring may be shaped with respect to a variety of internal considerations. For example, given the pervasiveness of IT and its operational and strategic impact, IT sourcing decisions are often substantive for organizations. In fact the common notion of IT Sourcing, as "the organizational arrangement instituted for obtaining IS services and the management of resources and activities required for producing these services (Dibbern, Goles, Hirschheim, and Bandula, 2004 p. 11), " suggests that IT sourcing portfolios need to be carefully managed vis-à-vis the organization's best interests. Further, as mentioned earlier, organizations may engage in offshoring for a variety of reasons such as for better managing costs (King and Torkzadeh 2008) to gain access to expertise/skills of global suppliers, for business or process performance improvements, and for access to new markets in offshore destinations (e.g., Carmel and Tjia 2005; Kaiser and Hawk 2004; Rao, Poole, Raven and Lockwood 2006; Sobol and Apte 1995). Similarly, organizations may choose to reduce or 
eliminate offshore engagements simply because there is no more need (e.g., major projects have been completed), or because there are other technical and economic considerations such as lack of desired cost savings, problems with more than expected extra costs, high turnover in offshore locations, and problems associated with knowledge transfer, among others (Dibbern et al., 2008; Iacovou and Nakatsu, 2008; King and Torkzadeh, 2008; Ranganathan and Balaji, 2007). To the extent organizational plans with respect to offshoring are to increase its overall offshore portfolio based on its internal logic, such plans will be at odds with institutional expectations to reduce offshoring. On the other hand if organizational plans are to decrease its overall offshore portfolio then institutional expectations are in line with organizational goals—-leading to greater responsiveness (cf., Goodstein, 1994; Oliver, 1991). Thus, if an organization plans to increase its offshore portfolio it is less likely to be responsive to anti-offshoring institutional expectations. This suggests the following hypothesis:

Hypothesis 3: Organizations that plan to increase their offshore portfolio will be less responsive to anti-offshoring pressures than organizations that plan to maintain or reduce their offshore portfolio.

\section{Complying Actions of Other Firms and Organizational Responsiveness}

Institutional control refers to the mechanisms through which pressures are imposed on organizations. Oliver (1991) discusses two such distinct processes: legal coercion and voluntary diffusion. In the absence of an overarching legal mandate prohibiting offshoring ${ }^{16}$, the extent, to which the phasing out or elimination of offshoring has voluntary been diffused in an organizational field may become the primary mechanism through which influence occurs (cf., Goodstein, 1994; Oliver, 1991). As organizations adopt norms or practices they become models

\footnotetext{
${ }^{16}$ There have been attempts at legislation to curb offshoring at both the federal and state levels in the United States. However, to our knowledge, there is yet to be a broadly applicable and potently enforced law which directly forbids offshoring. See the discussion on legislative attempts against offshoring in Section 2.
} 
for other organizations in an organizational field, reduce uncertainty with a specific innovation, and the norms and practices they adopt become increasingly legitimated (Goodstein, 1994; Zucker, 1987). This line of reasoning is consistent with DiMaggio and Powell's (1983) view on the mimetic mechanisms underlying organizational conformity. Overall, the more broadly diffused an institutional expectation or practice has become, the greater the likelihood that organizations will conform. On the other hand, the less widespread a set of values, practices, or expectations, the more likely that organizations will be skeptical and the greater the likelihood that organizations will resist (Oliver, 1991).

While the relevance of what is happening with respect to offshoring in an organization's field is clear from the above, it is important to note that institutional pressures are often mediated by the organization's immediate social structural context in terms of social network ties (Westpahl and Zajac, 2001). That is, in responding to external pressures, senior executives and managers are often influenced by information obtained from leaders of other firms in their network (cf., Westpahl and Zajac, 2001). In other words, for executives, a more nuanced indication of an impending drift away from offshoring, if any, may come from leaders of other firms in their social network. Prior research supports this line of reasoning. For example, Davis (1991) demonstrated how direct communication between managers across firms provided a mechanism of vicarious learning for focal firms with respect to the potential benefits and drawbacks of adopting "poison pills" as a takeover defense. Similarly, Westpahl and Zajac (2001) found that the likelihood of a focal firm decoupling stock buyback programs from actual practice increased when other firms in its network had also previously done so.

In sum, the extent to which the ideas of moving away from or further toward offshoring have diffused in an organizational field will determine an organization's response to institutional 
pressures against offshoring. However, the relationships of a focal firm's executives with senior managers at other firms provide the mechanism for vicarious learning--they provide information about the extent to which such diffusion has occurred and the potential benefits/drawbacks of different responses. Thus, to the extent that executives from the focal firm believe that senior managers at other firms in their network are moving away from offshoring, the focal firm is likely to follow suit. This notion is in line with both a network embeddedness perspective (Granovetter, 1985; Westpahl and Zajac, 2001) and a mimetic processes view in which administrators under uncertainty regarding the appropriate response will draw on and heed to what others are doing (DiMaggio and Powell, 1983; Milliken, 1987). This leads to the following hypothesis:

Hypothesis 4: The greater the extent to which senior managers at a focal firm believe that executives at other firms are curbing or eliminating offshoring, the greater the organizational responsiveness.

\section{Regulatory Environment Uncertainty and Organizational Responsiveness}

Finally, Oliver's (1991) framework maintains that the environmental context within which pressures are exerted on organizations is also likely to be a determinant of organizational responsiveness. Specifically, the regulatory environment uncertainty with respect to offshoring is predicted to affect the level of organizational responsiveness. Both resource dependence and institutional theorists have long argued that decision makers within organizations have strong preferences for certainty, stability, and predictability in organizational life (DiMaggio, 1988; DiMaggio and Powell, 1983; Meyer and Rowan, 1977; Oliver, 1991; Pfeffer and Salancik, 1978; Zucker, 1987). Oliver (1991) suggests that when the environmental context of institutional influence is highly uncertain and unpredictable, an organization will exert greater effort to reestablish control and stability over future organizational outcomes. In such cases when 
uncertainty is high, she predicts that organizations are less likely to actively resist and more likely to conform. However, as uncertainty diminishes, the need for stability, security and control decreases and organizations grow more confident in their predictions about future resource acquisition, legitimacy, and organizational outcomes (Oliver, 1991).

When top-level managers perceive a high level of uncertainty in terms of what actions constituents such as government regulatory bodies, might take (Milliken, 1987) they are more likely to err in favor of stability and control over their sourcing portfolio and eliminate or reduce the extent of offshoring. That is, managers are more likely to insulate the organization from unpredictable shifts in the environment and/or to diversify (their sourcing portfolio), by considering more domestic sourcing options vis-à-vis offshoring, so as to diminish the organization's vulnerability to conditions which are poorly understood (cf. Milliken, 1987). On the other hand, when perceived environmental uncertainty in terms of future regulatory action is low, managers are likely to view offshoring as less risky in terms of stability and control over their sourcing portfolio and more likely to resist institutional pressures against offshoring. Accordingly, we hypothesize:

Hypothesis 5: The lower the level of uncertainty in regulatory actions of Federal and State Government( $(s)$ with respect to offshoring, the lower the organizational responsiveness.

\section{Organizational Success with Offshoring and Organizational Responsiveness}

Oliver's (1991) framework explicitly adopts the assumption that organizational conformity to institutional pressures is a strategic choice and acknowledges the importance of both institutional and technical (i.e. task environment) determinants to this choice (Goodstein, 1994). The implicit theoretical rationale underlying the level of responsiveness to institutional expectations surrounds both the willingness and ability of organizations to conform to the 
institutional environment (Oliver 1991). In this sense, an organization's task environment considerations and strategic imperatives become crucial ingredients in how organizations respond to institutional expectations strategically. Prior research has contributed to this line of theorizing in at least two different ways. First, for example, Goodstein (1994) incorporated the technical-economic considerations in an explicit fashion along with Oliver's (1991) five institutional factors, in predicting organizational responses. Specifically, he demonstrated that to the extent institutional expectations were strong and the organizational actors perceived that the benefits of compliance outweighed the costs of compliance; acquiescence was the most likely response. Second, researchers have attempted to explicitly include managerial cognition into the mix by suggesting that variance in organizational compliance maybe in part due to the differences in managers' level of attention to issues and how they interpret such issues vis-à-vis their organization's technical/economic and strategic considerations (Julian et al., 2008; Milliken et al., 1998).

Both streams depict some aspects of the role of active agency which institutional theorists had opined for (Covaleski and Dirsmith, 1988; Oliver, 1991; Powell and DiMaggio, 1991), as it comes into play when organizations consider the responses to institutional pressures. However, both are silent on how active agency surfaces with respect to the strategic drivers and outcomes of the very organizational actions which are the subject of institutional pressures to begin with. To elaborate, managers often have certain strategic objectives in mind that they translate into certain decisions and actions geared toward attainment of such objectives (e.g., Hutzschereuter, Pedersen, and Volberda, 2007; Lewin et al., 2009). It is unclear, then, how active agency manifests itself when 1) the very actions toward attainment of certain strategic goals become the 
subject of counter institutional pressures, and 2) there is variation in the outcomes of such strategic actions which may have implications for the organization itself.

Offshoring provides a fertile context for the evaluation of such aspects of the internal considerations of organizations in responding to institutional expectations. As discussed in the literature review section, the most dominant strategic driver of offshoring reported in the literature is to realize cost savings through labor arbitrage (e.g., Kaiser and Hawk, 2004; Khan and Fitzgerald, 2004; King and Torkzadeh, 2008; Rao et al., 2006; Sobol and Apte, 1995). However, studies increasingly report other strategic motives such as access to skilled personnel offshore, attaining business or process performance improvements, and access to new markets as part of a larger global strategy, lead firms to offshoring (e.g., Carmel and Tjia, 2005; Kaiser and Hawk, 2004; Rao et al., 2006; Sobol and Apte, 1995). For example, based on the ORN longitudinal survey, Arie Lewin and his colleagues report that offshoring practices have evolved at a dramatic pace. By 2008 offshoring had become a major strategic concern of top management at many companies and many existing and planned offshore implementations dealt with innovation related activities such as research and development, new product and software development, and knowledge-intensive processes (Lewin et al., 2009). While these strategic motives may be driving companies to offshore, scholars have also reported substantial variation in the outcomes of such strategic endeavors (Dibbern et al., 2008; Lewin et al., 2009; Lewin and Peeters, 2006b; Manning, Massini, and Lewin, 2008; Rottman and Lacity, 2008). It is this variation in outcomes of past offshoring efforts with respect to various strategic motives is what we suggest will also play a role in organization's strategic responses to institutional pressures. This is both in addition to and in conjunction with the five institutional factors described earlier. Specifically, we contend that past success with offshoring will both have a direct effect on 
organizational responsiveness to institutional pressures against offshoring and also moderate the effects of the five institutional factors. We specify the related hypotheses next.

As noted earlier, a variety of firm level and environmental conditions have reportedly driven firms to consider offshoring. Prominent among these are lower costs, faster delivery speeds, ability to refocus on core business, increasing access to qualified personnel, accessing suppliers' technical capabilities, and achieving process improvements (e.g., Carmel and Agarwal, 2002; Carmel and Tjia, 2005; Lacity and Rottman, 2008; Rottman and Lacity, 2008). Managers have long been required to contain costs, ramp up projects quickly, find qualified and experienced personnel in fast moving technologies, and to innovate constantly (Carmel and Agarwal, 2002). Such requirements seemed to have intensified over-time. For example, a recent Gartner Inc. report ${ }^{17}$ suggests that CIOs are unlikely to see any increases in IT budgets but will be expected to do more than ever before - keep IT costs low while more rapidly respond to business changes, regulatory compliance and innovation. IT will be forced "to make the business of the past more productive, while IT must invest in the future at a rate that does not grow IT costs faster than the business (p. 13)." Similarly, scholars indicate that offshoring may be a key way forward in the global race for talent and innovation (Lewin et al., 2009).

However, many firms fail to realize the desired benefits from offshoring (Ranganathan and Balaji, 2007). Scholars indicate that it takes a tremendous amount of detailed management on both the client and supplier sides to realize the expected benefits of offshore outsourcing (Rottman and Lacity, 2006). Having the appropriate capabilities, strong relationship management and investments, a corporate wide strategy for offshoring, learning curve effects, and dynamic

\footnotetext{
${ }^{17}$ Lopez, J. and Raskino, M. -- Gartner Inc. (March 4, 2010), “CEO Concerns: Peering into 2010 and Beyond” ID: G00174004
} 
portfolios of control may all be attributed to success with offshoring (Carmel and Tjia, 2005;

Choudhury and Sabherwal, 2003; Lacity et al., 2010; Lacity and Rottman, 2008; Manning et al., 2008; Rottman and Lacity, 2008).

Thus, to the extent the strategic drivers of offshoring remain relevant for firms and managers believe that they have been successful in achieving the strategic benefits through their current offshoring efforts (while avoiding or mitigating some of the challenges of offshoring) they are more likely to continue offshoring. As a result they are also less likely to be responsive to anti-offshoring institutional pressures. These arguments lead to the following hypothesis:

Hypothesis 6: The greater the level of organizational success with offshoring, the lower the organizational responsiveness.

In addition to this direct effect, we expect that the level of organizational success with offshoring will strengthen the effects of those institutional factors which lower responsiveness and at the same time weaken the effects of those factors which increase organizational responsiveness. Institutional theorists have acknowledged that to the extent conformity to institutional pressures is perceived to conflict with organizational goals and economic interests, organizations will be more likely to resist such pressures (Covaleski and Dirsmith, 1988; Goodstein, 1994; Oliver, 1991; Powell and DiMaggio, 1991). Such inconsistency reflects organizational interests and strategic motives to be at odds with institutional expectations and provokes organizational doubts about the validity or legitimacy of institutional expectations (Oliver, 1991). That is, the likelihood that organizations will conform or resist to institutional pressures is not exclusively dependent on the five institutional factors identified above (Hypotheses $1-5$ ) but also in interaction with the discrepancy between institutional expectations and organizational strategic motives. We extend these arguments to not only include the strategic 
motives but more proximally, the outcomes of the actions geared toward achievement of such strategic goals. In other words, beyond the strategic drivers of offshoring initiatives (the subject of counter institutional pressures), it is the outcomes of current offshoring efforts in terms of the strategic objectives that will further determine the level of responsiveness to institutional pressures. Given the significant challenges with offshoring (e.g., Carmel and Tjia, 2005; Rottman and Lacity, 2006) those firms which did achieve some level of success with offshoring will be less responsive despite the institutional pressures against offshoring. These considerations lead to the following 5 moderation hypotheses:

Hypothesis 7a: The level of organizational success with offshoring moderates the relationship between the degree of social legitimacy perceived to be attainable from conformity to antioffshoring institutional pressures and organizational responsiveness: the relationship is less positive for those who report high, as opposed to low, success with offshoring.

Hypothesis 7b: The level of organizational success with offshoring moderates the relationship between the degree of dependence on Federal and State Governments and organizational responsiveness: the relationship is less positive for those who report high, as opposed to low, success with offshoring.

Hypothesis 7c: The level of organizational success with offshoring moderates the relationship between organizational plans for offshore portfolio and organizational responsiveness: the relationship is more negative for those who report high, as opposed to low, success with offshoring.

Hypothesis 7d: The level of organizational success with offshoring moderates the relationship between the extent to which senior managers at a focal firm believe that executives at other firms are curbing or eliminating offshoring and organizational responsiveness: the relationship is less positive for those who report high, as opposed to low, success with offshoring.

Hypothesis 7e: The level of organizational success with offshoring moderates the relationship between level of uncertainty in regulatory actions of Federal and State Government(s) with respect to offshoring and organizational responsiveness: the relationship is less positive for those who report high, as opposed to low, success with offshoring. 


\section{METHOD}

\subsection{Data Collection Approach and Target Respondents}

A web-based questionnaire survey served as the primary data collection method. The following factors guided this choice. First, Oliver (1991) suggests that research strategies to investigate responsiveness need to include perceptual measures of several of the proposed variables and that field interviews or questionnaires may be used (p. 172). Second, to our knowledge, there is currently no publicly available (or even available for purchase) archival data pertaining to the study variables. Organizations are currently not required to disclose their extent of offshore engagements and/or the reasons behind their plans to increase/decrease their offshoring initiatives. Given these considerations, we chose the questionnaire survey approach. Prior research has argued and shown that macro-organizational aspects, such as the focus of this study, are relatively less susceptible to mono-method biases compared to more microorganizational concepts such as job satisfaction, stress, and turnover intentions (Ang and Cummings 1997; Crampton and Wagner 1994). Further, scholars have suggested that in the absence of archival data, self-reported measures are acceptable at the organizational unit of analysis provided data is obtained from key respondents who are directly involved with and knowledgeable about the subject matter of interest (Chan, Huff, Copeland, and Barclay, 1997; Dess and Robinson, 1984; Peng and Luo, 2000; Sabherwal and King, 1995).

Target respondents: As indicated above, target respondents for the questionnaire were senior executives (King and Sabherwal, 1992) knowledgeable about the sourcing activities at each firm. However, accurate identification of individuals with such knowledge across a random sample of organizations proved to be challenge. For example, a recent IT sourcing related report from Gartner Research (Karamouzis, 2011) indicates that the constituents more typically 
responsible for the planning and execution of all IT sourcing initiatives within an organization include the $\mathrm{CIO}$ or those operational managers who directly report to the $\mathrm{CIO}$ or other senior executives in charge of IT. Further, executives within other functions such as procurement (e.g., Chief Procurement Officer), legal, and in some cases respective business units are also often in charge of sourcing.

To overcome this challenge of identifying executives knowledgeable of sourcing and in light of difficulties in obtaining data from busy executives we drew on a unique resource that directly provided us access to sourcing executives and professionals. Specifically, to find and gain access to such individuals, we sought help from the research wing of Everest Group, a reputable and fairly large advisory firm with offices in the United States, Canada, United Kingdom, and India. Among Everest Group's many service offerings, the firm provides research and consulting services to buyers and providers of outsourced services and has a significant focus on offshore or global sourcing. Its clients include Global 1000 firms from around the world and across all industry categories ${ }^{18}$. The Managing Partner for Research was our point of contact and championed our research efforts and access to Everest Group's database of sourcing executives.

The research firm's database comprised of names and email addresses of over 10,000 subscribers who draw on this firm's active industry research output and a variety of webinar style presentations related to global sourcing of business services. The research firm agreed to help us collect data from these subscribers. The subscribers represented mostly large organizations from across the world currently engaged in substantial offshore arrangements both

\footnotetext{
${ }^{18}$ Everest Group Website, About Us section: available online at http://www.everestgrp.com/about-us/. Accessed on February 24, 2012.
} 
via captive and third-party supplier models. The subscribers were at various levels within these organizations, ranging from C-level executives to project managers. This was an ideal pool of potential respondents for study purposes, access to which was otherwise very difficult. Thus, we capitalized on this excellent resource and sought to target the subscribers in Everest Group's mailing list. We did so while fully realizing the tradeoff of not having a traditional random sample of organizations.

\subsection{Instrument Refinement and Data Collection}

Instrument refinement: We took the following steps to ensure that the measures were reliable and valid during the design stage (steps carried out in the analysis stage are outlined below). First, we drew on established measures with demonstrated reliability and validity when possible. Second, the instrument was reviewed by two dissertation committee members with knowledge of broader offshoring research and practice. Each member was requested to carry an in-depth assessment of the measures given the study purposes. They were requested to specifically review the initial draft instrument to identify questions that are ambiguous, vague, or sources of possible bias (Bouquet and Birkinshaw, 2008). We iteratively incorporated any suggested changes and refinements. The changes pertained to re-wording of certain items, shortening of items, and elimination of redundant items to shorten the overall survey length. Third, we pre-tested the refined instrument with three executives. Two of these were former senior level IT executives at large organizations in the aerospace and financial services industries. The third executive had extensive experience with global sourcing throughout his career and is currently considered a leading outsourcing expert/consultant. We asked the executives to read the questionnaire carefully and to assess meaningfulness, relevance, and clarity of its items (King and Sabherwal, 1992). Again, changes were incorporated iteratively 
(Chan et al., 1997). The changes from executives pertained to wording changes in the instructions page of questionnaire and clarification/shortening of instructions for certain questions.

Fourth, representatives of the Everest Group went through the survey draft and suggested many changes to better fit the industry vernacular and the current offshoring environment. The managing partner of research, one vice-president of research, and two research analysts, carefully read the survey multiple times. We incorporated their suggestions related to survey length and wording for survey and question instructions iteratively. The survey length was reduced by approximately $40 \%$. All these pre-test respondents reported a survey completion time between 15 to 20 minutes.

Survey administration: The refined questionnaire was administered via the web using SurveyMonkey ${ }^{\mathrm{TM}}$, an online survey creation and data collection tool. The survey contained an introductory cover page and the second page consisted of definitions of important terms such as offshoring, captive centers, third-party suppliers etc. The third page contained a screening question aimed to filter out service-provider, consulting, and other types of firms as the study purpose was to assess responsiveness of client organizations. Only those respondents representing a client organization were allowed to move further. All others were redirected out of the client survey. The last page of survey had a section where respondents could provide their contact information so that a copy of the summarized survey results could be sent to them.

Data collection occurred between September and November, 2011. In the first wave of data collection, the research firm sent emails with a link to online survey to about half the subscribers. Three reminder emails were sent to this set one week apart from each other. This 
resulted in 44 responses. The research firm then sent emails to the second half of their subscribers list. A reminder email, one week later, was also sent to this second list. The number of responses received from the second set of emails was 18 . To increase the number of responses, we sent individual emails to approximately 550 subscribers. This personal outreach resulted in another 38 responses. Finally, we contacted approximately 30 executives at local firms within our region requesting participation. This effort resulted in another 10 responses. We checked for any significant differences among respondents based on these four different modes of contact as described in the next sub-section.

Thus, a total of 110 people responded to the survey invitation. Out of these 7 were representatives of service-provider firms, 9 belonged to consulting firms, and 7 did not specify their firm type. All such non-client respondents were discarded and 87 client organizations related responses were retained. Additionally, three client responses were overwhelmingly blank and had to be removed. All this resulted in a final set of 84 client organizations (buyers of offshore services--either through third-party service providers or own captives) which was used in analyses.

Checks for biases among the set of respondents: Given that the final set of 84 respondents were obtained from four different modes of contact (two separate mass emails and two separate personal outreach efforts) as described above, we compared these four groups using Analysis of Variance (ANOVA) with respect to two variables. ANOVA tests for Total Firm Revenue, F (3, $75)=.90, p>.05$, and for Total Number of Employees F $(3,79)=.69, p>.05$ both indicated that there were no significant differences between the four groups on these variables. Thus, we combined all sets of respondents. 
We compared early versus late respondents to approximate any differences between respondents and non-respondents. Following King and Sabherwal (1992) we compared the first $1 / 3$ with the last $1 / 3$ of the respondents and discarded the middle $1 / 3$ to ensure a clean separation between early and late respondents. ANOVA tests for Total Firm Revenue, F $(1,53)=1.68, \mathrm{p}$ $>.05$ and for Total Number of Employees, $\mathrm{F}(1,55)=2.13, \mathrm{p}>.05$, both indicated that there were no significant differences between early and late respondents. We also compared 40 of the known firms in this study (i.e. those firms whose names could be identified based on respondent information) with a sampling frame representative of the broader population of firms likely to engage in offshoring. Specifically, we compared the 40 known firms with the Fortune Global 500, year 2011 list of companies ${ }^{19}$. Independent samples t-test in terms of 2011 Revenues suggested no significant difference $t(538)=1.176, \mathrm{p}=.240$. Additionally, we compared the 40 known firms with the remaining 44 firms in our study, on all the study variables. ANOVA tests revealed no significant differences.

Sample Characteristics: Table 1 provides demographic characteristics of firms in the sample. Overall, 49 out of 84 respondents (58.3\%) provided a contact email for receiving a copy of survey results. $65 \%$ of firms had revenues of $\$ 5$ billion or greater and $25.3 \%$ had revenues in excess of $\$ 40$ billion. $79.6 \%$ had more than 5000 total employees and $24.1 \%$ had more than 100,000 employees. The firms operate in a diverse range of industries. $27.9 \%$ percent of firms belonged to banking, financial services, and insurance sectors. Healthcare and Manufacturing firms had slightly greater than $10 \%$ representation each and $8.8 \%$ of firms belonged to the electronics and hi-tech sectors. There were no public sector or transportation related firms. The firms had their headquarters (home country) located in a total of nine different countries. About

\footnotetext{
${ }^{19}$ Fortune Magazine, Global 500 List, Year 2011, Available online at: http://money.cnn.com/magazines/fortune/global500/2010/full_list/. Retrieved March 22, 2012.
} 
$70 \%$ of these were United States based firms and $10.7 \%$ were based out of the United Kingdom.

A majority of firms utilized third-party services providers for offshore services.

TABLE 1

Demographic Characteristics of the Sample

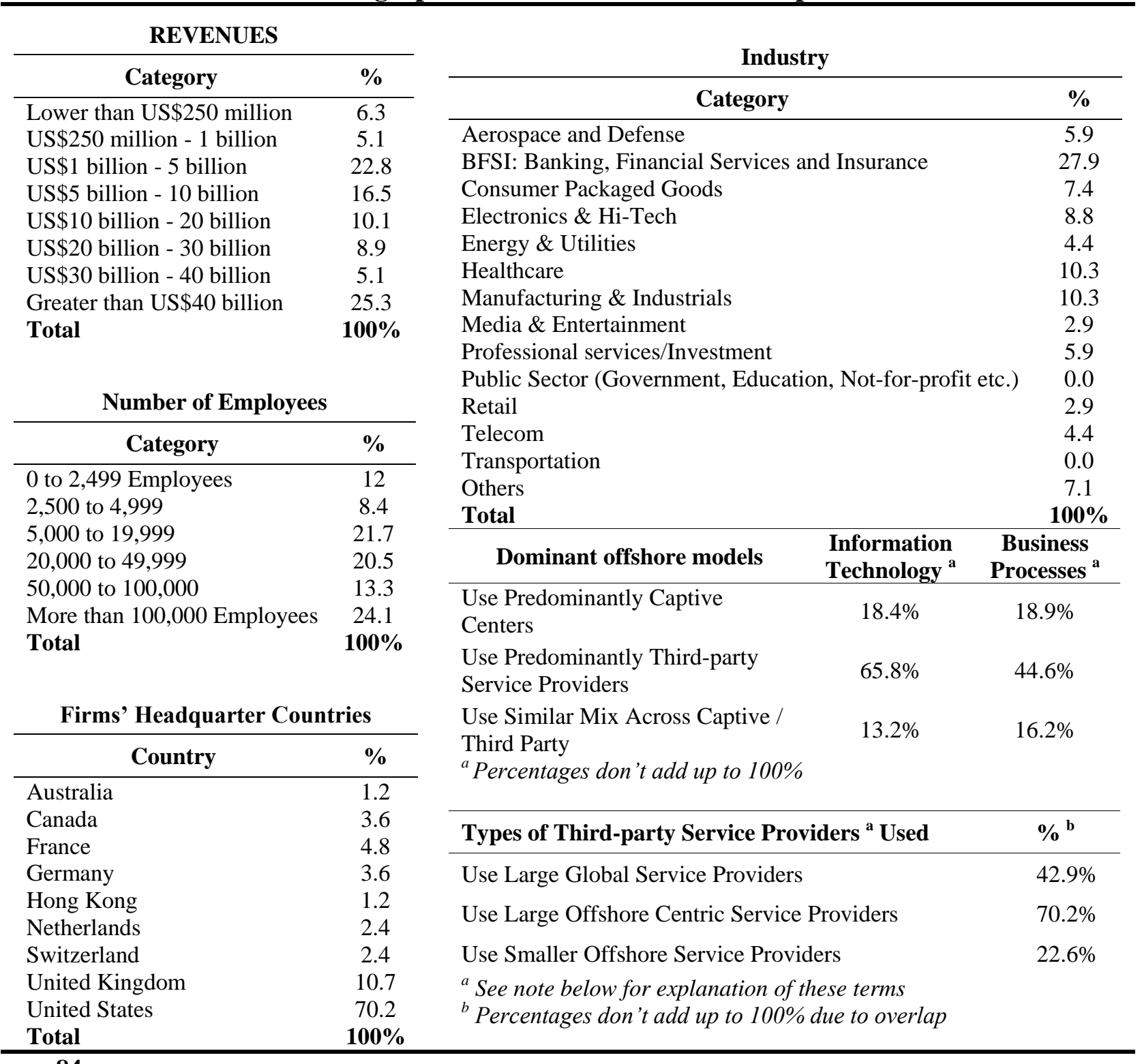

$n=84$

Global Service Providers: Also typically grouped as "Global Majors" are service providers which primarily originated in the US or Europe, and have since spread their operations to additional onshore and offshore countries. Such providers typically have less than 50-60\% of their total headcount based in offshore locations. Examples: Accenture, ACS, Atos, Capgemini, Convergys, CSC, Dell Services (now includes Perot), AON/Hewitt, HP (Enterprise Services), IBM (Global Services), Unisys, and possibly others.

Offshore-centric Service Providers: Also sometimes referred to as "Indian Heritage Service Providers" or 
"Offshore Majors"; these providers started their operations in India, gradually built scale, and then expanded to other offshore and onshore locations beyond India. They typically have $>70 \%$ of their headcount based in offshore locations, mainly India. Examples: Cognizant, EXL, Genpact, HCL Tech, Infosys, Mahindra/Satyam, Tata Consultancy Services (TCS), Wipro, WNS, and possibly others. 


\subsection{Measures}

Appendix 1 summarizes the measures and questionnaire items for all study variables.

\section{Dependent Variable}

Organizational responsiveness to anti-offshoring institutional pressures (Organizational Responsiveness): The dependent variable in this study is geared toward capturing organizational responsiveness to anti-offshoring institutional pressures within the context of organizations' IT and BP offshoring initiatives. Given this purpose, our attempt was to assess whether organizations were heeding to calls for a reduction in overall offshoring and doing so specifically as a result of broader anti-offshoring pressures. Due to a lack of archival data we included direct questions that assess the degree to which organizational actions depict such responsiveness (please see Appendix 1). Respondents were asked to indicate the extent to which they agree with four statements with respect to their organization's responses to anti-offshoring pressures. All of these statements were anchored on a 7-point Likert-type response scale where 1 indicates “Strongly Disagree” and 7 indicates "Strongly Agree." Items assessed overall responsiveness, responsiveness in terms of IT offshoring and BP offshoring, and overall moves toward avoiding new offshoring contracts. For example, "[I]n response to anti-offshoring pressures, our organization has reduced or plans to reduce the overall extent of offshore delivery." After subjecting these items to factor analyses and assessing their reliability we formed an index of these four items by taking their arithmetic mean to represent the construct organizational responsiveness (Cronbach's $\alpha=.874)$.

\section{Independent and Moderator Variables}

Expectations of Increase in Social legitimacy: This variable was assessed by a direct question based on Oliver's (1991) suggestions that senior managers may be asked about 
"whether they expect compliance to increase their organization's status or prestige (p. 172)." An item referring to the organizational expectations of increase in image as a socially responsible organization and organizational prestige was included-"We expect that our image as a socially responsible organization will be enhanced if we lower our overall extent of offshoring." The item was assessed on a 7-point Likert-type response scale where 1 indicates "Strongly Disagree" and 7 indicates "Strongly Agree". Higher ratings indicate greater expectations that lowering the extent of offshoring will enhance the organization's social legitimacy.

Dependence on Federal and State Governments: In creating this measure, we followed a traditional approach used in the corporate political activity literature (Hillman et al., 2004) that focuses on the percentage of revenues coming from governments as an indicator of a focal organization's dependence on government. The item assessed dependence on sales from Federal and State Governments - "A fairly significant portion of our organization's total sales (revenues) comes from Federal and/or State Government(s) as customers." The item was assessed on a 7-point Likert-type response scale where 1 indicates "Strongly Disagree" and 7 indicates "Strongly Agree". Higher ratings indicate greater dependence on government.

Organizational plans for offshore portfolio: Toward the beginning of the survey, respondents were asked to indicate the size of their organization's current offshoring portfolio (approximate offshore headcount in terms of Full-time Equivalent (FTE) workers). Following this respondents were asked of how their overall offshoring portfolio was going to change in the next three years. Response categories ranged from "Decrease by more than 2500 FTE" to "No Change" to "Increase by more than 2500 FTE". Using this data, we created a dummy variable as follows. Those who indicated plans to increase the offshore head-count were coded as " 1 " and those who indicated no change or a decrease in offshore head-count were coded as " 0 ". 
Complying actions of other firms: This variable was assessed in a manner similar to the dependent variable except that the referents for these actions were executives at other firms in the network of the focal firm's executive - "I know of executives at other firms who have responded to anti-offshoring pressures by reducing or planning to reduce the overall extent of offshore delivery." The item was assessed on a 7-point Likert-type response scale where 1 indicates "Strongly Disagree" and 7 indicates "Strongly Agree". Higher ratings indicate greater responsiveness to anti-offshoring institutional pressures by executives at other firms in the focal executive's network.

Regulatory environment uncertainty with respect to offshoring: The conceptualization of environmental uncertainty in this variable is similar to what Milliken (1987) termed 'State Uncertainty.' It captures the extent to which organizational actors "perceive the organizational environment or a particular component of that environment, to be unpredictable (p. 136)." Thus, with the focus on unpredictability and a desire to consider uncertainty in relation to the Federal and state regulatory environment, we drew on the Miles and Snow (1978) perceived environmental uncertainty scale as the building block. This scale has been extensively used and has demonstrated good measurement properties (e.g., Buchko, 1994). The scale requires respondents to rate the specific characteristics or behaviors pertaining to environmental components such as suppliers and government regulatory bodies, in terms of their predictability. The anchors include 1: Highly Predictable and 7: Highly Unpredictable. We adapted the items to reflect the offshoring context, and focused on the regulatory environment. This resulted in the measure containing a total of 5 items pertaining to Federal and State Government(s) Regulatory Actions related to offshoring. The items capture, the degree of predictability of changes in overall tax laws or agency policies, data privacy/security laws, intellectual property protection 
laws, hiring of foreign workers, and conditions surrounding fulfillment of state and federal contracts. Higher ratings indicate greater uncertainty. One item related to intellectual property protection was dropped during factor analyses. A composite based on the mean of the other four items was used to represent regulatory environment uncertainty (Cronbach's $\alpha=.809$ ).

Success with Offshoring: In the interest of gauging overall success with offshoring as opposed to specific offshoring transactions, we drew on the Grover, Cheon, and Teng (1996) IT outsourcing success measure and other studies (e.g., Ross and Beath, 2006; Slaughter and Ang, 1996; Winkler, Dibbern, and Heinzl, 2008) to create a six item overall measure of offshoring success. The approach was consistent with Grover et al. (1996) in that the items were geared toward assessing satisfaction with offshoring. Items covered aspects such as cost reduction, increased access to skilled personnel, improvements in overall flexibility, and increased speed to market or speed of delivery. Two items assessing overall satisfaction were also included (Grover et al., 1996). The items were assessed on a 7-point Likert-type response scale where 1 indicates "Strongly Disagree" and 7 indicates "Strongly Agree". After subjecting these items to factor analyses, we created an index as the average of these six items to represent success with offshoring. Higher values indicate greater success with offshoring (Cronbach's $\alpha=.872$ ).

\section{Control Variables}

US Firms vs. others: While some industry reports indicate that the US is the largest market for offshoring and that US firms are likely to lead the increase in demand for offshoring services in the coming years (Iyengar, 2011a), other reports indicate that there is a slow but noticeable trend among US and Canadian firms to shy away from offshore engagements (Reynolds, 2011). To control for such possible effects we included a dummy variable related to whether a firm's headquarters were within the US or outside of US. Respondents were requested 
to answer the questionnaire with respect to offshoring from their organization's headquarters (home) country. Respondents selected their home country from a list toward the beginning of survey. Organizations with their home country of United States were coded as "1" and all others were coded as " $0 . "$

Captive Operations vs. others: The nature of offshore engagement may also have an impact on the level of responsiveness to institutional pressures against offshoring. Prior research indicates that firms often engage in captive offshoring arrangements where they opt for internal control of offshore operations (captive offshoring) as opposed to or in conjunction with engaging offshore suppliers (Lewin et al. 2009). Captive arrangements involve greater investments of financial and other resources and are typically carried out by larger technology intensive firms (Carmel and Agarwal 2002). Although captive arrangements may be a stronger target for institutional pressures, they may be more difficult for firms to disentangle. On the other hand, captive facilities bring high risks such as of attrition of human assets which are highly mobile (Lewin et al. 2009; Manning et al. 2008). Respondents were asked to indicate the dominant model for their organization's offshore engagement. The response categories included 1) Predominantly Captive, 2) Predominantly Third-party Providers, 3) Similar Mix Across Captive / Third Party. Those who indicated either predominantly captive or some mix of captive and third party were coded as "1" having considerable captive operations and the rest were coded as "0".

Senior Most Respondents vs. others: Despite strong efforts to restrict responses to only senior executives, our lack of control in selecting potential respondents and the nature of this sample required that other respondents be included. Such respondents, although directly involved in the day-to-day operations may not be necessarily attuned to strategic overtones within an organization. Senior level respondents may be more aware of larger institutional shifts and their 
strategic implications for their organizations (Sutcliffe, 1994). To control for this possible effect, we dummy coded respondents as senior most or not. Respondents indicating their job titles to be either at the Chief Executive level (various functions) or one level below it were coded as "1" senior level respondents and the rest were coded as " 0 ", not senior level.

Internal Cost Reduction Pressures: We controlled for organizations' internal pressures to reduce costs as cost reduction has repeatedly been cited as the top reasons organizations choose offshoring (Dibbern et al., 2004; Lacity et al., 2010). Such pressures could explain organizational responsiveness and may very well counteract any effects from institutional factors. This variable was measured with the item "Overall, there are pressures from within our organization to reduce costs for Information Technology (IT) and/or Business Process (BP) related services." The item was assessed on a 7-point Likert-type response scale where 1 indicates "Strongly Disagree" and 7 indicates "Strongly Agree". Higher ratings indicate greater pressures from within the organization to reduce costs for IT and BP related services.

Imposed Offshoring Restrictions: Institutional control describes the means by which pressures are imposed on organizations and one such set of means relate to legal or government mandates and a range of coercive pressures directed at organizations (DiMaggio and Powell, 1983; Oliver, 1991; Scott, 1991). While, arguably, much may be going on in the institutional spheres with respect to offshoring, organizations may not directly feel the pressures to stop offshoring. On the other hand, those facing directly imposed restrictions on offshoring may be more responsive given government or legal mandate. To control for this important variable which may affect the degree of organizational responsiveness, we drew on Section 2 to measure directly imposed offshoring restrictions on organizations coming from four sets of constituents. Four items covered restrictions against offshoring imposed by Federal and/or State governments, 
customers, legal and contractual obligations, and employees/unions. For example, “Our organization faces customer imposed restrictions on offshoring." Two additional items covering overall imposed restrictions on IT and BP offshoring were also included. The items were assessed on a 7-point Likert-type response scale where 1 indicates "Strongly Disagree" and 7 indicates "Strongly Agree". Two items were dropped during factor analysis. A composite based on the mean of remaining four items was used as an indicator for imposed restrictions on offshoring. Higher ratings indicate greater imposed restrictions on offshoring (Cronbach's $\alpha=.882)$.

\subsection{Data Analyses}

Moderated Hierarchical Multiple Regression analyses were carried out to test the hypotheses. Prior to proceeding with hypotheses testing, we assessed the construct validity of all multi-item constructs and checked if the data conform to other important assumptions of Multiple Regression. We discuss these below.

Along with the steps taken during instrument development and refinement discussed above we took the following steps to further assess construct validity of the four multi-item constructs Organizational Responsiveness, Offshoring Success, Regulatory Environment Uncertainty, and Imposed Offshoring Restrictions. First, we performed Principal Component Analysis using Varimax rotation with Kaiser Normalization to ensure convergent and discriminant validity among the constructs (Straub, Boudreau, and Gefen, 2004). Principal Component Analysis requires that the Kaiser-Meyer-Olkin Measure of Sampling Adequacy (MSA) be greater than .50 for each individual item as well as for the overall set of items (Hair et al., 2006). The MSA for two items related to Imposed Offshoring Restrictions was below this threshold. These items were dropped in the first iteration. Further, one additional item related to 
TABLE 2

Factor Loadings and Cronbach's Alphas for Multi-item Constructs

\begin{tabular}{|c|c|c|c|c|}
\hline Items $^{a}$ & $\begin{array}{c}\text { Success with } \\
\text { Offshoring }\end{array}$ & $\begin{array}{c}\text { Imposed } \\
\text { Offshoring } \\
\text { Restrictions }\end{array}$ & $\begin{array}{l}\text { Organizational } \\
\text { Responsiveness }\end{array}$ & $\begin{array}{l}\text { Regulatory } \\
\text { Environment } \\
\text { Uncertainty }\end{array}$ \\
\hline OS1 & .657 & .041 & .071 & .081 \\
\hline OS2 & .785 & .140 & -.003 & -.082 \\
\hline OS3 & .832 & .032 & -.121 & .068 \\
\hline OS4 & .791 & .116 & .072 & -.112 \\
\hline OS5 & .755 & -.022 & -.120 & -.252 \\
\hline OS6 & .689 & -.198 & -.129 & .019 \\
\hline RSTRCT2 & .032 & .670 & .033 & .183 \\
\hline RSTRCT3 & .038 & .871 & .154 & .020 \\
\hline RSTRCT5 & -.039 & .841 & .156 & .142 \\
\hline RSTRCT6 & .082 & .864 & .143 & .096 \\
\hline RESP1 & -.054 & .230 & .785 & .158 \\
\hline RESP2 & .009 & -.003 & .900 & -.085 \\
\hline RESP3 & .099 & .127 & .895 & .086 \\
\hline RESP4 & -.290 & .178 & 691 & -.083 \\
\hline UNCT1 & -.103 & .193 & .090 & .794 \\
\hline UNCT2 & -.007 & .059 & .092 & .793 \\
\hline UNCT4 & -.155 & -.011 & -.105 & .732 \\
\hline UNCT5 & .107 & .235 & -.011 & .787 \\
\hline Cronbach's Alphas & .872 & .882 & .874 & .809 \\
\hline \multicolumn{5}{|c|}{$\begin{array}{l}\text { Extraction /Rotation Method: Principal Component Analysis / Varimax with Kaiser Normalization. } \\
\text { Rotation converged in } 5 \text { iterations. } \\
{ }^{\mathrm{a}} \text { : Appendix } 1 \text { provides the items as used in survey }\end{array}$} \\
\hline
\end{tabular}


Regulatory Environment Uncertainty was cross-loading on two factors. This item was also removed. For the final iteration, the MSA for all items was greater than .50 supporting their retention in the analysis. Further, the overall MSA for the set of items included in the analysis was .71, which exceeds the suggested threshold of .60 for overall MSA (Garson, 2011). The Bartlett's Test of Sphericity was also significant $(p<0.001)$. Communalities for all items exceeded the recommended threshold of .50 indicating that the constructs explain greater than 50\% variation in respective items (Hair et al., 2006). Overall, the Principal Component Analysis showed four factors, as desired, with Eigen-values greater than 1 . The four factors together explained $66.52 \%$ of the variance. All items loaded cleanly on their respective constructs and there were no further high cross loadings. The lowest loading was .657 which is well above the recommended minimum of .40 (Hair et al., 2006). Table 2 provides the factor loadings highlighted in bold for the designated constructs.

We also assessed construct reliability. Cronbach's Alphas for each of the four multi-item constructs, Responsiveness ( $\alpha=.87)$, Imposed Offshoring Restrictions $(\alpha=.88)$, Offshoring Success $(\alpha=.87)$, and Regulatory Environment Uncertainty $(\alpha=.81)$ were well above the recommended .70 threshold (Nunnally, 1978) thus indicating good internal consistency amongst respective items representing each construct (Garson, 2011). Overall, these analyses suggest that lack of construct validity is not a threat to this study's results.

To check for potential outliers and their influence, we first checked the standardized residuals for all cases to ensure they were below the recommended value of 3.3 (corresponding to the .001 alpha level) (Garson, 2011). Examination of standardized residuals revealed that all values were below 2.0 indicating no potential outliers. We also examined the standardized DfBetas for all predictors across all cases. Standardized DfBetas measure the change in $b$ 
coefficients of respective predictors, measured in standard errors, if a potential case were to be dropped from analyses. All standardized DfBetas were below the recommended cutoff of 2 divided by square root of sample size (Garson 2011).

To check whether error terms were normally distributed, we examined the histogram and the Normal P-P Plot of regression standardized residuals (Garson, 2011). Both indicated that the error terms conformed to a normal distribution. The Kolmogorov-Smirnov $(.068, \mathrm{p}>.20)$ and Shapiro-Wilk $(.985, \mathrm{p}=.46)$ tests were both not significant indicating no severe departures from normality. To ensure that Heteroscedasticity was not a problem, we plotted the standardized regression residuals by the predicted values in a scatter-plot. Examination of the scatter-plot revealed a "random cloud of dots" and no consistent pattern--as desired (Garson, 2011). In terms of non-linearity, Garson (2011) indicates that this is in general not a problem if the standard deviation of the dependent variable is greater than the standard deviation of the residuals. The standard deviation on the dependent variable (1.28) in our analyses was greater than the standard deviation of the residuals (.78) indicating that non-linearity was not a threat. We also examined all partial regression plots and found no significant departures from linearity. The residual plot explained above in relation to Heteroscedasticity was also in line with the partial regression plots.

Multicollinearity or the excessive inter-correlation of independent variables can be a serious threat for regression analyses (Aiken and West, 1991). High correlations increase the standard error of the beta coefficients and may mask the unique role of some or all independent variables (Garson, 2011). To minimize this potential problem in relation to the interaction terms and their main effect variables, we standardized all independent variables (including control variables but excluding dichotomous variables) prior to creating the cross-product interaction 
terms (Aiken and West, 1991; Dawson and Richter, 2006). To assess this threat after running the regressions, we examined the Tolerance and Variance Inflation Factors (VIFs) for all variables. All tolerance values were well above the more stringent recommended minimum of .2 and all VIF values were well below the recommended maximum of 4.0 (Garson, 2011). The lowest Tolerance and highest VIF values were .273 and 3.664 respectively and belonged to a crossproduct interaction term involving a dichotomous independent variable. Further, all Condition Index scores were well below the cut-off value of 30 and also below the desired cut-off of 15 . All these indicate that multicollinearity was not a threat for these analyses (Fox, 1997; Tabachnick and Fidell, 2001).

In order to minimize the threat of possible common method variance, we took some steps recommended by Podsakoff, MacKenzie, Lee and Podsakoff (2003). First, as noted above, reliability and validity of the measures were assessed before proceeding to hypotheses testing. The principal component analysis, using the study variables, indicates that none of the items cross-loaded on unintended constructs and highest cross loading was only .29 (Table 2). This suggests that common method variance was not strong enough to confound measurement of study constructs (Julian et al., 2008). Second, in order to ease the respondents' concern of leaking critical business information, they were assured that the survey is completely anonymous and only summarized results will be reported. Third, to provide a reference of the degree of common method variance in the study, we conducted Harman's one-factor test by entering all Likert-type items collected from the questionnaire into one principal components analysis. This obtained a solution with 18 factors with Eigen-values greater than 1 accounting for $80 \%$ of the variance. The first factor accounted for only $7.4 \%$ of the total variance which is less than onetenth of the total variance. Given no single factor accounted for the majority of the covariance 
we had grounds for assuming that common method variance is not responsible for the study results.

\section{Hypotheses test}

As indicated earlier, we used moderated hierarchical linear regressions with ordinary least squares method to test hypotheses. We first entered the five control variables to provide a baseline model (Model 1). We next entered the five (H1 to H5) independent variables in Model 2, followed by the moderator variable (H6) in Model 3. Models 4 to 8 incorporate the five interaction terms between the five independent variables and the moderator. As explained above, all variables were standardized prior to multiplying them to create interaction terms. This was to reduce the potential problem of multi-collinearity between interaction terms and their respective main effect variables (Dawson and Richter, 2006).

We assessed Hypotheses 1 to 5 based on the significance of $b$ coefficients of the respective variables after confirming the overall significance of model 2. We assessed Hypothesis 6 based on the significance of the $b$ coefficient in model 3 as well as the change in $\mathrm{R}^{2}$ between models 2 and 3. Hypotheses 7a to 7e were assessed based on models 4 to 8 respectively. Significance of each of the interaction terms with the hypothesized signs and a significant change in $\mathrm{R}^{2}$ upon adding the interaction term was used to determine support for the respective interaction hypotheses. IBM SPSS Statistics version 19 was used for all analyses. To facilitate interpretation of the significant interactions, we plotted the significant interactions at high and low levels of the moderator variable using values one standard deviation above and below the mean (Aiken and West, 1991; Dawson and Richter, 2006). 


\subsection{Results}

Table 3 provides Means, standard deviations, and Pearson correlations at the measure level for all variables in the analyses. Table 4 provides the regression analyses results for organizational responsiveness to anti-offshoring institutional pressures. Table 5 summarizes the results of hypotheses testing.

Hypothesis 1 stated that the greater the degree of social legitimacy perceived to be attainable from conformity, the greater the organizational responsiveness. As Model 2 in Table 4 indicates, the effect of social legitimacy on responsiveness is significant and positive $(\beta=.36, \mathrm{p}<.001)$ suggesting that organizational expectations for an enhancement in their image as a socially responsible organization are likely to result in their willingness to reduce the overall extent of offshoring. Hypothesis 1 was supported.

Hypothesis 2 stated that greater dependence on governments would lead to organizations being more responsive. The coefficient for dependence in Model 2 is not significant $(\beta=-.09, p$ $>$.05). Hypothesis 2 was not supported.

Hypothesis 3 suggested that the greater the consistency of institutional pressures with organizational goals the greater the responsiveness. Model 2 indicates that the effect of organizational plans to increase offshoring was negative and significant $(\beta=-.20, p<.05)$ suggesting that those organizations with goals to increase their offshore headcounts in the next three years showed lower levels of responsiveness as compared to those whose goals included lowering or maintaining their offshore headcounts. Hypothesis 3 was supported. 
TABLE 3

Means, Standard Deviations (s.d.), and Correlations

\begin{tabular}{|c|c|c|c|c|c|c|c|c|c|c|c|c|c|}
\hline Variable & Mean & s.d. & 1 & 2 & 3 & 4 & 5 & 6 & 7 & 8 & 9 & 10 & 11 \\
\hline 1. US Firm or Not & .70 & .46 & & & & & & & & & & & \\
\hline 2. Captive Operations or Not & .29 & .45 & -.17 & & & & & & & & & & \\
\hline 3. Senior Most Respondents or Not & .59 & .49 & .15 & -.22 & & & & & & & & & \\
\hline 4. Internal Cost Reduction Pressures & 6.05 & 1.34 & .02 & .03 & -.02 & & & & & & & & \\
\hline 5. Imposed Offshoring Restrictions & 3.27 & 1.49 & -.06 & .07 & .01 & .07 & & & & & & & \\
\hline 6. Social Legitimacy & 3.53 & 1.51 & -.05 & .02 & -.12 & .02 & $.47^{* *}$ & & & & & & \\
\hline 7. Dependence on Government & 3.28 & 1.93 & .05 & .06 & .08 & -.05 & $.43^{* *}$ & $.29^{*}$ & & & & & \\
\hline 8. Org. Plans for Offshore Portfolio & .73 & .14 & .15 & .20 & .19 & -.16 & .03 & -.12 & -.07 & & & & \\
\hline 9. Complying Actions of Other Firms & 3.64 & 1.71 & -.02 & .04 & .03 & .02 & $.30^{*}$ & $.33^{*}$ & $.33^{*}$ & -.24 & & & \\
\hline 10. Regulatory Environment Uncertainty & 4.51 & 1.09 & -.09 & -.12 & $.28^{*}$ & -.01 & .18 & .20 & .08 & -.06 & $.28^{*}$ & & \\
\hline 11. Success with Offshoring & 5.11 & 1.05 & .04 & .15 & .01 & .03 & .06 & -.24 & .08 & .14 & -.15 & -.05 & \\
\hline 12. Responsiveness & 2.87 & 1.21 & -.13 & -.18 & .12 & .15 & $.27^{*}$ & $.47^{* *}$ & .15 & $-.34^{* *}$ & $.50^{* * *}$ & .04 & -.06 \\
\hline
\end{tabular}

$* \mathrm{p}<.05$

$* * \mathrm{p}<.01$

Two-tailed tests 
TABLE 4

Results of Moderated Hierarchical Regression Analyses for Organizational Responsiveness

\begin{tabular}{|c|c|c|c|c|c|c|c|c|}
\hline Independent Variables & Model 1 & Model 2 & Model 3 & Model 4 & Model 5 & Model 6 & Model 7 & Model 8 \\
\hline US Firms vs. others & -.17 & -.16 & -.17 & $-.18^{*}$ & $-.18^{*}$ & $-.18^{*}$ & $-.18^{*}$ & $-.22^{*}$ \\
\hline Captive Operations vs. others & -.20 & -.17 & $-.19^{*}$ & $-.20^{*}$ & $-.20^{*}$ & $-.19^{*}$ & $-.20^{*}$ & $-.21^{*}$ \\
\hline Senior Most Respondents vs. others & .09 & $.22^{*}$ & $.23^{*}$ & $.24^{* *}$ & $.25^{* *}$ & $.26^{* *}$ & $.26^{* *}$ & $.24^{* *}$ \\
\hline Internal Cost Reduction Pressures & .13 & .10 & .09 & .09 & .06 & .06 & .05 & .08 \\
\hline Imposed Offshoring Restrictions & $.23^{*}$ & .07 & .05 & .01 & .03 & .04 & .05 & .09 \\
\hline Social Legitimacy & & $.36^{* * *}$ & $.39^{* * *}$ & $.43^{* * *}$ & $.39^{* * *}$ & $.39^{* * *}$ & $.38^{* * *}$ & $.37^{* * *}$ \\
\hline Dependence on Government & & -.09 & -.10 & -.07 & -.10 & -.11 & -.13 & -.12 \\
\hline Org. Plans for Offshore Portfolio & & $-.20^{*}$ & $-.21^{*}$ & $-.24^{* *}$ & $-.23^{*}$ & $-.24^{* *}$ & $-.25^{* *}$ & $-.22^{*}$ \\
\hline Complying Actions of Other Firms & & $.39^{* * *}$ & $.40^{* * *}$ & $.42^{* * *}$ & $.48^{* * *}$ & $.48^{* * *}$ & $.49^{* * *}$ & $.49^{* * *}$ \\
\hline Regulatory Environment Uncertainty & & $-.24^{*}$ & $-.24^{*}$ & $-.23^{*}$ & $-.25^{* *}$ & $-.25^{* *}$ & $-.26^{* *}$ & $-.28^{* *}$ \\
\hline Success with Offshoring & & & .13 & .15 & .16 & .24 & .25 & .19 \\
\hline Social Legitimacy X Success & & & & $-.20^{*}$ & $-.22^{*}$ & $-.22^{*}$ & $-.21^{*}$ & $-.20^{*}$ \\
\hline Dependence on Govt. X Success & & & & & .17 & .16 & .19 & .21 \\
\hline Org. Plans for Offshore Portfolio X Success & & & & & & -.10 & -.11 & -.08 \\
\hline Complying Actions of Other Firms X Success & & & & & & & -.05 & .01 \\
\hline Regulatory Env. Uncertainty X Success & & & & & & & & $-.19^{*}$ \\
\hline Intercept & 3.19 & 3.38 & 3.41 & 3.44 & 3.39 & 3.41 & 3.41 & 3.45 \\
\hline$R^{2}$ & .14 & .48 & .50 & .53 & .55 & .56 & .56 & .58 \\
\hline Adjusted $R^{2}$ & .09 & .41 & .42 & .45 & .47 & .47 & .46 & .48 \\
\hline$R^{2}$ Change $\left(\Delta R^{2}\right)$ & .14 & .35 & .01 & .03 & .02 & .00 & .00 & .03 \\
\hline Model F & $2.52^{*}$ & $6.85^{* * *}$ & $6.49^{* * *}$ & $6.72^{* * * *}$ & $6.68^{* * *}$ & $6.18^{* * * *}$ & $5.72^{* * * *}$ & $5.86^{* * * *}$ \\
\hline$F$ Change & $2.52^{*}$ & $9.76^{* * *}$ & 1.98 & $5.16^{*}$ & 3.44 & .44 & .20 & $4.10^{*}$ \\
\hline
\end{tabular}

Standardized regression coefficients are reported. $n=84$.

$* \mathrm{p}<.05$

$* * \mathrm{p}<.01$

$* * * \mathrm{p}<.001$ 
Hypothesis 4 stated that the greater the extent to which managers at a focal firm believe that executives at other firms are lowering their offshore engagements, the greater will be their responsiveness. Model 2 shows that the effect of complying actions of other firms is significant and positive $(\beta=.39, \mathrm{p}<.001)$. Hypothesis 4 was supported.

Hypothesis 5 stated that the greater the level of regulatory environment uncertainty the greater will be organization responsiveness. The coefficient for regulatory environment uncertainty in Model 2 is significant but the sign is negative $(\beta=-.24, p<.05)$ as opposed to the hypothesized positive effect. This indicates that organizations are instead less responsive when the executives perceive greater levels of uncertainty in regulations pertaining to the future of offshoring. Hypothesis 5 was not supported.

Hypothesis 6 stated that the greater the level of organizational success with IT offshoring, the lower the organizational responsiveness. As Model 3 indicates, upon entering the success with offshoring term, there was no significant increase in $R^{2}$ from Model 2 to $3\left(\Delta R^{2}=.01 ; F\right.$ Change $=1.98, p>.05)$. The coefficient for success with offshoring in Model 3 was not significant $(\beta=.13, \mathrm{p}>.05)$. Thus, Hypothesis 6 was not supported.

Hypotheses $7 \mathrm{a}$ to $7 \mathrm{~b}$ were in relation to the moderating impact of success with offshoring on the five relationships under Hypotheses 1 to 5 . Hypothesis 7a stated that success with offshoring will moderate the positive relationship between social legitimacy and organizational responsiveness such that the relationship will be less positive for those with high success with offshoring as opposed to those with low success with offshoring. Model 4 indicates that the interaction term between social legitimacy and success with offshoring is negative and significant $(\beta=-.20, p<.05)$ as hypothesized. Further, upon entering this interaction term the 
change in $\mathrm{R}^{2}$ from Model 3 to Model 4 was significant $\left(\Delta \mathrm{R}^{2}=.03\right.$; F Change $\left.=5.16, \mathrm{p}<.05\right)$.

The significant coefficient with the appropriate sign and significant change in $\mathrm{R}^{2}$ indicate support for Hypothesis 7a. To further explore the nature of this interaction, we plotted it at high and low levels of the moderator variable using values one standard deviation above and below the mean (Aiken and West, 1991). Figure 2a clearly shows that the otherwise strongly positive slope for the effect of social legitimacy on responsiveness becomes less positive when success with offshoring is high. Together, these results provided strong support for Hypothesis $7 \mathrm{a}$.

Hypothesis $7 \mathrm{~b}$ stated that success with offshoring will interact with dependence on government such that it will make the otherwise positive relationship, less positive. As Model 5 indicates, the coefficient for the interaction between dependence on government and success with offshoring is not significant $\left(\beta=.17, \mathrm{p}>.05\right.$ ). Further the change in $\mathrm{R}^{2}$ from Model 4 to 5 was also not significant $\left(\Delta \mathrm{R}^{2}=.02 ; \mathrm{F}\right.$ Change $\left.=3.44, \mathrm{p}>.05\right)$. Hypothesis $7 \mathrm{~b}$ was not supported.

Hypothesis 7c stated that success with offshoring will moderate the relationship between organizational plans to increase offshore headcounts and responsiveness such that it will make the negative relationship more negative when success with offshoring is high. Model 6 indicates that the coefficient for the interaction between organizational plans and success with offshoring is negative but not significant $(\beta=-.10, p>.05)$. The change in $\mathrm{R}$-square from Model 5 to 6 was also not significant $\left(\Delta \mathrm{R}^{2}=.00 ; \mathrm{F}\right.$ Change $\left.=.44, \mathrm{p}>.05\right)$. Hypothesis $7 \mathrm{c}$ was not supported.

Hypothesis $7 \mathrm{~d}$ suggested that the positive relationship between complying actions of other firms and responsiveness will be weakened when success with offshoring is high. As Model 7 indicates, the coefficient for the interaction between complying actions of other firms and success with offshoring is negative but not significant $(\beta=-.05, p>.05)$. The change in R-square 
from Model 6 to 7 was also not significant $\left(\Delta \mathrm{R}^{2}=.00 ; \mathrm{F}\right.$ Change $\left.=.20, \mathrm{p}>.05\right)$. Hypothesis $7 \mathrm{~d}$ was not supported.

Hypothesis 7e stated that success with offshoring will moderate the relationship between regulatory environment uncertainty and responsiveness such that the relationship will be less positive when success is high as opposed to when it is low. Model 8 indicates that the coefficient for the interaction between regulatory environment uncertainty and responsiveness is negative and significant $(\beta=-.19, p<.05)$ as hypothesized. Further, the change in R-square from Model 7 to 8 was also significant $\left(\Delta \mathrm{R}^{2}=.03\right.$; F Change $\left.=4.10, \mathrm{p}<.05\right)$ indicating support for Hypothesis 7e. To further explore this significant interaction, we plotted it using one standard deviation above and below the mean of the moderator variable (Aiken and West, 1991). Figure 2b shows that the slope of regulatory environment uncertainty becomes more negative when success with offshoring is low when compared to when success with offshoring is high. Together, these results indicated support for Hypothesis 7e. 
FIGURE 2a

Plot of Interaction between Social Legitimacy and Offshoring Success

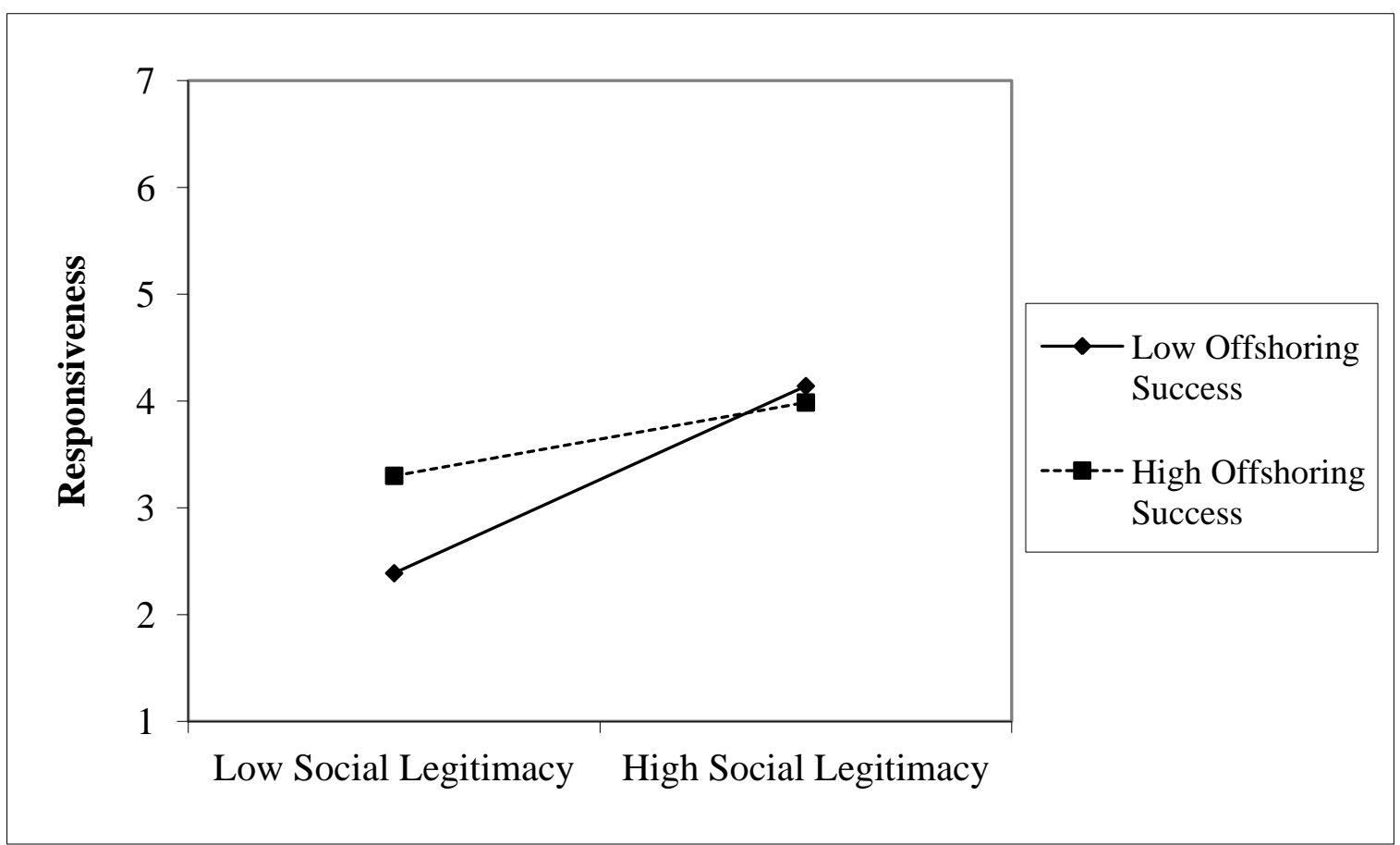

FIGURE 2b

Plot of Interaction between Regulatory Environment Uncertainty and Offshoring Success

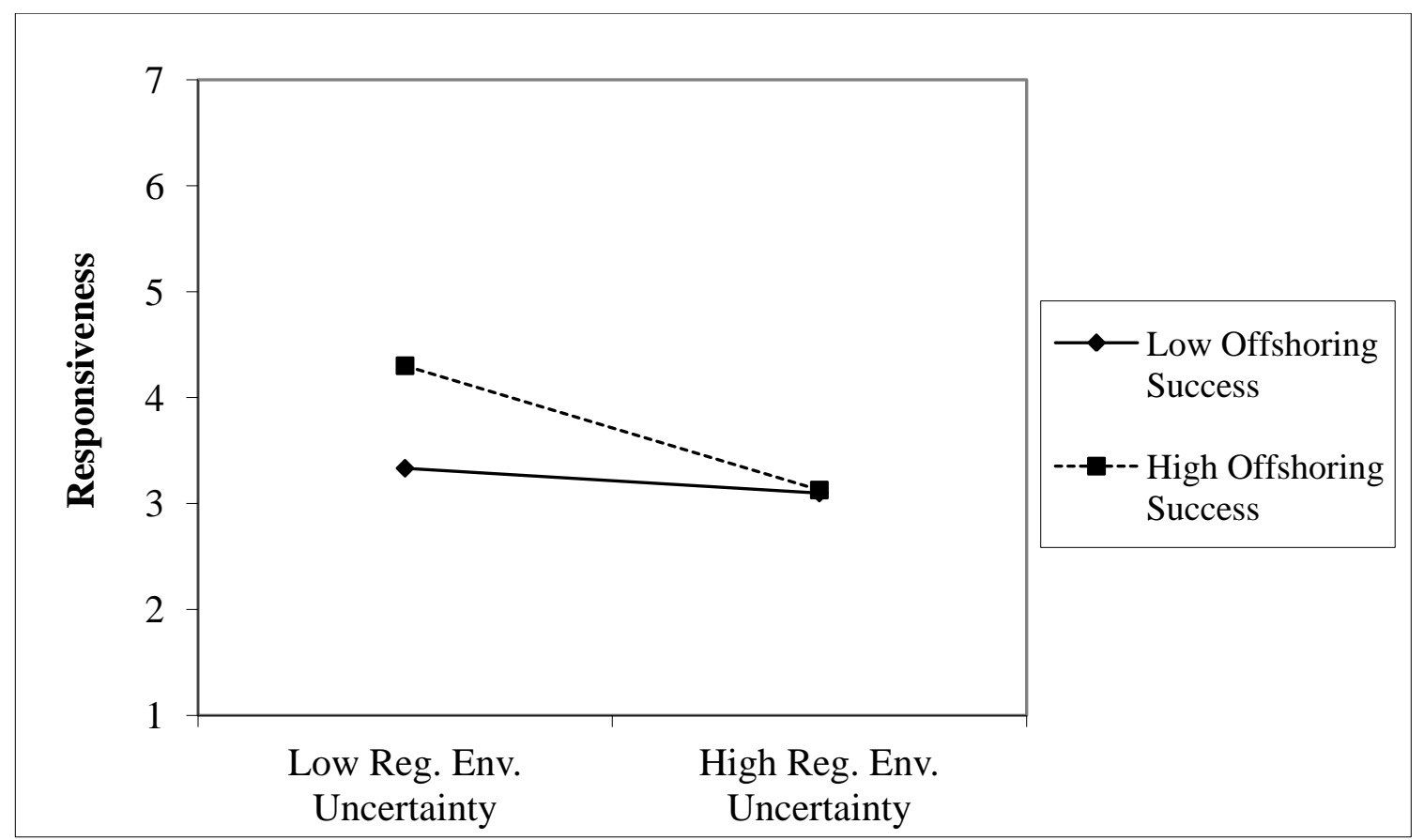


TABLE 5

Summary of Hypotheses Testing Results

\begin{tabular}{l} 
Hypothesis \\
\hline Hypothesis 1: The greater the degree of social legitimacy perceived to be attainable \\
from conformity to anti-offshoring institutional pressures, the greater the organizational \\
responsiveness. \\
Hypothesis 2: The greater the degree of organizational dependence on Federal and \\
State Governments, the greater the organizational responsiveness. \\
Hypothesis 3: Organizations that plan to increase their offshore portfolio will be less \\
responsive to anti-offshoring pressures than organizations that plan to maintain or \\
reduce their offshore portfolio. \\
Hypothesis 4: The greater the extent to which senior managers at a focal firm believe \\
that executives at other firms are curbing or eliminating offshoring, the greater the \\
organizational responsiveness.
\end{tabular}

Hypothesis 5: The lower the level of uncertainty in regulatory actions of Federal and State Government( $(s)$ with respect to offshoring, the lower the organizational responsiveness.

Result

Supported

Hypothesis 6: The greater the level of organizational success with offshoring, the lower the organizational responsiveness.

Not

Supported

Supported

Hypothesis 7a: The level of organizational success with offshoring moderates the relationship between the degree of social legitimacy perceived to be attainable from conformity to anti-offshoring institutional pressures and organizational responsiveness: the relationship is less positive for those who report high, as opposed to low, success with offshoring.

Hypothesis 7b: The level of organizational success with offshoring moderates the relationship between the degree of dependence on Federal and State Governments and organizational responsiveness: the relationship is less positive for those who report high, as opposed to low, success with offshoring.

Hypothesis 7c: The level of organizational success with offshoring moderates the relationship between organizational plans for offshore portfolio and organizational responsiveness: the relationship is more negative for those who report high, as opposed to low, success with offshoring.

Hypothesis 7d: The level of organizational success with offshoring moderates the relationship between the extent to which senior managers at a focal firm believe that executives at other firms are curbing or eliminating offshoring and organizational responsiveness: the relationship is less positive for those who report high, as opposed to low, success with offshoring.

Hypothesis 7e: The level of organizational success with offshoring moderates the relationship between level of uncertainty in regulatory actions of Federal and State Government(s) with respect to offshoring and organizational responsiveness: the relationship is less positive for those who report high, as opposed to low, success with

Supported offshoring. 


\section{DISCUSSION}

This study examined the impact of the nature of anti-offshoring institutional pressures on organizational responsiveness to such pressures. The objective was to understand how firms respond to calls for lowering or eliminating the practice of offshoring. Offshoring has been a target of backlash from opponents who cite domestic job loss as its primary negative effect (King, 2005; Venkatraman, 2004). Yet proponents view it as the inevitable shift in a global economy with many positives, especially in terms of reduced costs for organizations (King, 2005; Venkatraman, 2004). Given such reported benefits, firms may not be invariably responsive to institutional pressures and instead take their strategic considerations into account. Thus, we modeled organization's prior success with offshoring as an additional predictor of organizational responsiveness and as a moderator of the influence of institutional variables.

The findings are generally consistent with fundamental explanations of organizational responsiveness to institutional pressures that suggest that organizations do not uniformly conform to institutional pressures but adopt varying postures depending on the nature of institutional pressures that come to bear on them (Goodstein, 1994; Oliver, 1991; Powell and DiMaggio, 1991; Scott, 1991). However, there are some surprising and some interesting results that contribute to both the information systems literature and organization theory in general. We discuss the findings below and describe their implications in a later section.

The finding related to social legitimacy's strong positive effect on organizational responsiveness lends support to a key institutional theory paradigm that organizations respond to institutional pressures in order to maintain or garner social legitimacy (Deephouse, 1996; Oliver, 1991; Suchman, 1995). Expectations in increase of organizational image as socially responsible 
by reducing overall extent of offshoring were strongly and positively related to organizational responsiveness. An interesting note with respect to the measure of social legitimacy in this study is warranted here. The measure of expectations in increase of social legitimacy was based on Oliver's (1991) suggestions that executives be directly queried about such expectations. This approach departs from traditional conceptualizations of social legitimacy in terms of organizational size (e.g., revenues, number of employees). The argument with related to size as an indicator of social legitimacy has been that larger organizations due to their size and visibility, are likely to be under greater pressure to maintain their social legitimacy and hence be more responsive (e.g., Goodstein, 1994; Julian et al., 2008). Interestingly however, neither organizational revenues nor number of employees as indicators of size were significantly related to responsiveness in our analyses (not reported here). Nevertheless, the theoretical underpinnings seem to remain strong with respect to social legitimacy's effects on organizational responsiveness.

Dependence on governments, measured as percentage of revenues from government sales, was not related to organizational responsiveness. This finding is surprising given the strong precedence for the effects of dependence in the strategic adaptation and institutional theory explanations of organizational responsiveness (Oliver, 1991; Pfeffer and Salancik, 1978). Oliver (1991) suggests that greater dependence on pressuring constituents will lead organizations to be more responsive to constituent demands. One possible reason for this non-finding could be that governments may not be the only source of anti-offshoring pressures or perhaps a potent enough source - and this measure doesn't fully capture dependence on other constituents and/or the nature of this dependence. In order to explore this further, we conducted post-hoc analyses for this hypothesis using three alternative operationalizations of dependence. We used extent of 
government regulation for organizations, percentage of union representation in total workforce, and number of Information Systems employees within organizations. As indicated in section 2, unions have long argued against offshoring and are strong supporters of protectionist measures. Given this, the higher the percentage of union represented employees the greater the dependence and hence the greater the responsiveness. Similar logic was used for number of IS employees. Overall, all three alternative indicators did not change the results and were all not significant. Another explanation is that it is perhaps not dependence on such constituents that matters in this case but the multiplicity or conflict in expectations or demands among constituents that puts organizations in a precarious position - simple conformity in such instances is unlikely (Oliver, 1991; Pache and Santos, 2010).

With respect to organizational plans for their offshore portfolios the results suggest that those organizations that planned on increasing their offshore footprint in the next three years were less responsive than those organizations that planned to maintain or reduce their offshore headcounts. This finding is consistent with institutional theory accounts that suggest that, to the extent responsiveness to institutional pressures conflicts with organizational goals, organizations will be more likely to resist full conformity (Covaleski and Dirsmith, 1988; Oliver, 1991; Pache and Santos, 2010; Powell and DiMaggio, 1991).

The significant but negative effect of regulatory environment uncertainty on organizational responsiveness was in the opposite direction to our hypothesis. The results suggest that those organizations whose executives perceived greater levels of regulatory environment uncertainty with regard to offshoring were actually less responsive to institutional pressures against offshoring. This finding runs counter to Oliver's (1991) theorizing that suggests organizations will adopt more responsive strategies when the environmental context of institutional influence is 
highly uncertain and unpredictable (p. 170). One possible explanation for this reverse finding is that greater unpredictability in regulatory changes that could impact offshoring may not immediately translate into a need for lowering the extent of offshoring. This is possibly because, to the extent executives perceive that regulatory changes impacting offshoring are in fact predictable, they are more likely to take them into account in their immediate decision making. Such decisions may be, depending on what changes are perceived to be predictable, to either increase, decrease, or maintain offshoring. When any such changes are not predictable, then other things equal, they are likely to continue in their strategic course and adopt a posture of buffering their organizations from such unpredictability. For example, while organizations may choose not to lower the extent of offshoring given the unpredictability of impending regulation, they may adopt buffering strategies such as choosing to work with service providers who can shift from offshore delivery to onshore delivery if the need arises. This line of reasoning is consistent with Milliken's (1987) arguments that when the environmental context is not predictable, organizations adopt strategies to insulate themselves from sudden, unexpected shifts in the environment but do not commit to a particular strategic direction (p. 139). Future research may explore both responsiveness and other types of buffering strategies simultaneously as consequences of environmental uncertainty. Another possible explanation is that we focused only on the regulatory aspects of environmental uncertainty as opposed to including other aspects such as customers, competitors, suppliers, actions of labor unions, and financial markets (e.g., Miles and Snow, 1978). Inclusion of such other aspects may have changed these results. It is also possible that uncertainty in relation to different sectors may have different impacts on organizational responsiveness. Finally, it is plausible that this relationship is actually curvilinear. Overall, subject to further replication, this finding suggests that despite executives' preference 
for stability and control in their organizations, uncertainty in regulatory environment with respect to offshoring decreases organizational responsiveness.

One of the most interesting set of findings from this research relates to how the effects of organizations' prior success with offshoring come to bear on their responsiveness to antioffshoring pressures. The rationale behind inclusion of this variable was to assess how the extent to which success with an organizational practice or arrangement which is the very issue for institutional pressures, plays a role in organizations' responsiveness to such pressures. The following results shed light on this question.

The direct effect of success with offshoring (measured as satisfaction with overall offshoring outcomes) on organizational responsiveness was non-existent. We hypothesized that greater success with offshoring will result in lower organizational responsiveness. However, success with offshoring had no direct effect on responsiveness and remained consistently so across all models. Prior empirical work has shown that organizations are most responsive when institutional pressures and organizational considerations converge. Goodstein (1994) found that organizations were more responsive to institutional pressures for organizational involvement in work family issues when the technical benefits from responsiveness were also greater. His study included benefits in terms of organizational outcomes such as increased employee productivity, morale, and retention, among others. However, such logic doesn't seem to extrapolate well based on current results. That is, the potential for losing out on existing benefits from offshoring did not at least directly lower organizational responsiveness.

However, success with offshoring did attenuate the otherwise very strong positive effect of a key institutional variable. As results related to the interaction between social legitimacy and 
offshoring success indicate, greater success with offshoring modified the positive influence of social legitimacy expectations on organizational responsiveness. Specifically, when offshoring success was low, social legitimacy had a strong positive relationship with organizational responsiveness. However, when success was high, the otherwise strong positive relationship became much weaker (see Figure 2a). This is perhaps the most interesting finding from this study. It highlights the dynamics of institutional and resource dependence explanations behind the motives of organizational responses to external expectations - in that, compliance to external expectations under the institutional lens may be viewed as self-serving while non-compliance under the resource dependence perspective may also be considered self-serving (Oliver, $1991 \mathrm{pp}$. 149-150).

This logic rests on the idea that both theories suggest organizations attempt to obtain stability and legitimacy, both assume that organizations may be interest driven, and both highlight the importance of obtaining legitimacy for purposes of demonstrating social worthiness and garnering resources (DiMaggio, 1988; Dowling and Pfeffer, 1975; Greenwood and Hinings, 1996; Oliver, 1991; Powell and DiMaggio, 1991; Scott, 1991; Suchman, 1995). Under such logic then, Oliver (1991) suggests that the advantages of compliance from an institutional perspective include increased prestige and social legitimacy among others. On the other hand the advantages of non-compliance from a resource dependence perspective include the ability to maintain discretion or autonomy over internal processes and the flexibility to permit continual adaptation vis-à-vis the task environment. The results pertaining to the non-existent direct effect of offshoring success and the significant interaction effect with social legitimacy indicate that while strategic considerations do not blatantly result in non-responsiveness they do come into play in a 
much more subtle manner. Next, we discuss the implications of the study results for research and practice.

\section{IMPLICATIONS FOR RESEARCH}

Recent developments in the outsourcing literature have highlighted the importance of corporate social responsibility (CSR) and sustainability for both buyers and service providers of global outsourcing (e.g., Babin and Nicholson, 2009; Brown, 2008). Ideas relating to CSR in a global outsourcing context range from philanthropy, to compliance with global standards, to collaborative efforts between clients and service providers to create social value (Babin, Briggs, and Nicholson, 2011). Such an approach is consistent with past focus on the implications of CSR in manufacturing and procurement in general (Drumwright, 1994) and essentially addresses what Basu and Pallazo (2008) term as the span of organizational commitment to CSR. While such focus is certainly valuable and worthy of attention, one contribution of this study lies in its suggestion that the implications of social responsibility may extend to the very notion of offshoring to begin with. In other words, while socially responsible offshoring is certainly worthy of further research (e.g., buyer requirements for offshore providers to provide CSR capabilities: Babin et al. 2011), considering the implications of CSR on the very business decision of offshoring is also relevant. For example, in terms of the extent to which an organization's commitment to CSR manifests itself across various types of organizational activities, do business decisions such as outsourcing take into account the firm's professed CSR approach, or are made without such considerations. Are firms with certain characteristics more likely to expend greater effort in stakeholder consultation prior to an offshoring decision (Basu and Palazzo, 2008)? 
In a similar vein, the focus of extant IT and BP outsourcing literatures on the impacts of firm, transaction, relational, and governance characteristics on offshoring decisions is well documented (Lacity et al., 2010; Lacity et al., 2011). However, this study highlights the utility of incorporating both institutional and strategic explanations for offshoring. While institutional theory has been widely incorporated in the IS literature (e.g., Mignerat and Rivard, 2009), and to a certain extent for IT outsourcing (e.g., Ang and Cummings, 1997), its explicit consideration for offshoring had been relatively overlooked. In doing so, it addresses the call for consideration of the broader anti-offshoring sentiment in relation to offshoring (Lacity et al., 2010; Lacity et al., 2011). For instance, a recent industry report by research firm Technology Partners International claims a noticeable trend among US and Canadian firms to repatriate once offshored jobs and a growing preference to keep outsourced work within their countries (Reynolds, 2011). Better understanding and explanation of such trends may require research consideration of both organizational and transaction specific factors as well as external institutional and task environment constraints.

This study also has implications for the broader institutional theory applications within the IS literature. Specifically, the theoretical framework employed here considers the nature of institutional pressures as opposed to the more prevalent practice in the IS literature of focusing on the magnitude of pressures. While understanding the impact of the magnitude of mimetic, normative, or coercive isomorphic processes is important, this approach does not explicitly take into account organizations' strategic or task environment considerations. Oliver's (1991) framework on the other hand, accommodates such concerns more explicitly. Further, we modeled the organizational response on a continuum of responsiveness as opposed to strictly viewing compliance or defiance as is common in IS research (e.g. outsource/ not outsource, 
adopt / not adopt). However, as mentioned in the limitations section, the current study does not go far enough in this regard. Specifically, we were unable to consider the different types of strategic responses (i.e. acquiescence, compromise, avoidance, defiance, and manipulation) and the tactics within them. Mignerat and Rivard (2009) have lamented that a lack of consideration of such a range of possible organizational responses remains an issue in the institutional theory based IS literature (Mignerat and Rivard, 2009).

Finally, both the type of organizational considerations modeled and the type of institutional pressures studied in this research may improve the broader institutional theory based understanding of organizational responses. Such a theoretical contribution is possible as this study's context allowed us to consider institutional pressures against (anti-offshoring pressures) what may be viewed as strategic actions (offshoring) of organizations. This approach goes beyond the traditional studies on institutional pressures for compliance and the technical or task environment organizational considerations in terms of costs and benefits of compliance (e.g., Goodstein, 1994; Ingram and Simons, 1995). Specifically, this study contributes in highlighting how the past outcomes of the very strategic actions (prior offshoring success) that are the subject of counter institutional pressures may shape organizational responses.

\section{IMPLICATIONS FOR PRACTICE}

This study has some implications for both client (buyers) and service-provider organizations in relation to offshoring. At the outset, the overall extent of organizational responsiveness to antioffshoring institutional influences was quite low. Nevertheless, there are some key aspects which come to bear. Consider this background first. This study found that when viewed in absence of other institutional factors greater imposed restrictions on offshoring faced by organizations led to 
greater responsiveness. However, when viewed in conjunction with the nature of anti-offshoring pressures, the otherwise statistically significant effect of imposed restrictions became not significant. Similarly, organizational dependence on federal and state governments had no direct bearing on how responsive organizations were. Given this background, it seems that directly imposed restrictions on offshoring (coercive influences if you will) and organizational dependencies did not lead to greater responsiveness. This suggests that, either such restrictions/dependencies are not yet strong enough or that organizations are able to strategically manage them so as not to significantly alter their offshoring course.

However, and instead, one of the strongest factors influencing organizational responsiveness was related to organizational expectations that reducing or eliminating overall extent of offshoring would result in enhancement of organizational image as more socially responsible. This finding suggests that social responsibility implications are far more potent than any direct pressures or organizational dependencies that would lead them with no choice but to comply. Thus, client organizations may seek to match their social responsibility approach, whatever it may be, with the very business decision of offshoring. In other words, not only does an organization's social responsibility approach apply during offshore engagements but it also may apply during the decision making related to offshore engagements. Of course, such considerations may not apply to all organizations and would need to be carefully applied depending on a firm's professed social responsibility approach (Basu and Palazzo, 2008).

In terms of service-provider organizations, this study indicates that along with social responsibility implications on offshoring decisions, mimetic influences from peer firms may be a potent factor in determining organizational responsiveness to anti-offshoring institutional pressures. Further, client organizations' prior success with offshoring did not directly lower their 
responsiveness but, more subtly, reduced the otherwise strong effect of social legitimacy on responsiveness. These findings suggest that the value proposition of service providers may also need to include aspects that address the social responsibility implications of offshoring decisions and such a value proposition may need to go beyond the process of offshoring itself. Further, service provider organizations may need to actively manage client perceptions regarding the future of offshoring given the rather potent effect of mimetic influences in shaping organizational responses.

\section{LIMITATIONS AND SUGGESTIONS FOR FUTURE RESEARCH}

This study has several limitations that must be considered in interpreting its findings. First, in terms of study respondents, we could not draw a random sample from a known sampling frame. However, this set of respondents was ideal for the study purposes and access to such respondents would have otherwise proved very difficult in a random sample approach. Moreover, the firms in this study are likely to represent the broader population of firms actively engaged in offshoring. This is because subscribers in the email list we drew upon were actively involved with and interested in the topic of offshored services and in turn represent a diverse range of firms. The demographics listed in Table 1 lend support to such broad representation. The industry representation is also quite broad. More than $58 \%$ percent of respondents identified themselves and/or their firms. An examination of these firm names provides an additional degree of support that a majority of these firms were in fact large global organizations more likely to have considerable offshore engagements. Nevertheless, these results may have limited generalizability. Future replications and enhancements could draw on a random-sample of 
publicly traded firms such that archival data on a variety of firm characteristics may be easily obtained and assessments of response biases carried out more potently.

Second, the study takes a cross-sectional view on both the independent and dependent variables. The very nature of institutional pressures and their impact on strategic organizational responses may be best captured in a longitudinal design. This is because both the nature of the pressures and the organizational responses can be thought to change over time. Given a lack of archival data sources regarding the independent and dependent variables and in the interest of keeping this project feasible we resorted to a cross-sectional design. Although difficult, future research may capitalize on unique data sources such as the ORN Survey to incorporate a longitudinal design. Such a design may allow accounting for fluctuations (e.g., increased focus in election years) within the debate over offshoring itself.

Third, we focused only on anti-offshoring institutional pressures and did not take into account that organization's maybe facing "pro-offshoring” pressures from constituents such as consulting firms and powerful organizational actors such as the board of directors. In other words, there is a possibility of conflicting pressures on organizations with respect to offshoring, beyond their technical or operational concerns (i.e., we did control for internal organizational pressures for cost reduction). To the extent this is the case, organizational responses may be different as compared to when there is less fragmentation in the organizational field and consensus among institutional constituents on what is to be expected of organizations (Pache and Santos, 2010). This is an exciting area for future research. Divergence in expectations along with internal (organizational) representation of issues could be studied simultaneously with respect to organizational responses (Pache and Santos, 2010). 
Fourth, most of the study variables were measured by a self-report questionnaire. Again, given the complete lack of archival data sources, this seems reasonable. Further, prior research has argued and shown that macro-organizational aspects, such as the focus of this study, are relatively less susceptible to mono-method biases compared to more micro-organizational concepts such as job satisfaction, stress, and turnover intentions (Ang and Cummings, 1997; Crampton and Wagner, 1994). However, future research may draw on other data sources to at least measure aspects such as environmental uncertainty using objective measures (Dess and Beard, 1984).

Fifth, this study focused on the degree of responsiveness as the dependent variable. Given this focus, we did not predict specific response strategies (or tactics within strategies) as is possible using Oliver's (1991) framework. Sample size restrictions and low availability of resources precluded such investigation at this point. Future research may incorporate a mixed methods design to first fully elucidate the variety of tactics organizations are employing across different strategies using a qualitative approach. Following this, researchers may conduct a large scale survey or draw on archival sources to predict specific strategies such as defiance and acquiescence. For example, while organizations may not directly acquiesce to institutional pressures, how likely is it that they will adopt some buffering strategies such as choosing offshore suppliers which can move offshore work back to an organization's home-country if the need arises?

\section{CONCLUSION}

This study assessed the extent to which organizations are responsive to anti-offshoring institutional pressures by reducing and/or postponing their IT and BP offshoring. Further, it 
attempted to explain the extent of organizational responsiveness based on both the characteristics of anti-offshoring institutional pressures as well as organizations' prior success with offshoring while controlling for important organizational and external factors. In a descriptive sense, the results do not indicate an impending drift away from offshoring. However, an interesting set of findings emerged from this study.

Neither internal pressures to reduce costs nor externally imposed restrictions on offshoring had any significant impact on the extent of organizational responsiveness. Dependence on government also had no effect. More surprisingly, prior success with offshoring did not directly lower responsiveness. Instead, a majority of variance in organizational responsiveness was explained by expectations of enhanced organizational image as socially responsible and mimetic influences from other organizations-both resulting in greater responsiveness. Further, conflict of institutional expectations with organizational goals reduced responsiveness. Greater regulatory environment uncertainty also resulted in lower responsiveness. While organizational strategic considerations in terms of success with offshoring mattered, their effect was not a blatant rejection of institutional expectations but a more subtle attenuation of the strength of institutionally sanctioned social legitimacy obtained from compliance. Expectations of enhanced organizational image as socially responsible did not lead to as greater responsiveness when success with offshoring was high. On the other hand, prior success with offshoring exacerbated the negative effect of regulatory environment uncertainty. Greater regulatory environment uncertainty led to even lower responsiveness when success with offshoring was high.

As debate over the "true" macro-economic and societal impacts (positive or otherwise) of offshoring continues (Mankiw and Swagel, 2006), studying this issue further seems important for at least two reasons. On the one hand, to the extent one believes in the strategic inevitability of 
offshoring regardless of the anti-offshoring sentiment (Venkatraman, 2004) then understanding how potent is the impact of the institutional context in hindering or promoting offshoring becomes necessary. On the other hand, if one espouses that organizations should curb their offshore initiatives then understanding the efficacy/utility or lack thereof of the various institutional tactics geared toward obtaining organizational compliance becomes also necessary. 


\section{REFERENCES}

Aiken, L.S. and West, S.G. 1991. Multiple Regression: Testing and interpreting interactions Sage, Newbury Park, CA.

Ang, S. and Cummings, L. 1997. "Strategic Response to Institutional Influences on Information Systems Outsourcing," Organization Science (8:3), pp 235 - 256.

Babin, R., Briggs, S., and Nicholson, B. 2011. "Corporate Social Responsibility and Global IT Outsourcing," Communications of the ACM (54:9), pp 28-30.

Babin, R. and Nicholson, B. 2009. "Corporate social and environmental responsibility in global IT outsourcing," MIS Quarterly Executive (8:4), pp 123-132.

Bahli, B. and Rivard, S. 2003. "The information technology outsourcing risk: a transaction cost and agency theory based perspective," Journal of Information Technology (18:3), pp 211 $-221$.

Baron, D. 1995. "Integrated Strategy: Market and nonmarket components.," California Management Review (37:3), pp 47-65.

Basu, K. and Palazzo, G. 2008. "Corporate social responsibility: A process model of sensemaking," Academy of Management Review (33:1), pp 122-136.

Beulen, E. 2010. "Long-held perceptions of the consequences of IT offshoring will become a reality: fewer IS jobs in developed countries," Journal of Information Technology (25:4), pp 376-377.

Bhalla, A., Sodhi, M.S., and Son, B.-G. 2008. "Is more IT offshoring better? An exploratory study of western companies offshoring to South East Asia," Journal of Operations Management (26:2), pp 322 - 335.

Blaskovich, J. and Mintchik, N. 2011. "Information Technology Outsourcing:A Taxonomy of Prior Studies and Directions for Future Research," Journal of Information Systems (25:1), pp 1-36.

Bouquet, C. and Birkinshaw, J. 2008. "Weight versus voice: How foreign subsidiaries gain attention from corporate headquarters," Academy of Management Journal (51:3), pp 577601.

Brown, D. 2008. "It is good to be green: Environmentally friendly credentials are influencing business outsourcing decisions," Strategic Outsourcing: An International Journal (1:1), pp 87-95.

Bruce, D.J. and Martz, W.B. 2007. "Information systems offshoring: Differing perspectives of the value statement," The Journal of Computer Information Systems (47:3), pp 17 - 23.

Buchko, A. 1994. "Conceptualization and Measurement of Environmental Uncertainty: An Assessment of the Miles and Snow Perceived Environmental Uncertainty Scale," Academy of Management Journal (37:2), pp 410-425.

Canto, C.S.A. and van Gorp, D.M. 2007. "A comparative analysis of European and US regulatory responses to offshoring," Journal of Information Technology Case and Application Research (9:3), pp 31-48.

Carmel, E. and Agarwal, R. 2002. "The Maturation of Offshore Sourcing of Information Technology Work," MIS Quarterly Executive (1:2), pp 65 - 78.

Carmel, E. and Tjia, P. 2005. Offshoring Information Technology: Sourcing and Outsourcing to a Global Workforce Cambridge University Press, Cambridge.

Chan, Y.E., Huff, S.L., Copeland, D.G., and Barclay, D.W. 1997. "Business strategic orientation, information systems strategic orientation and strategic alignment," Information Systems Research (8:2), pp 125-150. 
Child, J. 1972. "Organizational structure, environment, and performance: The role of strategic choice," Sociology (6), pp 1-22.

Choudhury, V. and Sabherwal, R. 2003. " Portfolios of Control in Outsourced Software Development Projects," Information Systems Research (14:3), pp 291 - 314.

Covaleski, M.A. and Dirsmith, M.W. 1988. "An institutional perspective on the rise, social formation, and a fall of a university budget category," Administrative Science Quarterly (33), pp 562-587.

Crampton, S.M. and Wagner, J.A. 1994. "Percept-percept inflation in microorganizational research: An investigation of prevalence and effect," Journal of Applied Psychology (79:1), pp 67-76.

Creswell, J.W. 2009. Research design: qualitative, quantitative, and mixed methods approaches, (3rd ed.) Sage Publications, Thousand Oaks, CA.

Currie, W., Michell, V., and Abanishe, O. 2008. "Knowledge process outsourcing in financial services: The vendor perspective," European Management Journal (26:2), pp 94-104.

Davis, G.F. 1991. "Agents without principles? The spread of the poison pill through the intercorporate network.," Administrative Science Quarterly (36), pp 583-613.

Dawson, J.F. and Richter, A.W. 2006. "Probing three-way interactions in moderated multiple regression: Development and application of a slope difference test," Journal of Applied Psychology (91), pp 917-926.

Deephouse, D.L. 1996. "Does isomorphism legitimate?," Academy of Management Journal (39:4), pp 1024-1039.

Dess, G.G. and Beard, D.W. 1984. "Dimensions of organizational task enviroments," Administrative Science Quarterly (29), pp 52-73.

Dess, G.G. and Robinson, R. 1984. "Measuring organizational performance in the absence of objective measures," Strategic Management Journal (5), pp 265-273.

Dibbern, J., Goles, T., Hirschheim, R., and Bandula, J. 2004. "Information Systems Outsourcing: A Survey and Analysis of the Literature," Database for Advances in Information Systems (34:4), pp 6-102.

Dibbern, J., Winkler, J., and Heinzl, A. 2008. "Explaining variations in client extra costs between software projects offshored to india," MIS Quarterly (32:2), pp 333 - 366.

DiMaggio, P.J. 1988. "Interest and agency in insititutional theory," in: Institutional patterns and organizations: Culture and environment, L. Zucker (ed.), Ballinger, Cambridge, MA, pp. 3-21.

DiMaggio, P.J. and Powell, W.W. 1983. "The Iron Cage Revisited: Institutional Isomorphism and Collective Rationality in Organizational Fields," American Sociological Review (48), pp 147-160.

Dowling, J. and Pfeffer, J. 1975. "Organizational legitimacy: Social values and organizational behavior," Pacific Sociological Review (18), pp 122-136.

Drumwright, M.E. 1994. "Socially Responsible Organizational Buying: Environmental Concern as a Noneconomic Buying Criterion," Journal of Marketing (58:July), pp 1-19.

Earl, M.J. 1996. " The Risks of Outsourcing IT," Sloan Management Review (37:3), pp 26 - 32.

Finkelstein, S. and Hambrick, D.C. 1990. "Top-Management-Team Tenure and Organizational Outcomes: The Moderating Role of Managerial Discretion," Administrative Science Quarterly (35:3), pp 484-503.

Fox, J. 1997. Applied Regression, Linear Models, and Related Methods Sage, Thousand Oaks, CA. 
Garson, G.D. 2011. "Statnotes: Topics in Multivariate Analysis."

Gokhale, A.A. 2007. "OFFSHORE OUTSOURCING: A DELPHI STUDY," Journal of Information Technology Case and Application Research (9:3), pp 6 - 18.

Goodman, S.E. and Ramer, R. 2007. "Global sourcing of IT services and information security: prudence before playing," Communications of the AIS (20), pp 812 - 823.

Goodstein, J. 1994. "Institutional pressures and strategic responsiveness: Employer involvement in work-family issues," Academy of Management Journal (37), pp 350-382.

Granovetter, M.S. 1985. "Economic action and social structure: The problem of embeddedness.," American Journal of Sociology (91), pp 481-510.

Greening, D.W. and Gray, B. 1994. "Testing a model of organizational response to social and political issues," Academy of Management Journal (37:3), pp 467-498.

Greenwood, R. and Hinings, C.R. 1996. "Understanding Radical Organizational Change: Bringing together the Old and the New Institutionalism," Academy of Management Review (21:4), pp 1022-1054.

Grover, V., Cheon, M., and Teng, J. 1996. " The Effect of Service Quality and Partnership on the Outsourcing of Information Systems Functions," Journal of Management Information Systems (12:4), pp 89 - 116.

Gupta, A. 2010. "Offshoring, IS employment and the IS discipline: additional considerations," Journal of Information Technology (25:4), pp 378-379.

Gupta, A. and Sao, D. 2009. "Anti-Offshoring Legislation and United States Federalism: The Constitutionality of Federal and State Measures Against Global Outsourcing of Professional Services," Texas International Law Journal (44), pp 629-663.

Gupta, A., Seshasai, S., Mukherji, S., and Ganguly, A. 2007. "Offshoring: The Transition from Economic Drivers Toward Strategic Global Partnership and 24-Hour Knowledge Factory," Journal of Electronic Commerce in Organizations (5:2), pp 1 - 23.

Hair, J.E., Black, W.C., Babin, B.J., Anderson, R.E., and Tatham, R.L. 2006. Multivariate data analysis, (6th ed.) Prentice-Hall, Upper Saddle River, NJ.

Hillman, A.J. and Hitt, M.A. 1999. "Corporate political strategy formulation: A model of approach, participation, and strategy decisions," Academy of Management Review (24:4), pp 825-842.

Hillman, A.J., Keim, G.D., and Schuler, D. 2004. "Corporate Political Activity: A Review and Research Agenda," Journal of Management (30:6), pp 837-857.

Hirschheim, R., Loebbecke, C., Newman, M., and Valor, J. 2007. "Offshoring and its implications for the information systems discipline: Where perception meets reality," Communications of the AIS (20), pp 824 - 835.

Hirschheim, R. and Newman, M. 2010. "Houston, we've had a problem...... offshoring, IS employment and the IS discipline: perception is not reality," Journal of Information Technology (25:4), pp 358-372.

Hu, Q., Saunders, C., and Gebelt, M. 1997. " Research Report: Diffusion of Information Systems Outsourcing: A Reevaluation of Influence Sources," Information Systems Research (8:3), pp 288 - 301.

Hutzschenreuter, T., Lewin, A.Y., and Dresel, S. 2011. "Time to Success in Offshoring Business Processes: A Multi-level Analysis," Management International Review (51), pp 65-92.

Hutzschereuter, T., Pedersen, T., and Volberda, H. 2007. "The Role of Path Dependency and Managerial Intentionality: A Perspective on International Business Research," Journal of International Business Studies (38), pp 1055-1068. 
Iacovou, C.L. and Nakatsu, R. 2008. "A risk profile of offshore-outsourced development projects," Communications of the ACM (51:6), pp 89 - 94.

Ingram, P. and Simons, T. 1995. "Institutional and resource dependence determinants of responsiveness to work-family issues," Academy of Management Journal (38:5), pp 1466-1482.

Iyengar, P. 2011a. "CIO Concerns: Global Sourcing Demand-Side Trends," ID \#: G00213615, Gartner Research, Stampford, CT. 2 June 2011

Iyengar, P. 2011b. "CIO Concerns: Global Sourcing Supply-Side Trends," ID \#: G00213617, Gartner Research, Stampford, CT. 2 June 2011

Jacobe, D. 2004a. "Do Investors Support Outsourcing?," in: The Gallup Organization: http://www.gallup.com/poll/11506/Investors-Support-Outsourcing.aspx.

Jacobe, D. 2004b. "Will Outsourcing Fears Hurt Spending?," in: The Gallup Organization: http://www.gallup.com/poll/11014/Will-Outsourcing-Fears-Hurt-Spending.aspx.

Jayatilaka, B. and Hirschheim, R. 2009. "Changes in IT sourcing arrangements: An interpretive field study of technical and institutional influences," Strategic Outsourcing: An International Journal (2:2), pp 84-122.

Julian, S.D., Ofori-Dankwa, J.C., and Justis, R.T. 2008. "Understanding strategic responses to interest group pressures," Strategic Management Journal (29), pp 963-984.

Jurison, J. 1995. " The Role of Risk and Return in Information Technology Outsourcing Decisions," Journal of Information Technology (10), pp 239 - 247.

Kaarst-brown, M. 2010. "'Houston, we've had a problem ...'," Journal of Information Technology (25:4), pp 380-381.

Kaiser, K. and Hawk, S. 2004. " Evolution of Offshore Software Development: From Outsourcing to Co-Sourcing," MIS Quarterly Executive (3:2), pp 69 - 81.

Karamouzis, F. 2011. "Key Issues for IT Services Sourcing, 2011," G00210200, Gartner Research. 23 February 2011

Kassinis, G. and Vafeas, N. 2006. "Stakeholder pressures and environmental performance," Academy of Management Journal (49:1), pp 145-159.

Khan, N. and Fitzgerald, G. 2004. "Dimensions of Offshore Outsourcing Business Models," Journal of Information Technology Cases and Applications (6:3), pp 35 - 50.

King, W. and Torkzadeh, G. 2008. "Foreword: Information Systems Offshoring: Research Status and Issues," MIS Quarterly (32:2), pp 205-225.

King, W.R. 2005. "INNOVATION IN RESPONDING TO THE THREAT OF IT OFFSHORING," Information Systems Management (22:4), pp 80 - 81.

King, W.R. and Sabherwal, R. 1992. "The factors affecting strategic information systems applications: An empirical assessment," Information and Management (23), pp 217-235.

Kliem, R. 2004. "Managing the Risks of Offshore IT Development Projects," Information Systems Management (21:3), pp 22 - 27.

Knapp, K., Sharma, S., and King, K. 2007. "Macro-Economic and Social Impacts of Offshore Outsourcing of Information Technology: Practitioner and Academic Perspectives," International Journal of E-Business Research (13:4), pp 112 - 132.

Kotlarsky, J. and Oshri, I. 2008. "Country attractiveness for offshoring and offshore outsourcing: additional considerations," Journal of Information Technology (23), pp 228231.

Lacity, M., Khan, S.A., and Willcocks, L. 2009. "A Review of the IT Outsourcing Literature: Insights for Practice," Journal of Strategic Information Systems (18:3), pp 130-146. 
Lacity, M., Khan, S.A., Yan, A., and Willcocks, L. 2010. "A Review of the IT Outsourcing Empirical Literature and Future Research Directions," Journal of Information Technology (25), pp 395-433.

Lacity, M. and Rottman, J. 2008. Offshore Outsourcing of IT Work Palgrave Macmillan, Hampshire, United Kingdom.

Lacity, M. and Rudramuniyaiah, P. 2009. "Funny Business: Public Opinion of Outsourcing and Offshoring as Reflected in U.S. and Indian Political Cartoons," Communications of the AIS (24), pp 199-224.

Lacity, M., Solomon, S., Yan, A., and Willcocks, L. 2011. "Business process outsourcing studies: A critical review and research directions," Journal of Information Technology (26:4), pp 221-258.

Lewin, A.Y. 2008. "Strategic Offshoring Reaches C-Suite," Offshoring Research Network and The Conference Board (Web cast available online at: https://offshoring.fuqua.duke.edu/pdfs/Duke-TCB\%20Webcast.pdf). February 28, 2008

Lewin, A.Y., Massini, S., and Peeters, C. 2009. "Why are companies offshoring innovation? The emerging global race for talent.," Journal of International Business Studies (40:6), pp 901-925.

Lewin, A.Y. and Peeters, C. 2006a. "Offshoring work: business hype or the onset of fundamental transformation?," Long Range Planning (39:3), pp 221-239.

Lewin, A.Y. and Peeters, C. 2006b. "The Top-Line Allure of Off-shoring," Harvard Business Review (March), pp 22-24.

Loh, L. and Venkatraman, N. 1992. "Diffusion of Information Technology Outsourcing: Influence Sources and the Kodak Effect," Information Systems Research (3:4), pp 334358.

Mahajan, V., Sharma, S., and Bettis, R. 1988. "The Adoption of the M-Form Organizational Structure: A Test of Imitation Hypothesis," Management Science (34), pp 1188-1201.

Mankiw, N.G. and Swagel, P. 2006. "The politics and economics of offshore outsourcing," Journal of Monetary Economics (53), pp 1027-1056.

Manley, T.J. and Hobby, S.M. 2006. "Globalization of work: offshore outsourcing in the IT age," Emory International Law Review (18), pp 401-419.

Manning, S., Massini, S., and Lewin, A.Y. 2008. "A dynamic perspective on next-generation offshoring: The global sourcing of science and engineering talent," Academy of Management Perspectives (22:3), pp 35-54.

Meyer, J.W. and Rowan, B. 1977. "Institutional organizations: Formal structure as myth and ceremony," American Journal of Sociology (83:340-363).

Mignerat, M. and Rivard, S. 2009. "Positioning the institutional perspective in information systems research," Journal of Information Technology (24), pp 369-391.

Miles, R.E. and Snow, C.C. 1978. Organizational Strategy, Structure, and Process McGraw-Hill Book Company, New York.

Milliken, F.J. 1987. "Three types of perceived uncertainty about the environment: State, effect, and response uncertainty," Academy of Managment Review (12:1), pp 133-143.

Milliken, F.J., Martins, L.L., and Morgan, H. 1998. "Explaining organizational responsiveness to work-family issues: The role of human resource executives as issue interpreters.," Academy of Management Journal (41:5), pp 580-592. 
Miranda, S. and Kim, Y. 2006. " Professionalism Versus Political Contexts: Institutional Mitigation and the Transaction Cost Heuristic in Information Systems Outsourcing," MIS Quarterly (30:3), pp 725 - 753.

Mirani, R. 2007. "Procedural coordination and offshored software tasks: Lessons from two case studies," Information \& Management (44), pp 216 - 230.

Mitchell, R.K., Agle, B.R., and Wood, D.J. 1997. "Toward a theory of stakeholder identification and salience: Defining the principle of who and what really counts," Academy of Management Review (22:4), pp 853-886.

Mollitor, G.T. 1977. "How to anticipate public policy changes," Society for Advancement of Management: Advanced Management Journal (42), pp 4-13.

Mordecai 2005. "Anti-offshoring legislation: the new wave of protectionaism - the backlash against foregn outsourcing of American jobs.," Richmond Journal of Global Law and Business (5), pp 85-105.

Nunnally, J.C. 1978. Psychometric Theory, (2nd ed.) McGraw-Hill, New York.

Oliver, C. 1991. "Strategic Responses to Institutional Processes," The Academy of Management Review (16:1), pp 145-179.

Oshri, I. and Corbett, M.F. 2011. Offshoring Strategies: Evolving Captive Center Models MIT Press, Cambridge, MA.

Oshri, I., Kotlarsky, J., Rottman, J., and Willcocks, L. 2009a. "Global sourcing: recent trends and issues," Information Technology and People (22:3), pp 192-200.

Oshri, I., Kotlarsky, J., and Willcocks, L. 2009b. The Handbook of Global Outsourcing and Offshoring Palgrave Macmillan, London.

Overby, S. 2010 CIO Magazine "Outsourcing: Prepare Now for Anti-Offshoring Legislation," Wed, March 17, 2010 http://www.cio.com/article/582863/Outsourcing_Prepare_Now_for_Anti_Offshoring_Le gislation?page=2\&taxonomyId=3195: 06/25/2011

Pache, A.-C. and Santos, F. 2010. "When worlds collide: The internal dynamics of organizational responses to conflicting institutional pressures," Academy of Management Review (35:3), pp 455-476.

Peng, M.W. and Luo, Y. 2000. "Managerial Ties and Firm Performance in a Transition Economy: The Nature of a Micro-Macro Link," Academy of Management Journal (43:3), pp 486-501.

Perrow, C. 1985. "Review essay: Overboard with myth and symbols.," American Journal of Sociology (91), pp 317-330.

Pfeffer, J. 1981. Power in organizations Pitman, Marshfield, MA.

Pfeffer, J. and Salancik, G.R. 1978. The external control of organizations Harper \& Row, New York, NY.

Podsakoff, P.M., MacKenzie, S.B., Lee, J., and Podsakoff, N.P. 2003. "Common method bias in behavioral research: A critical review of the literature and recommended remedies.," Journal of Applied Psychology (88), pp 879-903.

Powell, W.W. and DiMaggio, P.J. 1991. The new institutionalism in organizational analysis University of Chicago Press, Chicago.

Ranganathan, C. and Balaji, S. 2007. " Critical Capabilities for Offshore Outsourcing of IS," MIS Quarterly Executive (6:3), pp 147 - 164. 
Rao, M.T., Poole, W., Raven, P.V., and Lockwood, D.L. 2006. "Trends, Implications, and Responses to Global IT Sourcing: A Field Study," Journal of Global Information Technology Management (9:3), pp 5 - 23.

Reynolds, P. 2011. "TPI Momentum 2011 Market Trends \& Insights Geography Report: http://www.tpi.net/web/TPITop5/," Technology Partners International, Inc., Stamford, CT.

Ross, J. and Beath, C. 2006. " Sustainable IT Outsourcing: Let Enterprise Architecture be Your Guide," MIS Quarterly Executive (5:4), pp 181 - 192.

Rottman, J. and Lacity, M. 2004. " Twenty Practices for Offshore Sourcing," MIS Quarterly Executive (3:3), pp 117 - 130.

Rottman, J. and Lacity, M. 2006. " Proven Practices for Effectively Offshoring IT Work," Sloan Management Review (47:3), pp 56 - 63.

Rottman, W. and Lacity, M. 2008. "A US Client's learning from outsourcing IT work offshore," Information Systems Frontiers (10), pp 259 - 275.

Sabherwal, R. and King, W.R. 1995. "An empirical taxonomy of the decision-making processes concerning strategic applications of information systems," Journal of Management Information Systems (11:4), p 177.

Sakthivel, S. 2007. "Managing Risk in Offshore Systems Development," Communications of the ACM (50:4), pp 69 - 75.

Scott, W.R. 1987. "The adolescence of institutional theory," Administrative Science Quarterly (32), pp 493-511.

Scott, W.R. 1991. "Unpacking institutional arguments," in: The new institutionalism in organizational analysis, W.W. Powell and P.J. DiMaggio (eds.), University of Chicago Press, Chicago, pp. 164-182.

Shao, B. and David, S.J. 2007. "The impact of offshore outsourcing on IT workers in developed countries," Communications of the ACM (50:2), pp 89 - 95.

Slaughter, S.A. and Ang, S. 1996. "Employment Outsourcing in Information Systems," Communications of the ACM (39:7), pp 47 - 54.

Smith, H.A. and McKeen, J.D. 2004. "Developments in practice XIV: IT outsourcing - how far can you go?," Communications of the AIS (14), pp 508 - 520.

Sobol, M. and Apte, U. 1995. " Domestic and Global Outsourcing Practices of America's most Effective IS Users," Journal of Information Technology (10), pp 269 - 280.

Straub, D.W., Boudreau, M.C., and Gefen, D. 2004. "Validation Guidelines for IT Positivist Research," Communications of the Association for Information Systems (13:24), pp 380427.

Suchman, M.C. 1995. "Managing legitimacy: Strategic and institutional approaches," Academy of Management Review (20), pp 571-610.

Sullivan, W.E. and Ngwenyama, O.K. 2005. "How are public sector organizations managing IS outsourcing risks? An analysis of outsourcing guidelines from three jurisdictions," The Journal of Computer Information Systems (45:3), pp 73 - 87.

Sutcliffe, K.M. 1994. "What executives notice: Accurate perceptions in top management teams," Academy of Management Journal (37:5), pp 1360-1378.

Tabachnick, B.G. and Fidell, L.S. 2001. Using Multivariate Statistics Allyn and Bacon, Boston, MA. 
Tate, W., Ellram, L., Bals, L., and Hartmann, E. 2009. "Offshore Outsourcing of Services: An Evolutionary Perspective," International Journal of Production Economies (120:2), pp $512-524$.

Taylor, H. 2006. "Critical risks in outsourced IT projects; the intractable and the unforeseen," Communications of the ACM (49:11), pp 74 - 79.

Tramacere, G. 2011. "The Evolution of Global Delivery in Outsourcing, 2010-2011," ID \#: G00208314, Gartner Research, Stampford, CT. 4 January 2011

Venkatraman, N.V. 2004. " Offshoring Without Guilt," Sloan Management Review (45:3), pp 14 $-16$.

Westpahl, J.D. and Zajac, E.J. 2001. "Decoupling policy from practice: The case of stock repurchase programs," Administrative Science Quarterly (46:2), pp 202-228.

Willcocks, L., Cullen, S., and Craig, A. 2010. The Outsourcing Enterprise: From cost management to collaborative innovation Palgrave, London.

Winkler, J.K., Dibbern, J., and Heinzl, A. 2008. "The impact of cultural differences in offshore outsourcing - Case study results from German-Indian application development projects," Information Systems Frontiers (10), pp 243 - 258.

Zucker, L.G. 1987. Institutional theories of organization. Annual Reviews, Palo Alto, CA. 


\section{Appendix 1: Measures}

Unless otherwise noted below, all items were measured on 7-point Likert-type anchors where 1 was "Strongly Disagree", 4 was "Neither Disagree nor Agree" and 7 was "Strongly Agree."

\section{CONTROL VARIABLES:}

\section{US Firm or Not}

This variable was dummy-coded as " 1 " if a respondent indicated that his/her organization's headquarters country was United States (US). All other countries were coded as " 0 "

\section{Captive Operations or Not}

Organizations having at least some captive operations in overseas locations were coded as " 1 " and those reporting no captive operations as part of their offshoring efforts, were coded as " 0 ".

\section{Senior Most Respondents or Not}

This variable was dummy-coded as follows. Respondents were requested to choose their job title category. The categories included:

C-Level Executive (CEO, CFO, COO, CAO, CIO, CTO, CSO, CKO, etc.)

Director, Executive VP, Senior VP, Vice President, Controller

Department or Business Unit Manager

IT or IS manager

other (please specify)

First, those marking "other" were appropriately categorized based on respondent specifications. Then all those respondents who chose either category 1 (C-level executive) or category 2 (Director, VP etc.) were coded as "1" senior respondents, and all others were coded as "0".

\section{Internal Cost Reduction Pressures}

Direct Question: Overall, there are pressures from within our organization to reduce costs for Information Technology (IT) and/or Business Process (BP) related services

\section{Imposed Restrictions on Offshoring}

RSTRCT1: Our organization faces Federal and/or State Government level regulatory restrictions on offshoring (dropped during factor analyses)

RSTRCT2: Our organization faces customer imposed restrictions on offshoring

RSTRCT3: Our organization faces other legal or contractual obligations that impose restrictions on offshoring

RSTRCT4: Our organization faces employee/union imposed restrictions on offshoring (dropped during factor analyses) 
RSTRCT5: Overall, our organization faces imposed restrictions on Information Technology Offshoring

RSTRCT6: Overall, our organization faces imposed restrictions on Business Process Offshoring

\section{DEPENDENT VARIABLE:}

\section{Organizational Responsiveness}

RESP1: In response to anti-offshoring pressures, our organization has reduced or plans to reduce the overall extent of offshore delivery

RESP2: In response to anti-offshoring pressures, our organization is scaling back or putting on hold originally planned growth in offshore delivery of Information Technology related services

RESP3: In response to anti-offshoring pressures, our organization is scaling back or putting on hold originally planned growth in offshore delivery of Business Process related services

RESP4: Our organization has decided to avoid signing longer-term offshore delivery contracts, at least within the next 12 Months

\section{INDEPENDENT VARIABLES:}

\section{Expectations of Increase in Social Legitimacy}

Direct Question: We expect that our image as a socially responsible organization will be enhanced if we lower our overall extent of offshoring

\section{Dependence on Government}

Direct Question: A fairly significant portion of our organization's total sales (revenues) comes from Federal and/or State Government(s) as customers

\section{Organizational Plans for Offshoring}

This variable was dummy-coded as follows. Toward the beginning of the survey, respondents were asked to indicate how their overall offshoring portfolio, in terms of Full-time Equivalent (FTE) workers, was going to change in the next three years. Response categories ranged from "Decrease by more than 2500 FTE" to "No Change" to "Increase by more than 2500 FTE". Those who indicated plans to increase the offshore head-count were coded as "1" and those who indicated "no change" or a decrease in offshore head-count were coded as " 0 ". 


\section{Complying Actions of other Firms}

Direct Question: I know of executives at other firms who have responded to anti-offshoring pressures by reducing or planning to reduce the overall extent of offshore delivery

\section{Regulatory Environment Uncertainty:}

[7 point anchors ranging from 1: Highly Predictable to 7: Highly Unpredictable]

UNCT1: Changes in tax laws or policies with respect to offshoring are:

UNCT2: Changes in Data Privacy/Security laws or policies that may impact offshoring are:

UNCT3: Changes in Intellectual Property Protection laws or policies that may impact offshoring are (dropped during factor analyses)

UNCT4: Changes in laws or policies that restrict offshore fulfillment of Government contracts are

UNCT5: Changes in laws or policies pertaining to hiring of foreign workers (e.g. H1-b visa policies in the U.S.) are:

\section{Success with Offshoring}

OS1: Overall, offshoring has helped us reduce costs

OS2: Overall, offshoring has helped us gain increased access to skilled personnel

OS3: Overall, offshoring has improved our overall flexibility

OS4: Overall, offshoring has helped us achieve increased speed to market or speed of delivery

OS5: We are satisfied with our overall benefits from Information Technology (IT) offshoring

OS6: We are satisfied with our overall benefits from Business Process (BP) offshoring 


\section{Appendix 2: Summary of Key Challenges and Risks in IT Sourcing}

\begin{tabular}{|c|c|c|c|c|c|}
\hline \multicolumn{6}{|c|}{ Summary of Key Challenges and Risks in IT Sourcing } \\
\hline 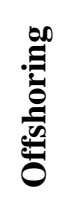 & 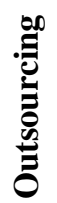 & 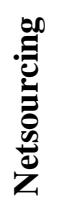 & $\begin{array}{l}\text { Challenges } \\
\text { and risks }\end{array}$ & Descriptive phrases in the literature & $\begin{array}{l}\text { Select References on } \\
\text { challenges and risks }\end{array}$ \\
\hline
\end{tabular}

Note: A " 1 " under the columns of "Offshoring" "Outsourcing" and "Netsourcing" indicates the challenge or risk is pertinent to that sourcing initiative according to the literature

\begin{tabular}{|c|c|c|c|c|c|}
\hline 1 & 1 & 1 & $\begin{array}{l}\text { Client's lack of } \\
\text { IT maturity, } \\
\text { experience with } \\
\text { outsourcing, } \\
\text { and inability to } \\
\text { manage } \\
\text { suppliers }\end{array}$ & $\begin{array}{l}\text { If an IT activity is poorly performing in-house and } \\
\text { has been badly managed in the first place, will the IT } \\
\text { managers be any better at managing an external } \\
\text { provider? To reduce initial risks in outsourcing, a } \\
\text { company must be capable of managing the IT service } \\
\text { first... (Earl, 1996) Possibility of Weak } \\
\text { Management... Lack of experience could lead to } \\
\text { poorly defined scope and requirements... Lack of } \\
\text { experience could give unfair advantage to suppliers... } \\
\text { lack of offshore project management know-how by } \\
\text { client... differences in development } \\
\text { methodology/processes... client's inability to manage } \\
\text { the supplier }\end{array}$ & $\begin{array}{l}\text { Earl (1996) } \\
\text { Jurison (1995) } \\
\text { Sullivan and } \\
\text { Ngwenyama (2005) } \\
\text { Kern et al. (2002) } \\
\text { Iacovou and Nakatsu } \\
\text { (2008) } \\
\text { Hazel (2006) }\end{array}$ \\
\hline 1 & 1 & 1 & $\begin{array}{l}\text { Suppliers' lack } \\
\text { of IT } \\
\text { capabilities }\end{array}$ & $\begin{array}{l}\text { Suppliers may not always maintain the latest in } \\
\text { technology skills... Lack of domain knowledge... } \\
\text { lack of experience with outsourcing... biased } \\
\text { portrayal by suppliers... supplier's oversold } \\
\text { capabilities... Poor development processes... } \\
\text { different standards... Outdated Technology Skills... } \\
\text { etc. }\end{array}$ & $\begin{array}{l}\text { Earl (1996) } \\
\text { Jurison (1995) } \\
\text { Sullivan and } \\
\text { Ngwenyama (2005) } \\
\text { Kern et al. (2002) } \\
\text { Sakthivel (2007) } \\
\text { Iacovou and Nakatsu } \\
\text { (2008) } \\
\text { Taylor (2006) }\end{array}$ \\
\hline 1 & \begin{tabular}{|l|}
1 \\
\end{tabular} & 1 & $\begin{array}{l}\text { Incomplete and } \\
\text { rigid contracts } \\
\text { despite } \\
\text { endemic } \\
\text { uncertainty } \\
\text { with respect to } \\
\text { IT }\end{array}$ & $\begin{array}{l}\text { IT operations and development are inherently } \\
\text { uncertain. IT contracts should be flexible and allow } \\
\text { for conflict resolution in face of inevitable } \\
\text { uncertainties. To the extent this is not possible a } \\
\text { company is better off keeping IT in-house. }\end{array}$ & $\begin{array}{l}\text { Earl (1996) } \\
\text { Bahli and Rivard (2003) } \\
\text { Kern et al. (2002) } \\
\text { Sakthivel (2007) } \\
\text { Iacovou and Nakatsu } \\
\text { (2008) } \\
\text { Taylor (2006) }\end{array}$ \\
\hline 1 & 1 & 1 & Hidden costs & $\begin{array}{l}\text { Often clients underestimate setup costs, } \\
\text { redeployment costs, relocation costs and longer than } \\
\text { expected handoff or parallel running costs. Clients } \\
\text { also underestimate management costs.... failure to } \\
\text { consider all costs... increased need of coordination } \\
\text { between business users of a client, IT staff of a client, } \\
\text { and supplier's IT specialists could turn into a messy } \\
\text { eternal triangle... all of these can erode the desired } \\
\text { cost savings }\end{array}$ & $\begin{array}{l}\text { Earl (1996) } \\
\text { Jurison (1995) } \\
\text { Bahli and Rivard (2003) } \\
\text { Sakthivel (2007) } \\
\text { Iacovou and Nakatsu } \\
\text { (2008) } \\
\text { Taylor (2006) }\end{array}$ \\
\hline 1 & 1 & 1 & $\begin{array}{l}\text { Technological } \\
\text { indivisibility/ } \\
\text { Relatedness }\end{array}$ & $\begin{array}{l}\text { To the extent what is being outsourced is not easily } \\
\text { broken down and highly interconnected, companies } \\
\text { will face problems in terms of responsibilities... } \\
\text { increased coordination efforts required... increased } \\
\text { strategic dependencies }\end{array}$ & $\begin{array}{l}\text { Earl (1996) } \\
\text { Bahli and Rivard (2003) }\end{array}$ \\
\hline
\end{tabular}




\begin{tabular}{|c|c|c|c|c|c|}
\hline \multicolumn{6}{|c|}{ Summary of Key Challenges and Risks in IT Sourcing } \\
\hline$\frac{\infty}{0}$ & 照 & 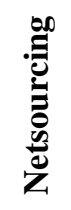 & $\begin{array}{l}\text { Challenges } \\
\text { and risks }\end{array}$ & Descriptive phrases in the literature & $\begin{array}{l}\text { Select References on } \\
\text { challenges and risks }\end{array}$ \\
\hline 1 & 1 & 1 & $\begin{array}{l}\text { Loss of control } \\
\text { over data, } \\
\text { security, and } \\
\text { intellectual } \\
\text { property } \\
\text { concerns }\end{array}$ & $\begin{array}{l}\text { data security... intellectual property rights... national } \\
\text { security concerns... regulatory concerns in financial } \\
\text { services and other industries... court rules requiring } \\
\text { availability and proof of integrity of electronically } \\
\text { stored information... threats to security of } \\
\text { information resources... }\end{array}$ & $\begin{array}{l}\text { Jurison (1995) } \\
\text { Sullivan and } \\
\text { Ngwenyama (2005) } \\
\text { Kern et al. (2002) } \\
\text { Kliem (2004) } \\
\text { Sakthivel (2007) } \\
\text { Goodman (2007) } \\
\text { Iacovou and Nakatsu } \\
\text { (2008) }\end{array}$ \\
\hline 1 & 1 & 1 & $\begin{array}{l}\text { Supplier lock- } \\
\text { in }\end{array}$ & $\begin{array}{l}\text { Supplier favorable power asymmetries... high } \\
\text { switching costs may shield the vendor... few viable } \\
\text { alternatives... highly specific assets... }\end{array}$ & $\begin{array}{l}\text { Jurison (1995) } \\
\text { Bahli and Rivard (2003) } \\
\text { Sullivan and } \\
\text { Ngwenyama (2005) } \\
\text { Kern et al. (2002) }\end{array}$ \\
\hline 1 & 1 & 1 & $\begin{array}{l}\text { Loss of core } \\
\text { competencies }\end{array}$ & $\begin{array}{l}\text { Fuzzy focus... loss of core... Contracting out key } \\
\text { process areas... missing out on any strategic benefits } \\
\text { of IT... treating IT as an undifferentiated commodity } \\
\text { and being unable to exploit IT for competitive } \\
\text { advantage... Loss of autonomy and control over IT } \\
\text { decisions... a client loses the core group of people } \\
\text { who were familiar with the activity and have } \\
\text { expertise to execute the activity in-house... }\end{array}$ & $\begin{array}{l}\text { Earl (1996) } \\
\text { Jurison (1995) } \\
\text { Sullivan and } \\
\text { Ngwenyama (2005) } \\
\text { Kern et al. (2002) } \\
\text { Aron et al. (2005) }\end{array}$ \\
\hline 1 & 1 & 1 & $\begin{array}{l}\text { Suppliers' } \\
\text { Financial } \\
\text { Viability }\end{array}$ & $\begin{array}{l}\text { Supplier's financial instability... supplier may cease } \\
\text { operations... supplier going out of business... is the } \\
\text { offshore supplier financially stable... }\end{array}$ & $\begin{array}{l}\text { Sullivan and } \\
\text { Ngwenyama (2005) } \\
\text { Kern et al. (2002) } \\
\text { Goodman and Ramer } \\
\text { (2007) } \\
\text { Iacovou and Nakatsu } \\
(2008) \\
\end{array}$ \\
\hline 1 & 1 & 1 & $\begin{array}{l}\text { Unrealistic } \\
\text { customer } \\
\text { expectations }\end{array}$ & $\begin{array}{l}\text { Client has inflated expectations of benefits from } \\
\text { outsourcing/offshoring... failure to manage end-user } \\
\text { expectations in offshore development projects... }\end{array}$ & $\begin{array}{l}\text { Kern et al. (2002) } \\
\text { Sakthivel (2007) } \\
\text { Iacovou and Nakatsu } \\
\text { (2008) } \\
\text { Taylor (2006) }\end{array}$ \\
\hline 1 & 1 & & $\begin{array}{l}\text { Inability to } \\
\text { obtain/retain } \\
\text { human } \\
\text { capital/Vendor } \\
\text { staffing issues }\end{array}$ & $\begin{array}{l}\text { Although hoped for, the supplier may not have the } \\
\text { best talent assigned to a customer account, while the } \\
\text { client runs the risk of losing some of the better talent } \\
\text { in house... lower productivity and skewed skills of } \\
\text { supplier employees... }\end{array}$ & $\begin{array}{l}\text { Earl (1996) } \\
\text { Sullivan and } \\
\text { Ngwenyama (2005) } \\
\text { Sakthivel (2007) } \\
\text { Iacovou and Nakatsu } \\
\text { (2008) } \\
\text { Taylor (2006) } \\
\end{array}$ \\
\hline 1 & 1 & & $\begin{array}{l}\text { Business } \\
\text { Uncertainty }\end{array}$ & $\begin{array}{l}\text { Business uncertainty in terms of long term direction } \\
\text { and needs increases opportunity costs. }\end{array}$ & Earl (1996) \\
\hline 1 & 1 & & $\begin{array}{l}\text { Loss of } \\
\text { opportunities } \\
\text { for } \\
\text { Organizational } \\
\text { Learning }\end{array}$ & $\begin{array}{l}\text { The strategic scope of systems often emerges as users } \\
\text { learn what is possible and as the business context and } \\
\text { needs change. By outsourcing a client may miss or be } \\
\text { late in organizational learning opportunities }\end{array}$ & Earl (1996) \\
\hline
\end{tabular}




\begin{tabular}{|c|c|c|c|c|c|}
\hline \multicolumn{6}{|c|}{ Summary of Key Challenges and Risks in IT Sourcing } \\
\hline 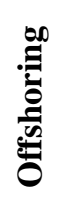 & 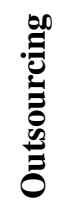 & 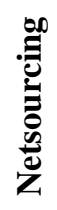 & $\begin{array}{l}\text { Challenges } \\
\text { and risks }\end{array}$ & Descriptive phrases in the literature & $\begin{array}{l}\text { Select References on } \\
\text { challenges and risks }\end{array}$ \\
\hline 1 & 1 & & $\begin{array}{l}\text { Loss of } \\
\text { Innovative } \\
\text { Capacity }\end{array}$ & $\begin{array}{l}\text { Innovation needs slack resources, organic and fluid } \\
\text { organizational processes, and experimental and } \\
\text { intrapreneurial competences -- all attributes that } \\
\text { external sourcing does not guarantee. If a company } \\
\text { has outsourced and downsized as well, its ability to } \\
\text { innovate may be impaired. }\end{array}$ & $\begin{array}{l}\text { Earl (1996) } \\
\text { Hoecht and Trott (2006) }\end{array}$ \\
\hline 1 & 1 & & $\begin{array}{l}\text { Opportunistic } \\
\text { behavior by } \\
\text { supplier }\end{array}$ & $\begin{array}{l}\text { Opportunistic behavior by supplier... breach of } \\
\text { contract by the vendor... opportunism... }\end{array}$ & $\begin{array}{l}\text { Jurison (1995) } \\
\text { Sullivan and } \\
\text { Ngwenyama (2005) } \\
\text { Goodman and Ramer } \\
\text { (2007) } \\
\text { Aron et al. (2005) }\end{array}$ \\
\hline 1 & 1 & & $\begin{array}{l}\text { Internal } \\
\text { Employee } \\
\text { Backlash / Low } \\
\text { Morale }\end{array}$ & $\begin{array}{l}\text { IT professionals and employees with clients, in } \\
\text { general consider outsourcing and particularly } \\
\text { offshoring as a threat to their survival and growth }\end{array}$ & $\begin{array}{l}\text { Kliem (2004) } \\
\text { Iacovou and Nakatsu } \\
\text { (2008) } \\
\text { Shao and David (2007) }\end{array}$ \\
\hline 1 & 1 & & $\begin{array}{l}\text { Communication } \\
\text { problems }\end{array}$ & $\begin{array}{l}\text { Extended time zones... geographic distance... } \\
\text { Language Barriers... geographic separation between } \\
\text { client and vendor and limitations in communications } \\
\text { and transmission systems... }\end{array}$ & $\begin{array}{l}\text { Kliem (2004) } \\
\text { Sakthivel (2007) } \\
\text { Goodman (2007) } \\
\text { Aron et al. (2005) } \\
\text { Iacovou and Nakatsu } \\
\text { (2008) }\end{array}$ \\
\hline 1 & 1 & & $\begin{array}{l}\text { Organizational } \\
\text { cultural } \\
\text { distance }\end{array}$ & $\begin{array}{l}\text { Inability of supplier employees to assimilate in } \\
\text { project teams... different work styles... }\end{array}$ & $\begin{array}{l}\text { Kliem (2004); Lacity } \\
\text { and Rottman (2008) }\end{array}$ \\
\hline 1 & & & $\begin{array}{l}\text { Socio-Political } \\
\text { Risks }\end{array}$ & $\begin{array}{l}\text { Trade barriers... border tensions... political } \\
\text { instability in offshore destinations... animosity } \\
\text { between cultures... exchange rate risk... sovereign } \\
\text { risk... }\end{array}$ & $\begin{array}{l}\text { Kliem (2004) } \\
\text { Sakthivel (2007) } \\
\text { Goodman and Ramer } \\
\text { (2007) } \\
\text { Aron et al. (2005) } \\
\text { Iacovou and Nakatsu } \\
\text { (2008) }\end{array}$ \\
\hline 1 & & & $\begin{array}{l}\text { National } \\
\text { culture distance }\end{array}$ & $\begin{array}{l}\text { Inability to resolve differences in values... culture } \\
\text { shock... cultural and ethical differences }\end{array}$ & $\begin{array}{l}\text { Kliem (2004) } \\
\text { Goodman (2007) } \\
\text { Iacovou and Nakatsu } \\
(2008)\end{array}$ \\
\hline 1 & & & $\begin{array}{l}\text { Negative } \\
\text { impact on } \\
\text { image of client }\end{array}$ & $\begin{array}{l}\text { political backlash against clients engaging in offshore } \\
\text { outsourcing... back lash from labor unions ... } \\
\text { perceived as unpatriotic... }\end{array}$ & $\begin{array}{l}\text { Iacovou and Nakatsu } \\
\text { (2008) } \\
\text { Shao and David (2007) } \\
\text { Smith and McKeen } \\
\text { (2004) }\end{array}$ \\
\hline
\end{tabular}

